\title{
Observational and epidemiological studies on the effects of solar ultraviolet radiation on immunity and infections
}

Citation for published version (APA):

Termorshuizen, F. (2004). Observational and epidemiological studies on the effects of solar ultraviolet radiation on immunity and infections. [Doctoral Thesis, Maastricht University].

https://doi.org/10.26481/dis.20040123ft

Document status and date:

Published: 01/01/2004

DOI:

10.26481/dis.20040123ft

Document Version:

Publisher's PDF, also known as Version of record

Please check the document version of this publication:

- A submitted manuscript is the version of the article upon submission and before peer-review. There can be important differences between the submitted version and the official published version of record.

People interested in the research are advised to contact the author for the final version of the publication, or visit the DOI to the publisher's website.

- The final author version and the galley proof are versions of the publication after peer review.

- The final published version features the final layout of the paper including the volume, issue and page numbers.

Link to publication

\footnotetext{
General rights rights.

- You may freely distribute the URL identifying the publication in the public portal. please follow below link for the End User Agreement:

www.umlib.nl/taverne-license

Take down policy

If you believe that this document breaches copyright please contact us at:

repository@maastrichtuniversity.nl

providing details and we will investigate your claim.
}

Copyright and moral rights for the publications made accessible in the public portal are retained by the authors and/or other copyright owners and it is a condition of accessing publications that users recognise and abide by the legal requirements associated with these

- Users may download and print one copy of any publication from the public portal for the purpose of private study or research.

- You may not further distribute the material or use it for any profit-making activity or commercial gain

If the publication is distributed under the terms of Article $25 \mathrm{fa}$ of the Dutch Copyright Act, indicated by the "Taverne" license above, 
Observational and epidemiological studies on the effects of solar ultraviolet radiation on immunity and infections 
Termorshuizen. Fabian

Observational and epidemiological studies on the effects of solar ultraviolet radiation on immunity and infections

Thesis University of Maastricht

Met een samenvatting in het Nederlands

ISBN: 90-9017571-7

Printed by: Print Partners Ipskamp, Enschede

(6) Fabian Termorshuizen, Den Haag, 2003

No part of this publication may be reproduced, stored in a retrieval system, nor transmitted, in any form or by any means, electronic, mechanical, photocopying, recording or otherwise, without prior permission of the author. 


\section{Observational and epidemiological studies on the effects of}

\section{solar ultraviolet radiation on immunity and infections}

(Observationele en epidemiologische studies naar het effect van solaire ultraviolette straling op weerstand en infecties)

Proefschrift

ter verkrijging van de graad van doctor aan

de Universiteit Maastricht,

op gezag van de Rector Magnificus, Prof. mr. G.P.M.F. Mols,

volgens het besluit van het College van Decanen, in het openbaar te verdedigen

op vrijdag 23 januari 2004 om 12.00 uur

door

Fabian Termorshuizen 
Promotor:

Prof. dr H. van Loveren

Co-promotor:

Dr F.R. de Gruijl (Leiden Universitair Medisch Centrum)

Beoordelingscommissie:

Prof. dr ir P.A. van den Brandt (voorzitter)

Prof. dr A. Bast

Prof. dr J.W. Cohen Tervaert

Prof. dr P.M. Steijlen

Dr M.B.M. Teunissen (Academisch Medisch Centrum, Amsterdam)

Financial support for the studies of this thesis was provided by the Dutch National Research Programme on Global Air Pollution and Climate Change (NOP. Project 952276) and by the Environment Programme of the EU (Project ENV4-CT96-0192). 
Dosis sola facit venenum."

Theophrastus Paracelsus (1493-1541)

(De dosis bepaalt het vergift.) 



\section{Contents}

Chapter 1 Introduction

1.1 Research question: UVR and infections in humans

1.2 A review of studies on the effects of ultraviolet irradiation on the resistance to infections: evidence from rodent infection models and verification by experimental and observational human studies

1.3 Hypotheses in relation to the presented studies in this thesis

Chapter 2

Skin infections in renal transplant recipients and the relation with solar ultraviolet radiation

\section{Chapter 3}

Amsterdam Cohort Study on HIV and AIDS: impact of exposure to UVR as estimated by means of a 2 -year retrospective questionnaire on immune parameters in HIV-positive males

\section{Chapter 4}

Seasonal influences on immunological parameters in HIV-infected homosexual men: searching for the immunomodulating effects of sunlight

\section{Chapter 5}

Vaccine-induced antibody responses in relation to season;

An analysis on hepatitis B, rubella and measles

Chapter 6

Exposure to solar ultraviolet radiation in young Dutch children: assessment by means of a six-week retrospective questionnaire

\section{Chapter 7}

Exposure to solar ultraviolet radiation and respiratory tract symptoms in 1year-old children

\section{Chapter 8}

Sunlight exposure and (sero)prevalence of epidermodysplasia verruciformisassociated human papillomavirus

Chapter 9 Summary and general discussion

Samenvatting in het Nederlands

Curriculum vitae

List of scientific publications 

Chapter 1 Introduction

In part published in Int Immunopharm 2002; 2: 263-275 


\subsection{Research question: UVR and infections in humans}

UVR has the potential to modulate the immune system in both humans and rodents Various studies in rodents have shown that ultraviolet radiation (UVR), even at suberythemal doses, has the potential to suppress immune functions and that this suppression may be followed by a lower resistance to tumours and infections, or a more severe course of an infection, once established [1 2]. Immunomodulating effects of UVR have been shown in experimental human studies as well [ 34 ]. It has been demonstrated in humans that exposure to UVR may lead to downregulation of specific immune responses to chemical (eg, contact hypersensitivity (CHS) response to 1chloro-2,4-dinitrobenzene (DNCB)) [5 6 7] or microbial antigens (eg, delayed type hypersensitivity (DTH) response to Candida albicans [8] and Mycobacterium Tuberculosis [9], and lepromin-induced granulomatous response in $M$. Leprae infection [10]). Furthermore, UVR may lead to immune alterations that are not directly associated with a specific response to an antigen, for example, a lower natural killer (NK) cell function, an initial epidermal T-cell depletion at the irradiated skin site followed by a selective influx of $\mathrm{CD}^{+} \mathrm{T}$ cells, a local increase in the $\mathrm{CD}^{+} / \mathrm{CD}^{+}$ $\mathrm{T}$-cell ratio, and a decrease in the $\mathrm{CD}^{+} \mathrm{T}$-cell number and $\mathrm{CD}^{+} / \mathrm{CD}^{+} \mathrm{T}$-cell ratio in blood [11-16].

Clinically manifest adverse health effects of solar UVR exposure have been shown in humans as well, notably sunburn, skin cancer, and ocular damage [17]. A high lifetime-cumulative exposure to UVR has been shown to be an important risk factor for skin cancer, especially squamous cell carcinoma [18]. The susceptibility to these UVR associated tumours appears to be enhanced in immunocompromised persons, for example renal transplant recipients receiving immunosuppressive therapy for prevention of graft rejection [19 20]. This indicates that immunosurveillance plays an important role in the pathogenesis of skin cancer, and suggests that UVR may exert its carcinogenic effect both by genotoxic and immunotoxic mechanisms [6 21]. Whether the immunotoxic effects of UVR in humans are associated with a lower resistance to infections or a more severe course of an infection, once established, is a question that remains to be settled [22].

It is important in this respect to note that the adverse effects of UVR on immunity and infections may come to light immediately following exposure, as was demonstrated in different rodent models. Hence, studies aimed at examining the effects of UVR on infections may require an approach that is different from studies aimed at examining the effects of UVR on malignancies [23]. Short-term assessment of both exposure and outcome is the most obvious approach to examine the relevance of UVR for the immune system and related susceptibility to infections. It has been shown that the immunomodulating effects of UVR are in part mediated by DNA damage in epidermal cells as keratinocytes and Langerhans cells [24 25]. Whether for this reason an association with a lifetime-cumulative measure of exposure to UVR may be hypothesized, is questionable. DNA-damage mediated immunomodulation is also a short-term effect, as DNA-repair mechanisms are immediately operative. Probably more important for a possible association with exposure in the past, it has been shown in rodents that short-term UVR exposure may cause antigen-specific tolerance and hence lasting reduced resistance to specific tumours and microbial agents will ensue [ $\left[\begin{array}{lll}26 & 27 & 28\end{array}\right]$. In addition, it has been demonstrated that induction of tumour tolerance develops under chronic UVR exposure, which indicates an effect of accumulated UVR exposure or the effect of a persistent UVR-related stimulus [21]. 
UVR-induced antigen-specific tolerance has been observed in humans as well, but its actual relevance remains a matter of debate [ $\left.3 \begin{array}{lll}3 & 5 & 7\end{array}\right]$.

\section{Research question: does exposure to UVR have consequences for resistance to infections in humans?}

Further studies are required to establish whether the potential of UVR to exert effects on the immune system has consequences for the occurrence or the severity of infections in human populations as well. Studies aimed at extrapolation of data from rodent models to the human situation were undertaken (see Chapter 1.2) [29 30]. Extrapolation studies can be useful, as they will give an impression whether UVR at doses relevant to outdoor exposure may influence host resistance to infections in humans. However, the results from such studies rely on various assumptions and hence validation is required. For example, it is assumed that differences between rodents and humans in sensitivity to UVR-induced suppression of an immune parameter (eg, mixed-skin lymphocyte response (MSLR)) reflects interspecies differences in sensitivity to UVR-induced suppression of host resistance to infections. Furthermore, possible adaptations to the immunosuppressive effects in humans, who are often exposed to ambient UVR on regular basis for decades, were not taken into account [4]. As it is unethical to infect human beings experimentally following irradiation with artificial or solar UVR, we are left with the conscientious analysis and interpretation of observational data on immunological parameters and infections. We have to keep in mind beforehand that observational data often do not enable the establishment of cause-effects relationships, or enable the disentangling of relationships that are operative in an opposite direction. However, observational data are still very important, as they may contribute to the evaluation of the relative importance of UVR as environmental factor among other determinants of health outcome in humans.

It would certainly strike many people as odd to expect sun exposure to promote infections. Most of common colds are observed in the cold and dark season, suggesting a protective effect of solar UVR on immunity and infections. Peak prevalence in winter season has also been established for corona virus, respiratory syncytial virus, and influenza virus [31]. However, seasonal effects on infections suggesting an inverse (ie, beneficial) relationship between UVR and outcome does possibly not hold true for many other non-respiratory or skin-associated infections. It is known that sun exposure may be immediately followed by a recurrence of herpes simplex virus infection [32] and that leprosy lesions occur primarily on sun-exposed sites [33]. In a recent observational study, it was shown that infections with cutaneous leishmaniasis during the dry season in French Guiana were associated with a more protracted course and a less effective antimicrobial treatment, suggesting a variation in host/ parasite balance, which may be due to the higher exposure to ambient UVR in the dry season [34]. Adverse effects of UVR on immune responses against cutaneous leismaniasis may be expected, as this parasitic infection has an intracellular localization and protective cellular immunity is T helper-1 (Th-1) associated [35 36]. It has been shown that Th-1 dominated immune responses are particularly affected by UVR exposure [37]. In another study, a peak prevalence of herpes zoster infection in the sunny season was observed [38]. The known seasonal effects on respiratory infections may be due to many other factors (for example humidity, indoor living, temperature effect on respiratory tract, prevalence of the micro-organism itself, behavioural factors) and the possible adverse effect of solar UVR on the resistance to 
these infections may become apparent when these seasonal influences are taken into account in study design or multivariate statistical analysis. Immune alterations indicative of depressed cellular immunity immediately following experimental exposure to sunlight were demonstrated [12]. Furthermore, it was demonstrated that travel to sunny countries in winter period was associated with a decline in the $\mathrm{CD}^{+}$/ $\mathrm{CD}^{+} \mathrm{T}$-cell ratio and serum IgG concentration, which was attributed to solar UVR exposure without prior adaptation [39].

In the next section (Chapter 1.2), the results from a number of studies that were aimed to elucidate the mechanism of UVR-induced immunosuppression and the related resistance to infections are reviewed. Furthermore, results from extrapolation studies aimed at estimating the possible consequences of UVR for the resistance to infections in humans and experimental human studies with single immune parameters as readout are presented. On the basis of this important background information, a number of hypotheses are launched (Chapter 1.3) to form the basis of the observational and epidemiological studies described in Chapter 2 - 8. 


\subsection{A review of studies on the effects of ultraviolet irradiation on the resistance to} infections: evidence from rodent infection models and verification by experimental and observational human studies

adapted from [40]

(List of abbreviations

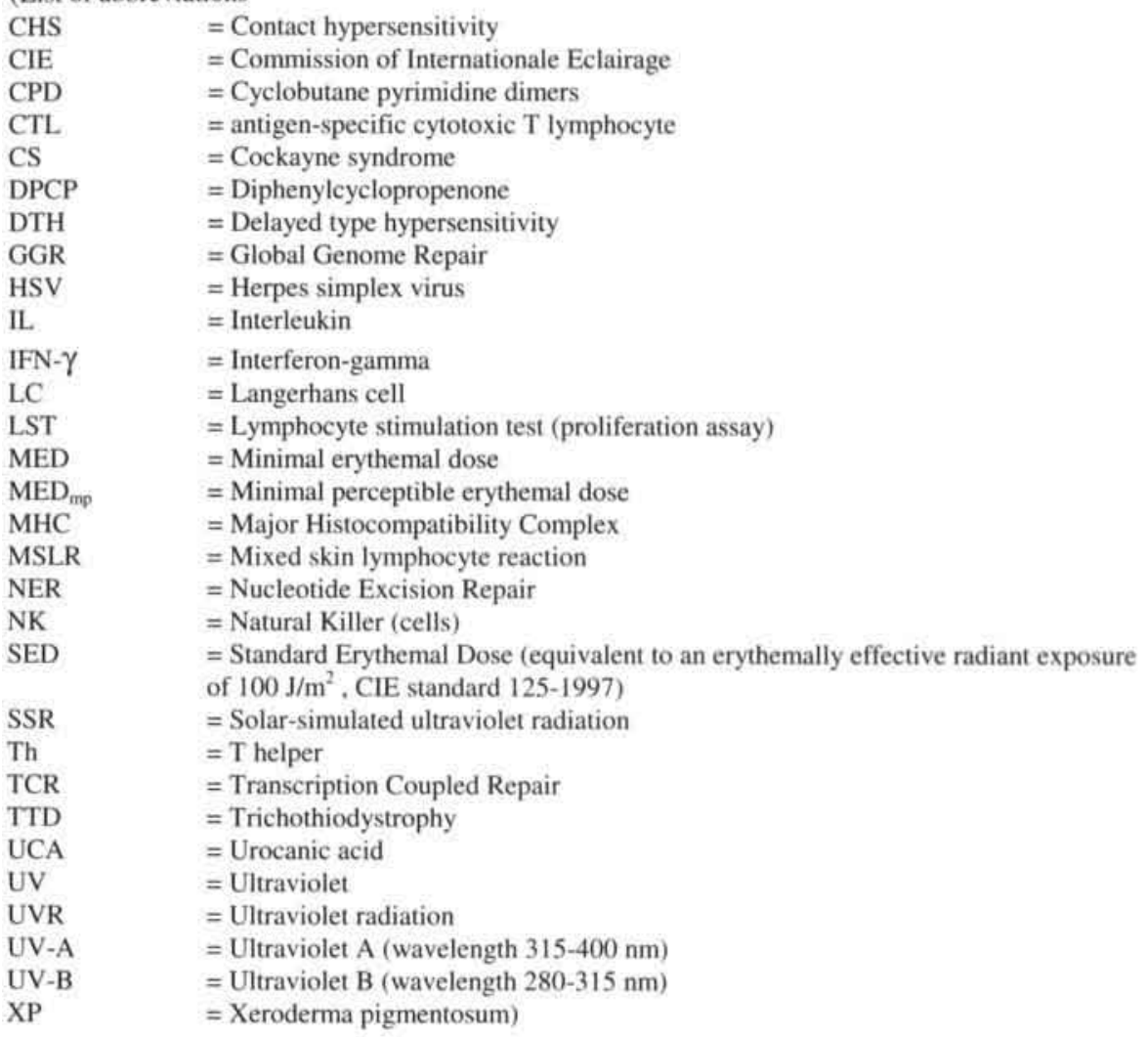




\subsubsection{Background}

As has been mentioned above, it was demonstrated in many studies that UVR, especially the B-waveband (UV-B, 280-315nm), has the potential to modulate immune mechanisms in addition to its genotoxic effects [17 26]. The biological function of this change might be to prevent unnecessary inflammation in the skin in response to UVR-induced neo-antigens or common environmental antigens [41]. If exposure to UVR occurs at the same time or prior to infection or oncogenesis, then this immunosuppression may be harmful to the host [2].

A multistep process is induced by UVR, starting with the absorption of photons by chromophores in the skin. The following steps involve the production of several mediators by keratinocytes and other cutaneous cells, and phenotypic and functional cellular changes such as in Langerhans cells (LC), the major antigen presenting cells of the epidermis. As a consequence, the activity of $\mathrm{T}$ cells can be modulated, and antigen-specific T suppressor cells are generated. There is evidence that UVR promotes production of the T helper-2 (Th-2) associated cytokines and reduces the production of T helper-1 (Th-1) associated cytokines [42]. The susceptibility to infections may be changed due to this differential effect on cytokine levels [2]. Th-1 cells secrete cytokines such as interleukin-2 (IL-2) and interferongamma (IFN- $\gamma$ ) and serve as helper cells for delayed type hypersensitivity reaction (DTH), contact hypersensitivity reaction (CHS) and, in mice, for the production of IgG2a, IgG2b and IgG3. Th- 1 cells play a crucial role in the resistance to intracellular pathogens such as viruses and certain bacteria (eg, Listeria monocytogenes). Th-2 cells, on the other hand, secrete cytokines such as $\mathrm{IL}-4$ and $\mathrm{IL}-10$, serve as helper cells for the production of $\mathrm{IgGl}$ and $\mathrm{IgE}$ (in mice) and suppress the function of Th-1 cells [43]. Th-2 cells play a dominant role in the resistance to many extracellular pathogens, including many bacteria and parasites. It should be noted that immune responses to infections generally comprise aspects of both Th- 1 and Th- 2 dependent responses.

Influences of UVR on the resistance to viral, bacterial, and parasitic infections and resulting pathology have been noted [2 35434445$]$. In several animal models of infection. UVR causes an increase in the microbial load and the severity of symptoms [2]. Although these models are helpful for elucidating how UVR may alter immune functions and impair the resistance to infections, the relevance in quantitative terms for humans remains unclear. We report herein the results of a number of studies within a project (1995-1998), that was funded by the European Union (Programme Environment) and in which the effects of UVR on infections were evaluated and as such was a continuation of a previous EU project (1991-1994) (Garssen et al., 1998)[1]. Experimental animal studies, extrapolation of animal data by means of a mathematical model and verification of the results of this model by empirical human studies were performed. Firstly, the aim of these studies was to broaden and refine the knowledge of the relationship between dose, wavelength and duration of exposure to UVR on the one hand, and the immune system and infections in humans on the other hand. Secondly, the aim was to provide a quantitative assessment of the risk of, or severity of, infectious diseases in the human population associated with exposure to UVR.

In the following sections we will first review findings on mechanisms of UVRinduced immunosuppression, in particular the role of photoreceptors as mediators of immunomodulation (section 1.2.2). Next, results of animal studies on the UVRinduced modulation of immune responses to microbial and non-microbial antigens and consequences for the resistance to infections are discussed (section 1.2.3). Data on 
immunomodulation by UVR in humans are then described (section 1.2.4), followed by the integration of animal and human data and the assessment of the risk of decreased host resistance as a consequence of UVR in the human population (section 1.2.5).

\subsubsection{Mechanisms of UVR-induced immunosuppression}

Although considerable information on the mechanisms of UVR-induced immunosuppression has become available during the last decades, many questions remain to be answered, including those relating to infectious diseases. It is important to understand the pathways involved for the purpose of making an accurate assessment of the risk of adverse effects in the population, and taking measures to prevent or lessen such risk. As UVR wavelengths, particularly the B-waveband (UVB), do not penetrate far into the skin, it is thought that cutaneous photoreceptors are needed to absorb the radiation, change as a result and initiate a complex cascade of responses ending in immunosuppression. Different photoreceptors have been suggested, including DNA and urocanic acid (UCA).

\section{DNA}

It is well known that UVR-induced DNA damage plays a pivotal role in UVR-induced carcinogenesis. Exposure to UVR induces cyclobutane pyrimidine dimers (CPDs) as well as pyrimidine (6-4) pyrimidone photoproducts in DNA. Keratinocytes with DNA damage respond by producing cytokines such as $\mathrm{IL}-6$ and $\mathrm{LL}-10$ that can modulate immune responses in the skin. In addition, LCs with DNA damage have been shown to migrate from the epidermis to the draining lymph node and to contribute to systemic immunosuppression [24]. In various studies, Kripke and co-workers demonstrated that DNA damage is at least partially involved in local as well as systemic UVR-induced immunomodulation. For example, Vink et al. found that excision repair of CPDs by liposomes containing T4N5 endonuclease in mice reversed the UVR-induced suppression of CHS [46 47]. In addition, CPDs mediated systemic suppression of the DTH to the inactivated Candida albicans, at least partially [48 49]. Additional evidence for a significant role of DNA damage in UVR-induced immunosuppression is provided by Miyauchi-Hashimoto et al. who demonstrated that in nucleotide repair deficient XP-A mice, local and systemic UVR-induced immunosuppression was increased compared with wildtype littermates [50]. In our laboratories, studies were performed on the sensitivity of 4 different transgenic mouse models to UVR-induced systemic immunomodulation (DTH and CHS) and acute skin effects (ie, oedema) [25]. At first, conventional gene targeting of the mouse XP-A gene yielded a model for the prototype DNA-repair syndrome, Xeroderma pigmentosum (XP), with a complete nucleotide excision repair (NER) defect [51]. Similarly, by targeting the XP-C gene, which is associated with a specific deficiency in the global genome repair (GGR) pathway, a second model for NER deficiency was developed [ 5253 54]. A third model, a model for Cockayne syndrome (CS) with a selective impairment of transcription-coupled repair (TCR), was obtained by mimicking a truncating CS-B null allele found in a CS group B patient [55]. The fourth model mimicked an XP-D point mutation of a patient suffering from trichothiodystrophy (TTD), resulting from deficiencies in both TCR and GGR. These latter deficiencies are less severe than those in XP-A [56 57]. In experiments in which these mutant strains were used, it was shown that the NER is crucial in the repair process of distant UVR-induced immunosuppression of CHS. The XP-A and CS-B knockout mice were highly sensitive to the acute sunburn/ erythema effects of UVR. 
However, the XP-A mutant mice were the most sensitive with respect to UVRinduced distant (or systemic) suppression of CHS, whereas CS-B mutant mice were not sensitive at all, even after exposure to burning UVR doses. In a recent study it appeared that XP-A and CS-B mice proved to be equally sensitive to UVR-induced local suppression of CHS, which indicates that a defect in transcription-coupled DNA repair causes a high sensitivity to local immunomodulation [58]. From these results, we conclude that UVR-induced systemic immunosuppression involves both TCR and GGR. The mechanisms of UVR-induced erythema and immunosuppression are different, and the sensitivity to acute sunburn effects of UVR may not fully correlate to the sensitivity to the immunosuppressive effects of UVR, at least in mice [25]. On the other hand, it was shown by Kelly et al.(2000) among human volunteers that the sensitivity to UVR-induced suppression of CHS and the sensitivity to erythema are highly correlated [59]. In addition, it was found that erythema is a prerequisite for systemic suppression of induction of CHS in humans (see section 1.2.4, paragraph "Effects on contact hypersensitivity"). Further elucidation of this issue is important for the assessment of the risk of UVR-exposure associated altered resistance to infections.

\section{Urocanic acid (UCA)}

A second photoreceptor involved in initiating UVR-induced immunosuppression, including reduced resistance to infections, is UCA [60 61]. The naturally occurring trans-UCA in the stratum corneum isomerises to cis-UCA after UVR exposure and cis-UCA has been shown to act as a downregulator of immune responses in a variety of systems. For example, a rat model of oral infection with the worm Trichinella spiralis was developed. It was found that exposure to either UVR or cis-UCA led to lowered immune responses to infection and to a higher parasitic load [44].

Furthermore, if rats were injected with a monoclonal antibody with specificity for cisUCA 2 hr prior to UVR exposure, the UVR-induced suppression of DTH to $T$. spiralis and the increase in larvae counts were significantly inhibited compared with rats that were similarly injected with a control antibody [1 44]. This result is of particular interest, as there is no skin involvement at any stage during the infection and, therefore, the cis-UCA must be acting systemically. From these data, it can be concluded that UCA is an important photoreceptor and that it plays a role in the mediation of the UVR-induced suppression of resistance to infections.

Most information regarding the biological activity of cis-UCA has been obtained following a single or few treatments, but under natural circumstances the cisUCA content in the stratum corneum is elevated throughout the summer months [1 62]. Therefore, it was examined whether adaptation occurs after subchronic treatment with cis-UCA by intradermal injecting mice three times a week for four weeks. This treatment resulted in a decrease in thymus weight accompanied by an increase in lymph node weight. A net accumulation of dendritic cells and lymphocytes in lymph nodes was found, but the percentages of $\mathrm{CD}^{+}{ }^{+}$-positive and $\mathrm{CD} 8^{+}$-positive $\mathrm{T}$ cells remained unchanged, indicating that there was no specific migration or proliferation of a particular subset of cells. The in vitro proliferation of lymph node cells to the mitogen concanavalin A was suppressed by cis-UCA treatment. The density of LCs in the epidermis of ears was unchanged in the cis-UCA group. but the mixed skin lymphocyte reaction (MSLR) utilizing epidermal cells from the ears, was suppressed. This indicates a systemic suppression, as the ears were not a site for injection of the UCA isomers. Remarkably, no suppression of CHS to oxazalone or of DTH to herpes 
simplex virus (HSV) occurred in cis-UCA-treated mice compared with the controls. Thus, subchronic treatment with cis-UCA led to a suppression of some, but not all, of the immune parameters tested. Differences in effects after acute or subchronic exposure may be attributed to possible adaptation of the immune system to the immunosuppressive activity of cis-UCA [63].

Three sources of UVR were used to compare the influence of different wavelengths on DTH, CHS, trans-to-cis photoisomerisation of UCA, and the minimal erythemal dose (MED) in mice. The broadband UV-B lamp (TL-12), the narrowband UV-B lamp (TL-01, wavelength $=313 \mathrm{~nm})$ and the UV-AI lamp $(340-400 \mathrm{~nm})$ were used to irradiate $\mathrm{C} 3 \mathrm{H} / \mathrm{HeN}$ mice. A comparatively high dose of UV-AI $\left(500,000 \mathrm{~J} / \mathrm{m}^{2}\right)$ was required to cause minimal erythema, suppression of CHS, and a mere $18 \%$ increase of cis-UCA. In contrast, a low dose of UV-AI $\left(1,000 \mathrm{~J} / \mathrm{m}^{2}\right)$ was sufficient to suppress DTH. A higher dose of TL-01 $\left(10,000 \mathrm{~J} / \mathrm{m}^{2}\right)$ was required to suppress DTH, but the percentage of cis-UCA increased up to $40 \%$ with this exposure. In contrast, the minimal dose from the three UVR lamps required for suppression of CHS correlated well with the trans-to-cis photoisomerisation of UCA by source (Table 1).

There was no correlation between the suppression of DTH on the one hand and the suppression of CHS and the concentration of cis-urocanic acid in the skin on the other hand. Thus, different mediators may modulate the various immune responses affected by ultraviolet exposure, depending on the wavelength of the radiation [64].

Table 1 Minimal doses of UVR needed to produce erythema, suppression of CHS (to oxazolone), DTH (to HSV), and increase of the percentage cis-UCA in $\mathrm{C} 3 \mathrm{H} / \mathrm{HeN}$ mice, by UVR source; TL-12, broadband UVR, TL-01, narrowband UVR $(313 \mathrm{~nm})$, $U V-A I(340-400 \mathrm{~nm})[64]$

Erythema CHS DTH cis-UCA

$\begin{array}{lllll}\text { TL-12 } & 1,500 \mathrm{~J} / \mathrm{m}^{2} & 5,000 \mathrm{~J} / \mathrm{m}^{2} & 100 \mathrm{~J} / \mathrm{m}^{2} & \text { After } 1,000 \mathrm{~J} / \mathrm{m}^{2}: 40 \% \\ \text { TL-01 } & 10,000 \mathrm{~J} / \mathrm{m}^{2} & 50,000 \mathrm{~J} / \mathrm{m}^{2} & 10,000 \mathrm{~J} / \mathrm{m}^{2} & \text { After } 10,000 \mathrm{~J} / \mathrm{m}^{2}: 40 \% \\ \text { UV-AI } & 500,000 \mathrm{~J} / \mathrm{m}^{2} & 500,000 \mathrm{~J} / \mathrm{m}^{2} & 1,000 \mathrm{~J} / \mathrm{m}^{2} & \text { After } 500,000 \mathrm{~J} / \mathrm{m}^{2}: 18 \%\end{array}$

From these data, it can be concluded that sunburn and various types of immune responses are influenced by different UVR wavelengths, presumably depending on different mechanisms involved.

Further evidence has been presented to indicate that UV-A exposure prior to treatment with cis-UCA inhibits the immunosuppressive effects of the latter [65]. This is in agreement with studies by Reeve et al.[66 67 68]. They showed that UV-A, either immediately after, or up to 24 hours before, could partially reverse the suppressed CHS response induced by UV-B, cis-UCA or solar-simulated UVR radiation (SSR). However, as simultaneous exposure to UV-A and UV-B as in SSR is still capable of inducing immunosuppression, the relevance of this interaction of different wavelengths needs to be further elucidated (see also section 1.2.4).

Wavelength dependency of effects of UVR was also investigated in humans [69]. UCA isomers were quantified after in vivo exposure of 5 healthy volunteers to monochromatic light from $270-340 \mathrm{~nm}$. The resulting action spectrum showing the efficiency of irradiation had a broad, flat peak from $280-310 \mathrm{~nm}$, which was redshifted from both the absorption peak of cis-UCA and the action spectrum for 
suppression of CHS in mice (both peak at $270 \mathrm{~nm}$ ). Thus, cis-UCA can be produced by UVR wavelengths that are very inefficient with respect to suppression of CHS. Albeit that the role of UV-A is currently a matter of debate and needs further investigation, these data illustrate the complexity of the effects.

From these data, it is evident that cis-UCA is a photoreceptor that has immunomodulatory activity and can cause reduction of resistance to infections. The cellular and molecular target of cis-UCA has not been resolved, and consequently the mechanism by which this molecule exerts its activity is not understood. In addition, it is evident that other immunosuppressive mechanisms, for instance through DNA damage or otherwise, are simultaneously active. The wavelength, combination of different wavelengths, and kinetics of exposure and subsequent antigen challenge all have their impact on the eventual health outcome of UVR exposure. At the present time, we are only just beginning to appreciate this complexity, which hampers a simple and straightforward assessment of the risk of infectious diseases in association with UVR exposure for the human population.

\subsubsection{Modulation of immune responses to microbial and other antigens by UVR in animal models}

As indicated earlier, a wide array of infections in laboratory animals has been shown to be affected by UVR. A particularly relevant model is HSV, since it is known that reactivation of this virus from latency is influenced by UVR exposure in humans $[32$ 70]. As the stimulus for recrudescence occurs after the establishment of latency and after the generation of the primary immune response in human subjects, a mouse model was developed to assess the impact of UVR on epidermal HSV infection following the establishment of immunity. Mice were therefore immunized with inactivated HSV and subsequently one group was UVR irradiated with a suberythemal dose. The next day, all mice were challenged intradermally with HSV. Most of the irradiated mice $(92 \%)$ developed severe lesions, whilst $59 \%$ of the nonirradiated group developed mild and $30 \%$ no lesions. The DTH to the virus was not affected by the UVR exposure. This finding contrasts with the suppression of DTH to the virus by UVR that is given prior to the primary HSV infection [28]. The ex vivo proliferative response of lymph node cells revealed a suppressed response to both $\mathrm{HSV}$ and concanavalin A in the irradiated group. As the MHC class II expression by dendritic cells was reduced by UVR exposure, this finding may suggest that UVR given prior to secondary infection with HSV may lead to a modulation of local antigen presentation [71].

UVR has been suggested to stimulate Th- 2 associated immune responses. It has been reported that antibody to $\mathrm{IL}-4$ blocked the UVR-induced suppression of the DTH response, which indicates that $\mathrm{IL}-4$ may be a key cytokine in the UVR-induced immunosuppression [72]. Furthermore, it was demonstrated that UVR-induced suppression of DTH to inactivated HSV following primary infection with HSV did not occur in IL-4 - -knockout mice [73]. The role of $\mathrm{IL}-4$ in immune responses to HSV and effects of UVR on protection against epidermal infection with HSV were investigated in $\mathrm{IL}-4^{-1-}$-knockout mice. Lymph node cells from infected $\mathrm{IL}-4^{-1-}$. knockout mice were less able to respond in vitro to HSV than cells from the normal strain. IL-4 - knockout mice were more susceptible to both the primary and secondary epidermal infection than the parent mice. The percentage of lymph node dendritic cells expressing la was $45 \%$ in the parent mice but only $18 \%$ in the knock out strain. Thus, IL-4 seems to protect against HSV infection. Consequently, one 
might expect UVR to stimulate protection against HSV. Following sub-erythemal UVR irradiation, no differences were observed between knock-out and normal littermates. More severe primary and secondary lesions, fewer lymph node dendritic cells expressing Ia and a suppressed HSV-induced lymphoproliferation were observed in both strains. Hence, no evidence was obtained for the involvement of IL -4 in the UVR-induced immunomodulation in this HSV-infection model [74]. In other words, a promotion of Th-2 cytokines resulting from the exposure was not indicated. This was further corroborated by experiments in which it was investigated whether UVR irradiation before or after primary infection with HSV influenced expression of specific antibody-subclass responses [75]. A small reduction in both Th-1 and Th-2 associated HSV-antibody isotypes was found. These data support the notion that, besides cellular immune responses, humoral immune responses are also influenced by UVR exposure. In addition, the results show that UVR does not induce a shift in the Th-1/Th-2 balance (ie, promotion of Th-2 and suppression of Th-1), which is in contrast to what has been hypothesized elsewhere [42]. Earlier studies using the parasite infection model Trichinella spiralis in the rat also indicated that UVR could affect antibody production and B-cell activity significantly. Goettsch et al. demonstrated that the production of specific $\mathrm{IgE}$ in a Trichinella spiralis infection model in the rat was significantly suppressed [45].

General suppressive effects of UVR on humoral immunity, especially the intrinsic activity of B cells, have also been described by Boonstra et al. [76]. To further study differential effects of UVR exposure on Th-1 and Th-2 responses, two models were used. The effect of UVR on Th-1 dependent responses was assessed in a classical model for Th-1 mediated immunity, ie, CHS responses to picrylchloride and to oxazolone (both low molecular weight chemical antigens) were used. The CHS responses to both contact sensitizers were significantly suppressed by pre-exposure to UVR at a distant locus. IFN- $\gamma$, IL-12 and IL-4, but not IL-10, were detectable in the spleens and draining lymph nodes of sensitized BALB/c mice. UVR exposure inhibited both IFN- $\gamma$ and IL-12, but not IL-4 [77]. In BALB/c mice sensitized with ovalbumin, which is a model for Th-2 mediated immunity, ovalbumin-specific IgE serum titre and cytokine profiles in the spleen were analysed. Pre-exposure to UVR resulted in a decreased IgE titre. Increased IFN- $\gamma$, IL-4 and IL-10 in the spleens of the ovalbumin-sensitized mice were observed. The production of IL-10 was significantly increased after exposure to UVR, which suggests upregulation of Th- 2 cells. It is remarkable that IFN- $\gamma$ is significantly suppressed by UVR in Th- 1 mediated immune reactions but not in Th- 2 mediated immune reactions. IFN- $\gamma$ even appears to be increased in the latter situation. The upregulation of IL-10 after exposure to UVR may represent a shift from Th- 1 to Th- 2 mediated immune mechanisms. However, IL-10 can also inhibit Th-2 responses, which might be the reason for a decreased IgE titre in the Th- 2 model [78]. The IgE titre can be seen as an important endpoint parameter for Th-2 mediated immunity. It is concluded that UVR exposure prior to sensitization may cause a shift from Th-1 towards Th- 2 associated cytokines, but eventually both Th-1 and Th-2 mediated immune responses may be inhibited [77].

As UVR has such an important influence on interleukin regulation, and since allergy often mirrors defence to infections [79], investigations have been performed on the influence of UVR on respiratory allergy using the model antigens picrylchloride and ovalbumin, as listed above. In both the picrylchloride and ovalbumin models, after sensitization and subsequent respiratory challenge, inflammatory responses were noted, and in both cases also airway hyperreactivity to 
non-specific stimuli was induced. In the former situation, the inflammatory infiltrate comprises mononuclear leukocytes, while in the ovalbumin model eosinophils were a more prominent feature. UVR exposure diminished the inflammation in the picrylchloride model, which is consistent with suppression of this response, which is essentially a Th-1 dependent response. In contrast, UVR did not affect the inflammation in the ovalbumin model, but suppressed specific $\operatorname{IgE}$ responses as well as airway hyperreactivity. One can conclude that in these models UVR can suppress both Th-1 and Th-2 responses. This lends further support to the notion that UVR does not cause a shift in the balance between Th-1 and Th-2, but rather suppresses both [80].

Taken together, these experiments suggest that the influence of UVR on resistance to infections, as has been noted in several infection models, is associated with influences on several immune responses to microbial antigens. These changes are probably mediated by interference with regulatory networks (ie, expression of cytokines). Even if some indications of suppression of Th-1 associated cytokines and promotion of Th- 2 cytokines exist, in the models that were presented these alterations did not result in suppression of Th-1 dependent immune responses and stimulation of Th-2 dependent ones. In stead, where Th- 1 dependent antibody and inflammatory responses were suppressed, Th-2 dependent antibody responses were also suppressed, while in a model using ovalbumin, Th-2 dependent inflammation was unaffected.

\subsubsection{Effects of UVR on immune responses to microbial and other antigens in humans}

For extrapolation of laboratory animal data to the human situation, it is important to examine whether effects as they have been observed in animals in fact occur in humans. It is obvious that experimental infections cannot be studied in humans. There are several published papers showing that UVR may cause HSV recrudescence in some people [32 70]. However, the importance of exposure to solar UVR for other (viral) infections (eg, HIV, human papillomavirus and others) in humans has still to be substantiated. Effects of controlled UVR exposure on a variety of immune responses that reflect the capacity of the host to react to infectious agents can readily be studied and may shed light on this issue.

\section{Effects on contact hypersensitivity}

One important immune response frequently described as being influenced by UVR in humans is CHS. CHS responses are considered adequate parameters of the functionality of the immune system. Resistance to infections include mechanisms that are not all operational in CHS, yet alterations in CHS may be indicative of alterations in host resistance. In part, these effects are considered to be due to perturbation of the antigen-presenting capacity within the skin.

UVR-induced immunosuppression of the afferent phase of cell-mediated immunity using the contact sensitizer diphenylcyclopropenone (DPCP) in local (sensitizer applied at the site of irradiation) and distant (sensitizer applied to UVR protected site) models in human volunteers was investigated. Local irradiation ( $5 \times 5$ $\mathrm{cm}$ skin area) with $600 \mathrm{~J} / \mathrm{m}^{2}$ erythemally effective SSR (6 SED), induced intense skin erythema and completely prevented contact sensitization in 11 of 12 individuals. However, this irradiation did not induce antigen-specific tolerance to DPCP, which means that subsequently the volunteers could be contact sensitized at the second immunization to the same contact allergen through non-irradiated skin [81]. The dose 
equivalent to 2 SEDs of SSR $\left(200 \mathrm{~J} / \mathrm{m}^{2}\right)$, which induced only a faint erythema at the site of the irradiation, could not prevent the sensitization in any of seven volunteers. These data suggest that UVR-induced inflammation (erythema) is needed for local UVR-induced immunosuppression and that specific tolerance is a complex phenomenon with unusual occurrence, as concluded also by Kelly et al. [82].

Irradiation of relatively large areas of skin ( $~ 70 \%$ of the total body surface) with a low, single UVR dose (previously tested minimal perceptible erythemal dose, $\mathrm{MED}_{\mathrm{mp}}$ ), which induced only a faint or no erythema at all, could not prevent contact sensitization at distant, non-irradiated skin site in any of ten volunteers. On the contrary, irradiation with four repeated similar large-area irradiations on consecutive days, that induced a moderate but distinct erythema on the trunk, completely prevented contact sensitization at a non-irradiated skin site in 2 of 22 volunteers. One of these two volunteers could not be sensitized to the same allergen when tested later through non-irradiated skin and, thus, showed specific immunological tolerance [81]. In additional studies, irradiation of a limited area $(5 \times 5 \mathrm{~cm})$ with an intensively erythematogenic dose, 6 SEDs of SSR, could completely prevent sensitization through distant non-irradiated skin in 2 of 9 persons tested, and in an additional 4 there was a downregulation in the level of contact sensitization. Even if the number of individuals that has been tested in these studies is limited, the data suggest that distant UVRinduced immunosuppression, demonstrated earlier in mice, can also be observed in humans, and that skin inflammation (erythema) is a prerequisite for systemic suppression. Other groups of investigators have corroborated the occurrence of human UVR-induced distant immunosuppression [7 82].

The results from these studies indicate that UVR exposure in humans may result in both local and distant suppression of contact hypersensitivity, as was shown in laboratory animals.

\section{Effects of UVR on cytokine expression}

As indicated by the studies in laboratory animals, suppression of both Th-1 and Th-2 dependent immune responses by UVR were observed. Previously, it was demonstrated that whole-body exposure with narrowband UVR (TL-01) systemically downregulated both Th- 1 and Th- 2 cytokine production by peripheral blood mononuclear cells in psoriatic patients [83]. It was postulated that, analogous to the effects seen in the murine system and in in vitro tests with human keratinocytes, the systemic effects of TL-01 and UV-AI (340-400 $\mathrm{nm}$ ) might be due to altered levels of immunoregulatory cytokines. Five healthy volunteers received 3 daily treatments of either TL-01 or UVAI radiation and blood samples were taken in the course of the 48 hours after the third treatment. Neither narrowband UVR nor UV-AI significantly altered IL-10, IL-12, IL8 , or TNF- $\alpha$ in the serum. These data suggest that the circulating cytokines do not reflect the systemic immunomodulation seen after whole-body TL-01 irradiation in psoriatics and despite upregulation in vitro, UV-AI had no detectable effect on IL-10 in vivo. Successful treatment of psoriasis by UVR may be due to local suppression of Th-1 responses and favoring of local Th-2 associated immune responses [84 85]. As such, this may be in agreement with data in the mouse, showing preferential suppression of Th-1 responses [42]. In an experimental model with picrylchloride, suppression of CHS as an example of Th-1 responses also occurred in the absence of an influence on IL-10 expression (see section 1.2.3) [77 80]. 


\section{Effects on specific anti-microbial cytotoxic lymphocyte responses}

In part, resistance to viral infections, including HSV, depends on immunologic memory. For this purpose, effects of UVR on antigen-specific cytotoxic T lymphocyte (CTL) responses were studied [14]. It was investigated whether UVR influences CTLs specific for HSV in healthy subjects undergoing phototherapy. Five HSV-seropositive subjects received whole-body irradiation thrice weekly for four weeks with incremental doses dependent on skin type. No modulation of CTL activity was observed, suggesting that this defence mechanism may not be involved in reduced resistance to HSV resulting from UVR exposure. In one subject a clear increase in CTL activity was observed, which was probably associated with the occurrence of a HSV-recrudescent lesion in the same subject. The CTLs could have been stimulated by the re-appearance of virus in the periphery triggered by the UVR exposure, thus helping to contain the lesion. In addition, no effects were observed on CD4 ${ }^{+}$and $\mathrm{CD} 8^{+}$ T-cell subsets [14]. Although the initial formation of memory cells may be suppressed by UVR radiation, the production of effector CTLs from memory cells is probably not [26 86].

\section{Effects on non-specific anti-microbial defence mechanisms}

Resistance to infectious diseases depends, in addition to specific immune responses, on non-specific defence mechanisms. Effects of UVR on a number of such systems in humans were studied. Natural killer (NK) cell responses were assayed in the same healthy HSV-seropositive subjects undergoing phototherapy as described above for the CTL activity. In contrast to the CTL results, the NK-cell activity was significantly reduced shortly after the initiation of the phototherapy. This activity continued to decline during the treatment and it recovered to the original level within a week of cessation of the irradiation [14]. These data indicate a differential effect of UVR exposure on specific and non-specific cytotoxic activity. As patients with psoriasis rarely suffer from recrudescence due to HSV infection as a result of UVR treatment (which may be hypothesized to be due to downregulation of Th-1 activity), especially when burning doses are avoided and the head is covered, the temporary downregulation in NK-cell activity may be compensated by other immune pathways [87].

The systemic effects of whole-body UVR irradiation on human peripheral blood phagocytes was studied at different time points, up to $24 \mathrm{hr}$ after a single erythemal dose of UVR radiation. Two phagocyte functions were tested, adhesion and phagocytosis, and both were found to be reduced by $50 \%$. This functional suppression was accompanied by a decrease in the expression of complement- (CR1 and CR3) and IgG Fc- (FcRII and FcRIII) receptors. These data suggest that UVR irradiation may suppress some important functions of circulating phagocytic cells that may have consequences for resistance to infections [88].

In conclusion, some host-defence mechanisms in human subjects may be affected by UVR exposure. Even if UVR has clear effects on T-cell dependent immune responses in humans such as CHS, especially at erythema-inducing doses, no clear effects either on T-cell subsets, or on specific immune responses as cytotoxic T-cell responses as indicator of memory activity were found. It remains unsettled whether host resistance to infections in humans is affected by UVR. 


\subsubsection{Risk assessment in humans by extrapolation from animal models}

From the data above, it follows that exposure to UVR leads to molecular changes in the skin, such as DNA damage and isomerisation of UCA and perturbations of cutaneous and systemic immune responses. As a result, altered resistance to experimental infectious challenges in rodents occurs. Some, but not all of these findings have been reported in humans as well. Furthermore, indications of effects of UVR on the resistance to infections are still lacking.

For quantitative risk assessment, information on the dose response relationships between the infectious disease parameters (microbial load, clinical symptoms) and exposure to UVR in humans is required. As such information is not available in humans, but is available from laboratory animal studies, it was attempted to extrapolate from these animal models to the human situation. It was assumed in the extrapolation studies that the difference in sensitivity to UVR-induced modulation of in vitro or ex vivo in situ immunological parameters between rodents and humans reflects the difference in sensitivity to UVR-induced impairment of the resistance to infections between rodents and humans ('parallellogram approach'). For example, dose response studies in rats infected intravenously with Listeria monocytogenes indicated that $6.8 \mathrm{~kJ} / \mathrm{m}^{2}$ UVR (FS40 lamps) inhibited the specific cellular immune response MSLR by $50 \%$. The suppression corresponded with the delay in clearance of the bacteria from the spleen. In order to extrapolate from the rat to the human situation, this dose was multiplied by a factor representing the interspecies difference in sensitivity to the effect of UVR as assessed in the MSLR, which is an in situ test. Humans are less sensitive to UVR-induced suppression of the MSLR by a factor of approximately 4 than rats [ $\left[\begin{array}{ll}1 & 29\end{array}\right]$. This means that humans have to be exposed to 4 times more UVR in order to induce suppression of the MSLR by the same order as rats $(50 \%)$. For NK-cell function the difference was 3 fold, which is about the same as the MSLR interspecies difference [30]. Furthermore, a factor for individual differences in sensitivity to UVR, as was assessed in a study group of 17 human volunteers, all with skin type II, was applied (intraspecies factor=0.5). Starting from these data and the biologically effective doses of sunlight as calculated by De Fabo et al.[89], which means that the action spectrum for suppression of CHS was applied, it could be estimated that exposure for 92 minutes (cumulative dose received during 7 consecutive days) at $40^{\circ} \mathrm{N}$ in July at local noon could lead to $50 \%$ suppression of specific T-cell mediated responses to L. monocytogenes in humans [ 129 89]. For extrapolation from artificial to solar UVR an action spectrum is required. As it is still unknown what action spectrum is the most relevant to UVR-associated immunosuppression, other action spectra were also used and yielded a number of minutes in the same order of magnitude (action spectrum for DNA [90]: 146 minutes; action spectrum for UCA absorption [60]: 119 minutes; action spectrum for MSLR [91]: 131 minutes). The effect of ozone depletion on the level of ambient UVR and hence on the possible immunosuppression during outdoor exposure could be estimated in these models as well. A $20 \%$ decrease in ozone resulted in a considerably lower estimated number of minutes of outdoor exposure required to cause a $50 \%$ suppression of cellular immunity to L. monocytogenes (for example, using the CHS action spectrum: 82 minutes) [30].

In the extrapolation exercise so far, the UVR dose that might lead to a suppression of antigen-specific immune responses in humans was predicted. A next step is to predict the clinical outcome of such effects. For this reason, a model for systemic HSV infection in the rat was used. HSV is neurotropic and intranasal 
infection may cause neurological symptoms (paralysis, nervousness) that are aggravated by exposure to UVR. In this infection model, the viral load, the clinical outcome, the exposure to UVR prior to infection, and their interrelationships could be properly quantified. By applying the action spectrum for suppression of $\mathrm{CHS}$, it was estimated that exposure to ambient UVR at $40^{\circ} \mathrm{N}$ in July at clear sky and at local noon during 302 minutes (cumulative dose received during 7 consecutive days) leads to a $10 \%$ increase of neurological symptoms due to systemic infection with HSV in humans. Applying other action spectra in the extrapolation yielded alternative estimated number of minutes, but in the same order of magnitude (action spectrum for DNA: 478 minutes; action spectrum for UCA absorption: 390 minutes; action spectrum for MSLR: 425 minutes). It was estimated that a $20 \%$ decrease in ozone was associated with a much lower exposure time necessary for the same $10 \%$ increase of symptoms (for example, using the CHS action spectrum: 271 minutes) [30].

In conclusion, we may say that extrapolation of animal data enabled us to provide an estimate of the immunosuppressive effects of UVR in human populations. UVR at doses relevant to outdoor exposure may impair the human immune system. As the extrapolation relies on many assumptions, and data on daily exposure to ambient UVR have not been incorporated yet, experimental studies with human volunteers and observational epidemiology are needed to verify these results.

\subsubsection{Preliminary conclusions}

Immunomodulating effects of UVR on the immune system were observed in both animals and humans. In different infection models in the rodent, a clear suppressive effect of UVR exposure on the host resistance could be established, leading to both impairment of specific immune response and an increase of microbial load and clinical symptoms. We may hypothesize that this effect is also relevant to human populations, leading to higher incidences of infection and/ or a more severe clinical course after infection. However, the risk of increased incidence or severity of infections associated with UVR exposure in humans is not known. For different reasons we may question whether UVR has indeed such a clear and unequivocal effects on infections.

It should be mentioned that UVR-induced immunosuppression may have different consequences for different infections. For instance, an improvement of the clinical skin lesion in Leishmania infection was observed due to an impairment of the Th-1 associated DTH response to this parasite [35]. On the other hand, worsening of clinical symptoms of labial HSV upon exposure to UVR has been observed. This finding may be caused in part by a direct activating effect of UVR on this specific virus [92]. This has also been suggested to occur for HIV [93]. This means that it may be hard to draw general conclusions concerning the effects of UVR on different types of infection.

Obviously, effects of UVR on immune responses in animal models and humans, even if they are comparable to a large extent, are not identical. A higher dose of UVR was needed to get the same impairment of NK-cell function and the epidermal antigen presentation in the MSLR in humans compared to rats. Suppression of CHS in humans both locally and distantly was observed, but UVR doses inducing an erythema may be a prerequisite for this effect. Other studies indicated that, even if erythema is not a prerequisite, the immunomodulating effects of UVR in humans are correlated with the erythema-inducing effect of UVR . In animal models, suberythemal UVR doses were often sufficient to demonstrate immunosuppression and 
impaired resistance to infections. This difference needs to be further substantiated, as it is an important issue when assessing the risk of immunosuppression by UVR.

Another problem encountered in the interpretation of animal data is the comparability of UV-B, which is often used in experimental animal settings, with solar UVR. UVR in sunlight comprises both UV-B and UV-A wavelengths. The role of UV-A is controversial. In some studies, it appeared that UV-A has immunosuppressive effects. In other ones, a protection against the UV-B-induced immunosuppressive effects was suggested [65 66 67]. A suppressive effect of sunlight, SSR, and broadspectrum UVR on various immune parameters could be established, which indicates that the UV-A waveband in sunlight does not abolish the immunosuppressive effects of UV-B [ $\left[\begin{array}{llll}11 & 12 & 39 & 82\end{array}\right.$ 94]. The effects of the UV-A waveband and the relevance to exposure to solar UVR need further investigation.

In animal experiments, UVR is given mostly during a few days, and only rarely much longer. We do not know what happens when UVR is given at high doses during months, as is the case in humans in sunny season, or during years or even decades, as is the case in humans living next to the equator. Adaptation to the immunosuppressive effects of UVR during chronic exposure may occur and keep the impairment of the host resistance within bounds [95]. However, as chronic UV exposure leads to tumour tolerance, we may also hypothesize that exposure for longer periods of years may still contribute to impaired host resistance.

In an extrapolation model (the 'parallelogram-approach'), data from animal experiments were extrapolated to humans taking interspecies differences in sensitivity to UVR-induced reduction of the MSLR into account. Exposure to UVR at doses relevant to human outdoor exposure appeared to be enough for a suppression of specific immune responses to Listeria monocytogenes and for an increase of clinical symptoms due to systemic infection with HSV. The dose needed to give an increase of clinical symptoms in the HSV model was 2 - 3 times higher than the dose needed to give an effect on immune parameters in the Listeria model. This may reflect differences between the two infection models or the possibility that impaired host resistance is not in a direct line with impaired immune responses. The extrapolation model must be further improved by taking the effects of different wavebands of sunlight and the role of adaptation into account, in addition to the influence of different micro-organisms, or at least classes thereof. 


\subsection{Hypotheses in relation to the presented studies in this thesis}

Observational and epidemiological studies are needed to get insight into the daily exposure to ambient UVR in human populations and to examine whether this exposure has an effect on the human immune system and the occurrence and severity of infectious diseases among other immunomodulating factors. The principal aim of the presented studies in this thesis was to investigate whether evidence is present that daily and non-experimental exposure to ambient UVR in humans is associated with reduced resistance to infections or a more severe course of an infection, once established.

Given the potential of UVR to induce immunosuppression, we may bring a number of hypotheses to the fore, but still keep in mind that other factors may overrule the immunosuppressive effects of UVR. At first, we hypothesized that the immunomodulating effect of UVR may lead to a higher occurrence of infections especially in those who are immunocompromised. For this reason, we investigated the incidence of skin infections in relation to exposure to solar UVR in renal transplant recipients, who were treated with immunosuppressive medication for prevention of renal graft rejection (Chapter 2). The effects of both lifetime-cumulative exposure, which had already been estimated by means of a self-administered questionnaire for a previous study on skin cancer, and short-term exposure were investigated [20]. No short-term exposure assessment was performed in this cohort of renal transplant recipients. For this reason, season of diagnosis was regarded as best available proxy of short-term measure of UVR exposure at the time of clinical manifestation of infection. The possibility to analyse the independent effects of a lifetime-cumulative and a shortterm estimate of UVR exposure on infections rendered this study uniqueness. It appeared from experimental studies (both animal and human) that UVR might have a short-term and possibly reversible suppressive effect on the immune system [ $\left[\begin{array}{ll}11 & 12\end{array}\right.$ 96]. For this reason, it was expected that the acute short-term exposure be of greater importance than the lifetime-cumulative exposure to solar UVR. Seasonal effects on skin-associated infections may be of special importance in relation to studies on UVR, because these infections occur at the anatomical site that is immediately involved in UVR-induced alterations (ie, the skin). On the other hand, it has been shown in both tumour and infection models that UVR has the potential to induce immunological tolerance and, as a consequence, an effect of exposure in the past may be present [ 26 28].

Secondly, we hypothesized that the possible detrimental effects of ambient UVR on the immune system and the course of an infection may become apparent especially in those who bear an immunomodulating virus, which replication is known to be enhanced by UVR [97]. We studied the effect of exposure to UVR, as reported in a self-administered two-year retrospective questionnaire, on the course of immunological parameters that are known to be relevant to disease progression in HIV infection in a small group of HIV-infected homosexual men (Chapter 3).

Furthermore, we analysed seasonal influences on the same immunological parameters in a much greater cohort of homosexual men, reasoning that the effects of ambient UVR on the HIV virus itself and related immune disorder may overrule other important seasonal effects on immunity and infections (Chapter 4).

Thirdly, we hypothesized that a vaccination given during sunny season is followed by a lower immune response and possibly even a lower level of immunoprotection compared to a vaccination given in winter. This was studied in 
vaccinations to hepatitis $\mathrm{B}$, measles, and rubella in healthy persons from the general Dutch population (Chapter 5). This study may give an important impression on the population level whether seasonal effects on antibody formation exist and whether these effects are in direct line with the postulated UVR-induced suppression of antibody formation following first encounter with an antigen, which was demonstrated in animal models [76 98]. In this study, important seasonal effects on immunity apart from ambient UVR could not be taken into account. However, ambient UVR may be especially important when exposed to just prior to or at the time of first encounter with a specific antigen. Seasonal effects on immune reactions immediately following contact with specific allergens have been described, and the UVR-induced immunosuppression as explanation has been strongly suggested [99 100]. Seasonal effects on specific immune responses may be established especially in countries far from the equator, as the difference between summer and winter ambient irradiation is greater at higher latitudes [99 101 102]. Responses to vaccination are important for studies on the immunotoxic effects of UVR, because these immune responses are immediately involved in the protection to an infection. Furthermore, studying responses to the above-mentioned vaccinations in relation to ambient UVR is important, as it may give an impression whether exposure to UVR may have consequences for non-skin associated immune responses in humans.

Next, we hypothesized that a higher exposure to ambient UVR may appear to be associated with a higher occurrence of respiratory tract symptoms when adjustments for the known seasonal influence on common colds are made in multivariate analysis. In a group of 1-year-old children, who participated in a birthcohort study on asthma and mite allergy, we studied the relationship between personal exposure to solar UVR on the one hand and respiratory tract symptoms on the other hand. Symptoms were analysed in relation to personal exposure, which was estimated by means of a 6-week retrospective questionnaire. The study was restricted to the months April through September. These months of the year are associated with comparatively high levels of ambient UVR in the Netherlands and differences in outdoor behaviour may lead to differences in personal exposure to solar UVR. It was reasoned that in young children such symptoms are mainly infection driven and asthma and respiratory allergies at this age are still low prevalent [103]. The exposure assessment is described in Chapter 6, the analyses of outcome are given in Chapter 7.

Finally, we hypothesized that exposure to UVR is associated with a higher susceptibility to human papilloma virus (HPV) (Chapter 8). HPV is known to be involved in the development of skin cancer, especially squamous cell carcinoma [2 21]. However, the exact role of HPV in skin carcinogenesis remains to be established. The higher risk for non-melanoma skin cancer associated with a higher lifetimecumulative exposure to sunlight may be caused by both the genotoxic and immunotoxic mechanisms of UVR. In addition, UVR may promote HPV infection and along this infectious way promote skin carcinogenesis as well. We investigated the relationship between the occurrence of a number of HPV types that are often found in epidermodysplasia verruciformis, skin warts, actinic keratoses, and nonmelanoma skin cancer (HPV type 5, 8, 15, 20, 24, and 38) and lifetime-cumulative sunlight exposure in a cross-sectional case-control study on skin cancer. 


\section{References}

1. Garssen J, Norval M, El-Ghorr A, Gibbs NK, Jones CD. Cerimele D. De Simone C, Caffieri S, Dall'Acqua F, De Gruijl FR, Sontag Y, Van Loveren H. Estimation of the effect of increasing UVB exposure on the human immune system and related resistance to infectious diseases and tumours. J Photochem Photobiol B: Biology 1998; 42: 167-179.

2. Norval M, Garssen J, Van Loveren H, El-Ghorr AA. UV-induced changes in the immune response to microbial infections in human subjects and animal models. J Epidemiol 1999; 9: S84-S92.

3. Duthie MS, Kimber I, Norval M. The effects of ultraviolet radiation on the human immune system. Br J Dermatol 1999; 140: 995-1009.

4. Sleijffers A, Garssen J, Van Loveren H. Ultraviolet radiation, resistance to infectious diseases, and vaccination responses. Methods 2002; 28: 111-121.

5. Friedmann PS, White SI, Parker S, Moss C, Matthews JN. Antigenic stimulation during ultraviolet therapy in man does not result in immunological tolerance. Clin Exp Immunol 1989; 76: 68-72.

6. Yoshikawa T, Rae V, Bruins-Slot W, Van den Berg JW, Taylor JR, Streilein JW. Susceptibility to effects of UVB radiation on induction of contact hypersensitivity as a risk factor for skin cancer in humans. J Invest Dermatol 1990; 95: 530-536.

7. Cooper KD, Oberhelman L, Hamilton TA, Baadsgaard O, Terhune M, LeVee G, Anderson T, Koren H. UV exposure reduces immunization rates and promotes tolerance to epicutaneous antigens in humans: Relationship to dose, CDla-DR+ epidermal macrophage induction, and Langerhans cell depletion. Proc Natl Acad Sci USA 1992; 89: 8497-8501.

8. O' Dell BL, Jessen T, Becker LE, Jackson RT, Smith EB. Diminished immune response in sun-damaged skin. Arch Dermatol 1980; 116: 559-561.

9. Damian DL, Halliday GM, Taylor CA, Barnetson R StC. Ultraviolet radiation induced suppression of Mantoux reactions in humans. J Invest Dermatol 1998; 110: 824-827.

10. Cestari TF, Kripke ML, Baptists PL, Bakos L, Bucana CD. Ultraviolet radiation decreases the granulomatous response to lepromin in humans. J Invest Dermatol 1995; 105: 8-13.

11. Hersey P, Hasic E, Edwards A, Bradley M, Haran G, McCarthy WH. Immunological effects of solarium exposure. Lancet 1983; I: 545-548.

12. Hersey P, Haran G, Hasic E, Edwards A. Alteration of T cell subsets and induction of supressor T Cell activity in normal subjects after exposure to sunlight. J Immunol $1983 ; 31: 171-174$.

13. Sleijffers A, Garssen J, De Gruijl FR, Boland GJ, Van Hattum J, Van Vloten WA, Van Loveren $\mathrm{H}$. Influence of Ultraviolet B exposure on immune responses following hepatitis B vaccination in human volunteers. J Invest Dermatol 2001; 117: 11441150 .

14. Neill WA, Halliday KE, Norval M. Differential effect of phototherapy on the activities of human natural killer cells and cytotoxic T cells. J Photochem Photobiol B: Biology 1998; 47: 129-135.

15. Di Nuzzo S, de Rie MA, van der Loos CM, Bos JD, Teunissen MBM. Solasimulated ultraviolet irradiation induces selective influx of CD4+ T lymphocytes in normal human skin. Photochem Photobiol 1996: 64: 988-993. 
16. Di Nuzzo S, Sylva-Steenland RMR, de Rie MA, Das PK, Bos JD, Teunissen MBM. UVB radiation preferentially induces recruitment of memory $\mathrm{CD} 4^{+} \mathrm{T}$ cells in normal human skin: long-term effect after a single exposure. J Invest Dermatol 1998: 110: 978-981.

17. De Gruijl FR. Health effects from solar UV radiation. Radiation Protection Dosimetry 1997; 72: 177-196.

18. Vitasa BC, Taylor HR, Strickland PJ, Rosenthal FS, West S, Abbey H, Ng SK, Munoz B, Emmet EA. Association of nonmelanoma skin cancer and actinic keratosis with cumulative solar ultraviolet exposure in Maryland Watermen. Cancer 1990; 65: 2811-2817.

19. Hartevelt MM, Bouwes Bavinck JN, Kootte AMM, Vermeer BJ, Vandenbroucke JP. Incidence of skin cancer after renal transplantation in the Netherlands.

Transplantation 1990; 49: 506-509.

20. Bouwes Bavinck JN, De Boer A, Vermeer BJ, Hartevelt MM, Van der Woude FJ, Claas FHJ, Wolterbeek R, Vandenbroucke JP. Sunlight, keratotic skin lesions and skin cancer in renal transplant recipients. Br J Dermatol 1993; 129: 242-249.

21. De Gruijl FR. Ultraviolet radiation and tumor immunity. Methods 2002; 28 : 122 129.

22. Taylor JR, Schmieder GJ, Shimizu T, Tie C, Streilein JW. Interrelationship between ultraviolet light and recurrent herpes simplex in man. J Dermatol Sci 1994; 224-232.

23. Selgrade MJK, Repacholi MH, Koren HS. Ultraviolet radiation-induced immune modulation: potential consequences for infectious, allergic, and autoimmune disease. Environ Health Perspect 1997: 105: 332-334.

24. Sontag Y, Guikers CLH, Vink AA, De Gruijl FR, Van Loveren H, Garssen J, Roza L, Kripke ML, Van der Leun JC, Van Vloten WA. Cells with UV-specific DNA damage are present in murine lymph nodes after in vivo UV irradiation. J Invest Dermatol 1995: 104: 734-738.

25. Garssen J, van Steeg H, De Gruijl FR, De Boer J, Van der Horst GTJ, Van Kranen H, Van Loveren H, Van Dijk M, Fluitman A, Weeda G, Hoeijmakers JHJ. Transcription-coupled and global genome repair differentially influence UV-Binduced acute skin effects and systemic immunosuppression. J Immunol 2000; 164: 6199-6205.

26. Fisher MS, Kripke ML. Further studies on tumor-specific suppressor cells induced by ultraviolet radiation. J Immunol 1978: 121: 1139-1144.

27. Kripke ML, Fisher MS. Immunological aspects of tumor induction by ultraviolet radiation. Natl Cancer Inst Monogr 1978; 50: 179-183.

28. Norval M, El-Ghorr AA. UV-induced immunosuppression in virus infections. Mutation Res 1998; 422: 131-138.

29. Goettsch W, Garssen J, Slob W, De Gruijl FR, Van Loveren H. Risk assessment for the harmful effects of UVB radiation on the immunological resistance to infectious diseases. Environ Health Perspect 1998; 106: 71-76.

30. Garssen J, Norval M, Van Loveren H. UVB-induced immunomodulation: a health risk. Polar Research 1999; 18: 339-343.

31. Nelson RJ, Demas GE, Klein SL, Kriegsfeld LJ. The influence of season, photoperiod and pineal melatonin on immune fuction. J Pineal Res 1995; 19: 149165. 
32. Perna JJ, Mannix ML, Rooney JF, Notkins AL, Straus SE. Reactivation of latent herpes simplex virus infection by ultraviolet light: a human model. J Am Acad Dermatol 1987; 17: 473-478.

33. Patki AH. Hypothesis: solar ultraviolet radiation and the initial skin lesions of leprosy. Int J Leprosy 1991; 59: 492-493.

34. Nacher M, Carme B, Sainte Marie D, Couppié P, Clyti E, Guibert P, Pradinaud R. Seasonal fluctuations of incubation, healing delays, and clinical presentation of cuteneous Leishmaniasis in French Guiana. J Parasitol 2001; 87: 1495-1498.

35. Giannini MSH. Suppression of pathogenesis in cutaneous leishmaniasis by UV irradiation. Infection and Immunity 1986; 51: 838-843.

36. Paul WE. Infectious diseases and the immune system. Scientific American September 1993: 57-63.

37. Simon JC, Mosmann T, Edelbaum D, Schopf E, Bergstresser PR, Cruz PD: In vivo evidence that ultraviolet-B-induced suppression of allergic contact sensitivity is associated with functional inactivation of Th1 cells. Photodermatol Photoimmunol Photomed 1994; 10: 206-211.

38. Gallerani M. Manfredini R. Seasonal variation in herpes zoster infection. Br J Dermatol 2000; 142: 588 .

39. Falkenbach A, Sedlmeyer A. Travel to sunny countries is associated with changes in immunological parameters. Photodermatol Photoimmunol Photomed 1997: 13: 139-142.

40. Termorshuizen F, Garssen J, Norval M. Koulu L, Laihia J. Leino L, Jansen CT, De Gruijl FR, Gibbs NK, De Simone C, Van Loveren H. A review of studies on the effects of ultraviolet irradiation on the resistance to infections: evidence from rodent infection models and verification by experimental and observational human studies. Int Immunopharm 2002; 2: 263-275.

41. Kölgen W, Van Weelden H, Den Hengst S, Guikers KLH, Kiekens RCM, Knol EF, Bruijnzeel-Koomen FM, Van Vloten WA, De Gruijl FR. CD1lb+cells and ultraviolet-B-resistant CDIa+cells in skin of patients with polymorphous light eruption. J Invest Dermatol 1999; 113: 4-10.

42. Ullrich SE. Does exposure to UV radiation induce a shift to a Th-2-like immune reaction? Photochem Photobiol 1996; 64: 254-258.

43. Halliday KE, Norval M. The effect of ultraviolet radiation on infectious diseases. Rev Med Microbiol 1997; 8: 179-188.

44. Garssen J, Norval M, Crosby J, Dortant P, Van Loveren H. The role of urocanic acid in UVB-induced suppression of immunity to Trichinella spiralis infection in the rat. Immunology 1999; 96: 298-306.

45. Goettsch W. Garssen J, Deijns A, de Gruijl F. Van Loveren H. UVB exposure impairs resistance to infections with Trichinella spiralis. Env Health Perspectives 1994; 102: 298-301.

46. Vink AA, Moodycliffe AM, Shreedhar V. Ullrich SE, Roza L, Yarosh DB, Kripke ML. The inhibition of antigen-presentating activity of dendritic cells resulting from UV irradiation of murine skin is restored by in vitro photorepair of cyclobutane pyrimidine dimers. Proc Natl Acad Sci USA 1997; 94: 5255-5260.

47. Applegate LA, Ley RD, Alcalay J, Kripke ML. Identification of the molecular target for the suppression of contact hypersensitivity by UV radiation. J Exp Med 1989; 170: 1117-1131. 
48. Kripke ML, Cox PA, Alas LG, Yarosh DB. Pyrimidine dimers in DNA initiate systemic immunosuppression in UV-irradiated mice. Proc Natl Acad Sci USA 1992; 89: 7516-7520.

49. Nishigori C, Yarosh DB, Ullrich SE, Vink AA, Bucana CD, Roza L. Kripke ML. Evidence that DNA damage triggers interleukin-10 cytokine production in UVirradiated murine keratinocytes. Proc Natl Acad Sci USA 1996; 93: 10354-10359.

50. Miyauchi-Hashimoto H, Horio T, Tanaka K. Enhanced inflammation and immunosuppression by ultraviolet radiation in xeroderma pigmentosum group $\mathrm{A}$ (XPA) model mice. J Invest Dermatol 1996; 107: 343-348.

51. De Vries A, Van Oostrom CTM, Hofhuis FMA, Dortant PM, Berg RJW, De Gruijl FR, Wester PW, Kreijl CF, Capel PJA, Van Steeg H, et al. Increased susceptibility to ultraviolet-B and carcinogens of mice lacking the DNA excision repair gene XPA. Nature 1995; 377: 169-173.

52. Sands AT, Abuin A, Sanchez A, Conti CJ, Bradley A. High susceptibility to ultraviolet-induced carcinogenesis in mice lacking XPC. Nature 1995; 377: 162-165.

53. Cheo DL, Meira LB, Hammer RE, Burns DK, Doughty AT, Friedberg EC. Synergistic interactions between XPC and p53 mutations in double-mutant mice: neural tube abnormalities and accelerated UV radiation-induced skin cancer. Curr Biol 1996; 6: 1691-1694.

54. Cheo DL, Ruven HJ, Meira LB. Hammer RE. Burns DK, Tappe NJ, Van Zeeland AA, Mullenders LH, Friedberg EC. Characterization of defective nucleotide excision repair in XPC mutant mice. Mutat Res 1997; 374:1-9.

55. Van der Horst GTJ, Van Steeg H, Berg RJW, Van Gool AJ, De Wit J, Weeda G, Morreau H, Beems RB. Van Kreijl CF, De Gruijl FR, Bootsma D, Hoeijmakers JH. Defective transcription-coupled repair in Cockayne syndrome $\mathrm{B}$ mice is associated with skin cancer predisposition. Cell 1997: 89: 425-435.

56. De Boer J, De Wit J, Van Steeg H, Berg RJW, Morreau M, Visser P, Lehmann AR, Duran M, Hoeijmakers JHJ, Weeda G. A mouse model for the basal transcription/DNA repair sndrome trichiodystrophy. Moll Cell 1998: 1: 981-990.

57. De Boer J, Van Steeg H, Berg RJW, Garssen J, De Wit J, Van Oostrom CTM, Beems RB, Van der Horst GTJ, Van Kreijl CF, De Gruijl FR, Bootsma D. Hoeijmakers JHJ, Weeda G. Mouse model for DNA repair/ basal transcription disorder trichothiodystrophy reveals cancer predisposition. Cancer Res 1999; 59: 3489-3494.

58. Kölgen W, Van Steeg H, Van der Horst GTJ, Hoeijmakers JHJ, Van Vloten WA, De Gruijl FR, Garssen J. Association of transcription-coupled repair but not global genome repair with ultraviolet-B-induced Langerhans cell depletion and local immunosuppression. J Invest Dermatol 2003; 121: 751-756.

59. Kelly DA, Young AR, McGregor JM, Seed PT, Potten CS, Walker SL. Sensitivity to sunburn is associated with susceptibility to ultraviolet radiation-induced suppression of cutaneous cell-mediated immunity. J Exp Med 2000; 191: 561-566.

60. De Fabo EC. Noonan FP. Mechanism of immune suppression by ultraviolet irradiation in vivo I. Evidence for the existence of a unique photoreceptor in skin and its role in photoimmunology. J Exp Med 1983; 157: 84-98.

61. Kammeyer A, Pavel S, Asghar SS, Bos JD, Teunissen MBM. Prolonged increase of cis-urocanic acid levels in human skin and urine after single total-body ultraviolet exposures. Photochem Photobiol 1997; 65: 593-598. 
62. De Fine Olivarius F, Wulf HC, Crosby J, Norval M. Seasonal variation in urocanic acid isomers in human skin. Photochem Photobiol 1997; 66: 119-123.

63. El-Ghor AA, Norval M. The effect of chronic treatment of mice with urocanic acid isomers. Photochem Photobiol 1997; 65: 866-872.

64. El-Ghorr AA, Norval M. The UV waveband dependencies in mice differ for the suppression of contact hypersensitivity, delayed-type hypersensitivity and cisurocanic acid formation. J Invest Dermatol 1999; 112: 757-762.

65. Garssen J, De Gruijl F, Mol D, de Klerk A, Roholl P, Van Loveren H. UVA exposure affects UVB and cis-urocanic acid induced systemic suppression of immune responses in Listeria monocytogenes infected Balb/c mice. Photochem Photobiol 2001; 73: 432-438.

66. Reeve VE, Bosnic M, Boehm-Wicox C, Nishimura N, Ley RD. Ultraviolet A radiation (320-400 $\mathrm{nm}$ ) protects hairless mice from immunosuppression induced by ultraviolet B radiation ( $280-320 \mathrm{~nm}$ ) or cis-urocanic acid. Int Arch Allergy Immunol 1998: 115: 316-322.

67. Reeve VE. Ley RD. Cis-urocanic acid-induced suppression of contact hypersensitivity in Monodelphis domestca is prevented by ultraviolet $\mathrm{A}$ radiation/photoreactivating light. Int Arch Allergy Immunol 1997; 112:257-261.

68. Shern J, Bao S, Reeve VE. Modulation of Il10, Il12, and interferon-gamma in the epidermis of hairless mice by UVA $(320-400 \mathrm{~nm})$ and UVB $(280-320 \mathrm{~nm})$ radiation. J Invest Derm 1999: 113: 1059-1064.

69. Jones CD, Barton AK. Crosby J, Norval M, Gibbs NK. Investigating the red shift between in vitro and in vivo urocanic acid photoisomerization action spectra. Photochem Photobiol 1996; 63: 302-305.

70. Rooney JF, Bryson Y, Mannix ML, Dillon M, Wehlenberg CR, Banks S, Wallington CL, Notkins AL, Straus SC. Prevention of ultraviolet-light-induced herpes labialis by sunscreen. Lancet 1991; 338: 1419-1422.

71. El-Ghorr AA, Norval M. The effect of UV-B irradiation on secondary epidermal infection of mice with herpes simplex virus type 1. J Gen Virol 1996; 77: 485-491.

72 . Rivas JM, Ullrich SE. The role of IL-4, ILl0, and TNF-alfa in the immune suppression induced by ultraviolet radiation. J Leucocyte Biol 1994; 56: 769-775.

73. El-Ghorr AA, Norval M. The role of interleukin-4 in ultraviolet B light-induced immunosuppression. Immunology 1997; 92: 26-32.

74. El-Ghorr AA, Norval M. The effect of UV-B irradiation on primary and secondary HSV-1 infections in interleukin-4 knockout mice. Arch Dermatol Res 1999; $291: 459-465$.

75. El-Ghorr AA, Horsburgh G, Norval M. The effect of UVB irradiation on antibody responses during herpes simplex virus type 1 (HSV-1) infections of mice.

Photodermatol Photoimmunol Photomed 1998; 14: 17-25.

76. Boonstra A, Van Oudenaarden A, Barendregt B, An L, Savelkoul HFJ. Effect of short-term UVB irradiation on humoral immunity. Photochem Photobiol 1999; 69: $98 \mathrm{~S}$.

77. Garssen J, Vandebriel RJ, De Gruijl FR, Wolvers DAW, Van Dijk M, Fluitman A, Van Loveren H. UVB exposure-induced systemic modulation of TH1 - and TH2mediated immune responses. Immunology 1999; 97: 506-514.

78. Wynn TA, Morawetz R, Scharton-Kersten T, Hieny S, Morse HC 3rd, Kuhn R, Muller W, Cheever AW, Sher A. Analysis of granuloma formation in double 
cytokine-deficient mice reveals a central role for IL-10 in polarizing both $\mathrm{T}$ helper cell 1- and T helper cell 2-type cytokine responses in vivo. J Immunol 1997; 159: 5014-5023.

79. Bach JF. The effect of infections on susceptibility to autoimmune and allergic diseases. N Engl J Med 2002; 347: 911- 920.

80. Van Loveren H, Boonstra A, Van Dijk M, Fluitman A, Savelkoul HFJ, Garssen J. UV Exposure alters respiratory allergic responses in mice. Photochem Photobiol 2000; 72: 253-259.

81. Jansen C, Leszczynski D, Pastila R, Koulu L, Laihia J et al. Immunosuppressive, carcinogenic and metastase-related effects of solar UV radiation. Publications of The Finnish Research Programme on Environmental Health, SYTTY 2000; 1: 241-247.

82. Kelly DA, Walker SL, McGregor JM, Young AR. A single exposure of solar simulated radiation suppresses contact hypersensitivity responses both locally and systemically in humans: quantitative studies with high-frequency ultrasound. $\mathrm{J}$ Photochem Photobiol B: Biology 1998; 44: 130-142.

83. Jones CD, Guckian M, El-Ghorr AA, Gibbs NK, Norval M. Effects of phototherapy on the production of cytokines by peripheral blood mononuclear cells and on systemic antibody responses in patients with psoriasis. Photodermatol Photoimmunol Photomed 1996; 12: 204-210.

84. Piskin G, Koomen CW, Picavet D, Bos JD, Teunissen MBM. Ultraviolet-B irradiation decreases IFN- $\gamma$ and increases IL- 4 expression in psoriatic lesional skin in situ and cultured dermal T cells derived from these lesions. Exp Dermatol 2003; 12: $172-180$.

85. Di Nuzzo S, Sylva-Steenland RMR, Koomen CW, Nakagawa S, van Breemen M, de Rie MA, Das PK, Bos JD, Teunissen MBM. UVB irradiation of normal human skin favors the development of type-2 T-cells in vivo and in primary dermal cell cultures. Photochem Photobiol 2002; 76: 301-309.

86. Fisher MS, Kripke ML. Systemic alterations induced in mice by ultraviolet irradiation and its relationship to ultraviolet carcinogenesis. Proc Natl Acad Sci USA 1977; $74: 1688-1692$.

87. Gilmour JW, Vestey JP, Norval M. The effect of UV therapy on immune function in patients with psoriasis. Br J Dermatol 1993; 129: 28-38.

88. Leino L, Saarinen K, Kivisto K, Koulu L, Punnonen K. Jansen J. Systemic suppression of human peripheral blood phagocytic leukoytes after whole-body UVBirradiation. J Leukocyte Biol 1999; 65: 573-582.

89. De Fabo EC, Noonan FP, Frederick JE. Biologically effective doses of sunlight for immune suppression at various latitudes and their relationship to changes in stratospheric ozone. Photochem Photobiol 1990; 52: 811-817.

90. Matsunaga T, Hieda K, Nikaido O. Wavelength dependent formation of thymine dimers and (6-4) photoproducts in DNA by monochromatic ultraviolet light ranging from 150 to $365 \mathrm{~nm}$. Photochem Photobiol 1991; 54: 403-410.

91. Hurks HMH, Out-Luiting C, Vermeer BJ, Claas FHJ, Mommaas AM. The actionspectra for UV-induced suppression of MLR and MECLR show that immunosuppression is mediated by DNA damage. Photochem Photobiol 1995; 62: 449-453.

92. Norval M, El-Ghorr AA, Garssen J, Van Loveren H. The effects of ultraviolet light irradiation on viral infections. Br J Dermatol 1994; 30: 693-700. 
93. Akaraphanth R, Lim HW. HIV, UV and Immunosuppression. Photodermatol Photoimmunol Photomed 1999; 15: 28-31.

94. Whitmore SE, Morison WL. The effect of suntan parlor exposure on delayed and contact hypersensitivity. Photochem Photobiol 2000; 71: 700-705.

95. Sleijffers A, Garssen J, Van Loveren H. Chronic low dose UVB exposure can prevent UVB-induced suppression of DTH in a mouse model for hepatitis B vaccination, but not suppression of CHS responses. Submitted, 2003.

96. Goettsch W, Garssen J, Timmerman HH, Dortant P, Kuper F, De Gruijl FR, Van Loveren H. Systemic effects of UVB irradiation on basal immune parameters in the rat. In: Biological Effects of Light 1993 (Jung EG, Holick MF, eds). Berlin: Walter de Gruyter, 1993: 637-641.

97. Breuer-McHam J, Simpson E, Dougherty I, Bonkobara M, Ariizumi K, Lewis DE, Dawson DB, Duvic M, Cruz PD. Activation of HIV in human skin by ultraviolet B radiation and its inhibition by NFKB blocking agents. Photochem Photobiol 2001; 74: 805-810.

98. Sleijffers A, Garssen J, De Gruijl FR, Boland GJ, Van Hattum J, Van Vloten WA, Van Loveren H. UVB Exposure impaires immune responses after Hepatitis B vaccination in two different mouse strains. Photochem Photobiol 2002, 75, 541-546.

99. Edman B. Seasonal influence on patch test results. Contact Dermatitis 1989; 20: 226.

100. Bruze M. Seasonal influence on routine patch test results. Contact Dermatitis $1986 ; 14: 184$.

101. Dooms-Goossens A, Lesaffre E, Heidbuchel M, Dooms M, Degreef H. UV sunlight and patch test reactions in humans. Contact Dermatitis 1988; 19: 36-42. 102. Katsarou A, Kalogeromitros D, Armenaka M, Koufou V, Stratigos J. The influence of climatic factors on patch test results in Athens. Contact Dermatitis $1993 ; 28: 301-302$.

103. Illi S, von Mutius E, Lau S, Bergmann R, Niggeman B, Sommerfeld C, Wahn U, and the MAS Group. Early childhood infectious diseases and the development of asthma up to school age: a birth cohort study. BMJ 2001; 322: 390-395. 
Chapter 2 Skin infections in renal transplant recipients and the relation with solar ultraviolet radiation

F. Termorshuizen', A.A. Hogewoning ${ }^{2}$, J.N. Bouwes Bavinck ${ }^{2}$, W. Goettsch' ${ }^{1}$ J.W. de Fijter ${ }^{3}$, H. van Loveren ${ }^{1}$

'Laboratory for Toxicology, Pathology, and Genetics, National Institute of Public Health and the Environment (RIVM), Bilthoven, The Netherlands; Departments of ${ }^{2}$ Dermatology and ${ }^{3}$ Nephrology, Leiden Universitary Medical Centre, Leiden, The Netherlands. 


\section{Summary}

Ultraviolet radiation (UVR) is an important risk factor for skin cancer in transplant recipients. In view of the potential of UVR to induce immunosuppression, it was examined whether exposure to UVR was also associated with the occurrence of various skin infections.

In a cohort of renal transplant recipients $(n=137)$, lifetime-cumulative exposure to sunlight was assessed by means of a retrospective questionnaire.

Diagnosed skin infections since renal transplantation were extracted from the patient's medical charts. Season of diagnosis was regarded as indicative of short-term sun exposure.

In comparison with winter, a high rate of herpes simplex infections was found in spring ( $R R=4.09,95 \%$-CI: $1.15-14.47)$, and high rates of herpes zoster infections $(\mathrm{RR}=1.62,95 \%-\mathrm{CI}: 0.75-3.50)$ and fungal/ yeast infections in summer $(\mathrm{RR}=2.06$, 95\%-CI: 1.27-3.36). A higher lifetime exposure ( $\mathrm{RR}=2.31,95 \%-\mathrm{CI}: 1.04-5.13)$ and a greater lifetime number of painful sunburns $(R R=2.34,95 \%-C I: 1.06-5.14)$ were independently associated with a higher risk of bacterial infections.

The seasonal association with the occurrence of clinical herpes infections indicates an effect of short-term UVR. Our data suggest that the number of sunburn episodes in the past is also relevant to the susceptibility to certain skin infections.

\section{Introduction}

It is known that transplant recipients are at an increased risk of acquiring several types of skin infections due to their immunosuppressive therapy [llllll. It has also been shown that renal transplant recipients are at increased risk of non-melanoma skin cancer [4]. This applies especially to squamous cell carcinomas, and these skin cancers occur mostly on sun-exposed sites like face and hands [4 5]. Both immunosuppressive therapy and the lifetime-cumulative exposure to sunlight are believed to be important risk factors for the development of skin cancers in transplant recipients [5]. The purpose of the present analysis was to examine the possible association between exposure to solar ultraviolet radiation (UVR) and the occurrence of different skin infections in renal transplant recipients.

Experimental animal data show that UVR at doses relevant to outdoor exposure may affect specific cellular and non-specific immune responses and reduce the resistance to viral, bacterial and parasitic agents [ 67 8]. It has also been shown that exposure to artificial UVR or sunlight may suppress important immune parameters in humans [9-13]. It is still an unresolved issue whether this acute UVRinduced immunosuppression is associated with an increased risk of infections or with a more severe clinical course following infection in human populations [14 15].

In a cohort of renal transplant recipients, who were initially included in a study on skin cancer, we retraced the medical records and checked them for the presence of viral, bacterial and fungal/ yeast skin infections since the time of renal transplantation [3 5]. The infections found in these charts and their occurrence in the course of time since the renal transplantation have been described before [3].

It appeared from experimental studies (both animal and human) that UVR may have a short-term and possibly reversible suppressive effects on the immune system [9 16]. For this reason, it was expected that the acute short-term exposure to solar UVR was of greater importance than the lifetime-cumulative exposure, which is associated 
with cumulated DNA damage in the skin and as a consequence the induction of skin malignancies. We hypothesized that in these immunosuppressed patients a high, probably short-term exposure to solar UVR is associated with an increased risk of skin infections.

\section{Methods}

\section{I Study group}

The cohort maintained at the Transplant Unit of the Leiden University Medical Centre consisted of 137 renal transplant recipients, who had received their first transplant between July 20, 1967 and December 22, 1980 and who were still alive with a functioning graft on August 1, 1989. The selection of this group of patients has been described before [ 355 17]. For the study on infections, the follow-up of the cohort was extended to July 1, 1996. Between August 1, 1989 and July 1, 199625 patients died. All but three charts could be retraced from the Transplant Unit. The occurrence of skin infections in these patients has been described by time since renal transplantation before [3].

\subsection{Assessment of exposure to sunlight}

Between August 24, 1988 and December 31, 1989, a retrospective questionnaire on sunlight exposure was administered [5 17]. Each patient's lifetime-cumulative exposure to sunlight was calculated by adding the hours of exposure associated with occupational activities to those associated with non-occupational activities, such as outdoor recreation, holidays and residence in the tropics. This questionnaire was designed to explore the association between the lifetime-cumulative exposure to solar UVR and the risk of skin cancer. (The questionnaire and the protocol for assessing the personal exposure are available from Dr Bouwes Bavinck on request). For the present analysis, the estimated number of hours exposed was divided by the individual time covered by the questionnaire (ie, from birth till 1988/1989). This yielded a measure for the patient's habitual sun exposure (mean number of hours/ day), in which the lifetime- cumulative exposure had been calculated in, but also differences in age and time periods covered by the questionnaire had been taken into account. The patients were also asked to indicate the number of painful sunburns in relation to age intervals.

It is well known that there is a strong association between season and exposure to ambient UVR in human populations [18]. As the short-term exposure to sunlight could not be measured day-by-day in these patients, the season of the year at the time of the diagnosis of an infection was regarded as indicative of the exposure at the time of or prior to that infection.

\subsection{Statistical analysis}

We explored the association between the occurrence of skin infection and exposure to sunlight by means of a multivariate Poisson regression analysis for repeated measurements. Rate ratios (RR) and their statistical significance were calculated to estimate the relative risk associated with one category of exposure with respect to a reference category, which was chosen according to the expectation of lowest risk. The effects of clinical parameters that also may influence the occurrence of infections were taken into account: time since renal transplantation [ $\left[\begin{array}{lll}1 & 2 & 3\end{array}\right]$, treatment regimen with immunosuppressive medication [2 192021 ], suffering from diabetes [22 23], skin type (I-IV) and number of treatments for rejection. Those variables were included in 
the multivariate analysis that appeared to be associated with the occurrence of skin infections after adjustment for the effect of time since renal transplantation only. A P value of 0.10 (90\%-confidence interval $(\mathrm{CI})$ ) was regarded as the level of statistical significance in the bivariate models. In the multivariate analysis a P value of 0.05 $(95 \%-\mathrm{CI})$ was regarded as the level of statistical significance. All analyses were performed for viral, bacterial and fungal/ yeast infections separately [3].

\section{Results}

An overview of all registered skin infections since renal transplantation is given in Table 1. A total of 340 skin infections in 105 patients were detected. For 24 patients out of these 105 patients, herpes zoster ('shingles') was the first diagnosed infection since renal transplantation $(22.8 \%)$; for 18 patients, Candida albicans $(17.1 \%)$ was the first diagnosed infection since renal transplantation. The infections were 97 times of viral, 97 times of bacterial and 146 times of fungal/ yeast origin. Herpes zoster and herpes simplex infections formed the majority of viral skin infections. In 48 patients out of the 134 patients for whom the medical charts could be retraced, a herpes zoster infection was diagnosed once or more since renal transplantation. Folliculitis was diagnosed in 29 patients once or more since renal transplantation.

The herpes zoster infections were often localized on the trunk $(52.9 \%)$ and head/face $(21.6 \%)$, herpes simplex infections often on the head/ face $(56.5 \%)$, the other herpes simplex infections mainly on the trunk and extremities $(30.4 \%)$. No genital herpes simplex infections were found in the medical charts. Bacterial infections were often diagnosed on the extremities $(42.4 \%)$ and trunk $(29.4 \%)$; fungal/ yeast infections were also often diagnosed on extremities $(30.7 \%)$ and trunk $(31.4 \%)$ (data not shown).

In Table 2, the associations with the lifetime exposure, number of painful sunburns, and season, as were established in the multivariate Poisson regression analysis, are shown. The analysis was performed for the different classes of infection separately. A higher lifetime exposure to sunlight tended to be associated with a higher rate of bacterial infections, but no clear gradient was established, as the highest rate of these infections was found in the group of participants with intermediate lifetime sunlight exposure. No associations with the cumulative sunlight exposure as estimated for the time since renal transplantation only could be established for either class of skin infections (data not shown). A comparatively high number of reported sunburns $(\geq 3)$ appeared to be associated with a higher risk of bacterial skin infections.

A comparatively high occurrence of viral and fungal/ yeast infections was found during spring and summer. The analysis was also performed for herpes simplex-and herpes zoster infections separately, as it is known that exposure to solar UVR may facilitate the recurrence of herpes viruses. The highest incidence of herpes simplex was found in spring, whereas the highest incidence of herpes zoster was found in summer. The highest incidence of bacterial skin infections was found in spring, which was statistically significantly higher than the comparatively low incidence of these infections in summer.

When categorising the seasonal fluctuation of ambient UVR in 'high' (April through September) and 'low' (October through March), a statistically significant seasonal effect on herpes simplex infections (RR of infection for quarters with high ambient UVR compared with quarters with low ambient UVR was $3.8,95 \%$-CI: 1.6 9.1 ) and fungal/ yeast infections ( $R R=1.5,95 \%-C I: 1.1-2.1)$ could still be established. 
However, when dichotomising in this way, no differences between the 'UVR-high' and the 'UVR-low' season in the occurrence of herpes zoster infections ( $R R=0.97$, 95\%-CI: 0.56-1.69) and bacterial skin infections ( $\mathrm{RR}=1.08,95 \%$-CI: $0.78-1.49)$ were found.

When restricting the analysis on fungal/ yeast infections to Candida albicans infections only, the same tendency towards higher incidence in spring ( $R=2.2,95 \%$ CI: $0.8-5.8)$ and summer ( $R R=2.3,95 \%-C I: 0.96-5.4)$ was found. No statistically significant and independent associations between skin type and the occurrence of skin infections were established (data not shown).

The high occurrence of herpes zoster infections in summer appeared to be due to infections on the trunk $(72.2 \%)$, and the high occurrence of herpes simplex in spring was due to infections on head/ face $(58.3 \%)$. The decline of bacterial infections in summer was due to fewer infections on extremities and trunk, while the majority of registered bacterial infections on frequently sun exposed sites (head/ face and hands) were found during sunny season ( 12 out of the 17 bacterial infections that were diagnosed on head/ face or hands). The majority of fungal/ yeast infections diagnosed in summer were found on the extremities $(37.5 \%)$ and trunk $(35.4 \%)$, while the number of those on sun-exposed sites in summer was small $(<5 \%)$.

\section{Discussion}

In a cohort of renal transplant recipients. we examined the association between exposure to solar UVR and the incidence of various skin infections. This was done by means of an estimate of short-term exposure ('season') and by means of a questionnaire-based estimate of lifetime exposure. The lifetime-cumulative estimate of sunlight exposure was initially used for a study on skin cancer.

The highest rate of herpes simplex infections was found in the sunny season. For herpes zoster, the association with the seasonal fluctuation of ambient UVR was less apparent. Still, the highest rate of herpes zoster was found in the summer months. It is known that UVR may induce the recurrence of herpes simplex, although we found no other studies in which a clear seasonal variation was established [24-27]. In a population-based study, a statistically significant seasonal influence on the referred number of patients with acute herpes zoster viral infection was found [28]. The highest rates were found in summer, lower rates in autumn and winter and the lowest rates in spring, which is in accordance with our findings. In a recent study, it was also found that summer months were associated with the greatest number of patients with herpes zoster [29]. In another population-based study, no seasonal effect on the occurrence of herpes zoster was found [30]. The adverse effects of UVR on the occurrence and severity of infections may come to light more easily in persons who are immunocompromised, as was also indicated for the carcinogenic effects of UVR [5]. As both humoral and cellular immune responses are important to maintain control of viral replication, it is possible that the observed seasonal fluctuation of herpes infections is related to yearly variations in immune responses and that these variations are associated with exposure to solar UVR [29 31]. In addition to UVR, the high rate of fungal/ yeast infections in summer may also be due to the seasonal difference in ambient and skin temperature and/ or humidity.

No clear seasonal association with the occurrence of bacterial skin infections that might indicate a short-term immunosuppressive effect of UVR was found. It is remarkable that the lowest incidence of bacterial skin infections was found in summer, 
which contradicts with the postulated immunosuppression due to high ambient levels of UVR. More data are needed to examine whether the high incidence of herpes simplex and bacterial infections in spring and the decline thereafter is due to a possible physiological adaptation to the immunomodulating effects of UVR [32 33]. As other environmental and behavioural factors that have a seasonal association may also account for seasonal fluctuations, our data have to be interpreted with caution. For the bacterial skin infections, a tendency towards a higher incidence at a higher lifetime exposure and a greater number of sunburns was found. DNA damage is one possible mediator of UVR-induced immunosuppression. Whether for this reason an association with a lifetime-cumulative measure of exposure to UVR may be hypothesized, is questionable. DNA-repair mechanisms are immediately operative and, as a consequence, DNA-damage mediated immunomodulation is probably also a short-term effect [ 34 35]. More important for a possible association with exposure in the past, it has been shown in rodents that short-term UVR exposure may cause antigen-specific tolerance and hence lasting reduced resistance to specific tumours and microbial agents will ensue [ 3637 ]. In addition, it has been demonstrated that induction of tumour tolerance develops under chronic UVR exposure, which indicates an effect of accumulated UVR exposure or the effect of a persistent UVR-related stimulus [38]. Induction of immunological tolerance following localized sunburn has been observed before in an experimental human study [39]. It has been suggested in experimental human studies that erythema is a prerequisite for the immunomodulating effects of UVR or that there is at least a strong correlation between erythema and immunomodulation [40 41].

We may raise different objections to our study design. The limited validity of lifetime-retrospective questionnaires, inter-individual differences in the number of visits to the clinic and lack of detailed daily information on -for example- use of immunosuppressive medication may have biased the results. However, these objections do probably not apply to the found seasonal effects on infection rates, as the date of diagnosis of an infection was registered with high reliability and associations between season and the number of visits to the clinic or the doctor's prescription of immunosuppressive medication are unlikely. Still, more data are needed to establish a possible causal relationship between solar UVR and the occurrence of infections in humans, and to examine whether our results are also relevant to non-immunocompromised humans.

\section{Acknowledgements}

We thank dr. N.J.D. Nagelkerke and C. de Lezenne Coulander, both statisticians, for their support in the statistical analyses. This study was supported by the Dutch National Research Programme on Global Air Pollution and Climate Change (NOP, Project 952276) and Project ENV4-CT96-0192 of the Programme Environment of the EU. 


\section{Tables}

Table 1 The number and type of skin infections registered in the medical records since the time of renal transplantion (modified from Hogewoning et al. 2001 [3])

All infections together

$\begin{array}{lll}\text { First infection since } & \begin{array}{l}\text { Number of } \\ \text { transplantation per }\end{array} & \begin{array}{l}\text { Number of } \\ \text { patients }\end{array} \\ \text { patient } & & \text { sincections } \\ & & \text { transplantation }\end{array}$

\section{Infection}

Viral

Herpes zoster ('shingles')

Herpes simplex

$24(22.8 \%)$

48

$55(16.2 \%)$

Molluscum contagiosum

$9(8.6 \%)$

17

$26(7.6 \%)$

$4(3.8 \%)$

$16(4.7 \%)$

\section{Bacterial}

Impetigo vulgaris

$7(6.7 \%)$

$2(1.9 \%)$

14

$19(5.6 \%)$

Ecthyma

$15(14.3 \%)$

3

Folliculitis

Erysipelas

$4(3.8 \%)$

$0(0.0 \%)$

29

$3(0.9 \%)$

$50(14.7 \%)$

Erythrasma

\section{Fungal/ Yeast}

Candida albicans

\begin{tabular}{cr}
$18(17.1 \%)$ & 28 \\
$13(12.4 \%)$ & 40 \\
$4(3.8 \%)$ & 12 \\
$5(4.8 \%)$ & 11 \\
\hline $105(100 \%)$ &
\end{tabular}

$46(13.5 \%)$

Dermatomycosis

Onychomycosis

Tinea versicolor

No infections

Charts not retraced

\section{9}

$\frac{3}{137 \text { patients }}$

$63(18.5 \%)$

$18(5.3 \%)$

$19(5.6 \%)$

340 infections 
Table 2. The effect of sumlight exposure on skin infections since renal transplamation; results of the multivariate Poisson regression unalysis

\begin{tabular}{|c|c|c|c|c|c|c|c|c|c|c|}
\hline \multirow{3}{*}{$\begin{array}{l}\text { lifetime exposure to } \\
\text { sunlight }\end{array}$} & \multicolumn{2}{|c|}{$\begin{array}{l}\text { All viral } \\
\text { infections }\end{array}$} & \multicolumn{2}{|c|}{$\begin{array}{c}\text { Viral } \\
\text { herpes simplex }\end{array}$} & \multicolumn{2}{|c|}{ herpes zoster } & \multicolumn{2}{|c|}{ Bacterial } & \multicolumn{2}{|c|}{ Fungal/ Yeast } \\
\hline & $\mathrm{RR}$ & $95 \%-\mathrm{CI}$ & RR & $95 \%-\mathrm{Cl}$ & RR & $95 \%-\mathrm{Cl}$ & RR & $95 \%-\mathrm{CI}$ & $\mathrm{RR}$ & $95 \%-\mathrm{Cl}$ \\
\hline & & & & & & & & & & \\
\hline$<0.52$ hours/ day & & * & & a & & a & 1.00 & & 1.00 & \\
\hline $0.52-0.77 \cdots$ & & & & & & & 2.31 & $1.04-5.13$ & 1.71 & $0.96-3.05$ \\
\hline$>0.77 \cdot$ & & & & & & & 1.58 & $0.6 .3-3.95$ & 1.07 & $0.56 \cdot 2.05$ \\
\hline $\begin{array}{l}\text { timated number of } \\
\text { inful sunburns }\end{array}$ & & & & & & & & & & \\
\hline 0.1 . ог 2 & & b & & $"$ & & $n$ & 1.00 & & & h \\
\hline 3 or more & & & & & & & 2.34 & $1.06-5.14$ & & \\
\hline ason of diagnosis & & & & & & & & & & \\
\hline January - March & 1.00 & . & 1.00 & . & 1.00 & & 1.00 & & 1.00 & \\
\hline April -June & 1.23 & $0.65-2.33$ & 4.09 & $1.15-14.47$ & 0.64 & $0.25-1.65$ & $1.48^{d}$ & $0.99-2.21$ & 1.54 & $0.96-2.48$ \\
\hline July - September & 1.58 & $0.92-2.73$ & 2.06 & $0.59 \cdot 7.23$ & $1.62^{r}$ & $0.75-3.50$ & 0.83 & $0.50-1.38$ & 2.06 & $1.27-3.36$ \\
\hline Oclober - December & 1.27 & $0.69-2.33$ & 0.66 & $0.12-3.68$ & 1.32 & $0.61-2.88$ & 1.13 & $0.64=1.98$ & 1.39 & $0.82-2.37$ \\
\hline
\end{tabular}

"As the estimate for the lifetime exposure was not statistically significantly associaled with the occurrence of viral skin infections in the bivariate model (see methods), this variable was not included in the multivariate model for this class of infections. "As the number of painful sunburns was not statistically significantly associaled with either the occurrence of viral infections or fungal/ yeast infections in the bivariale model (see methods), this variable was not included in the multivariate models for these classes of infection. "The difference berween the rate in 'July - September' and the rate in 'April - June'

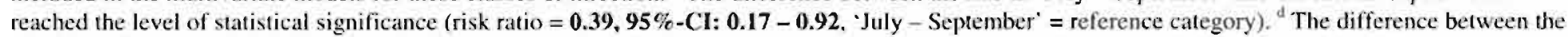
rate in 'July - September' and the rate in 'April - June' reached the level of statistical significance (risk ratio $=1.79,95 \%$-CI: $1.06-3.00$. 'July September' $=$ reference calegory). 


\section{References}

1. Fishman JA, Rubin RH. Infection in organ-tranplant recipients. New Engl J Med 1998; 338: 1741-1751.

2. Rubin RH. Infection in the Organ Transplant Recipient. In: Clinical Approach to Infection in the Compromised Host (Rubin RH, Young LS, eds). Third edition, New York and London: Plenum Medical Book Company, 1994: 629-686.

3. Hogewoning AA, Goettsch W, Van Loveren H, De Fijter JW, Vermeer BJ, Bouwes Bavinck JN. Skin infections in renal transplant recipients. Clin Transplantation 2001; 15: 32-38.

4. Hartevelt MM, Bouwes Bavinck JN, Kootte AMM, Vermeer BJ, Vandenbroucke JP. Incidence of skin cancer after renal transplantation in the Netherlands.

Transplantation 1990; 49: 506-509.

5. Bouwes Bavinck JN. De Boer A, Vermeer BJ, Hartevelt MM, Van der Woude FJ, Claas FHJ, Wolterbeek R, Vandenbroucke JP. Sunlight, keratotic skin lesions and skin cancer in renal transplant recipients. Br J Dermatol 1993; 129: 242-249.

6. Goettsch W, Garssen J, Slob W, De Gruijl FR, Van Loveren H. Risk assessment for the harmful effects of UVB radiation on the immunological resistance to infectious diseases. Environ Health Perspect 1998; 106: 71-76.

7. Garssen J, Norval M, El-Ghorr A, Gibbs NK, Jones CD, Cerimele D, De Simone C, Caffieri S, Dall'Acqua F De Gruijl FR, Sontag Y, Van Loveren H. Estimation of the effect of increasing UVB exposure on the human immune system and related resistance to infectious diseases and tumours. J Photochem Photobiol B: Biology 1998: 42: 167-179.

8. Ryan LK, Neldon DL, Bishop LR, Gilmour MI, Daniels MJ, Sailstad DM, Selgrade MJK. Exposure to ultraviolet radiation enhances mortality and pathology associated with influenza virus infection in mice. Photochem Photobiol 2000: 72: 497-507.

9. Hersey P. Hasic E. Edwards A, Bradley M. Haran G. McCarthy WH. Immunological effects of solarium exposure. Lancet 1983; I: 545-548.

10. Hersey P, Haran G, Hasic E, Edwards A. Alteration of T cell subsets and induction of supressor T Cell activity in normal subjects after exposure to sunlight. J Immunol 1983; 31: 171-174.

11. Falkenbach A, Sedlmeyer A. Travel to sunny countries is associated with changes in immunological parameters. Photodermatol Photoimmunol Photomed 1997: 13: 139-142.

12. Kelly DA, Walker SL, McGregor JM, Young AR. A single exposure of solar simulated radiation suppresses contact hypersensitivity responses both locally and systemically in humans: quantitative studies with high-frequency ultrasound. J Photochem Photobiol B: Biology 1998; 44: 130-142.

13. Whitmore SE, Morison WL. The effect of suntan parlor exposure on delayed and contact hypersensitivity. Photochem Photobiol 2000; 71: 700-705.

14. Chapman RS, Cooper KD, De Fabo EC et al. Solar ultraviolet radiation and the risk of infectious disease: summary of a workshop. Photochem Photobiol 1995: 61: 223-247.

15. Norval M, Garssen J, Van Loveren H, El-Ghorr AA. UV-induced changes in the immune response to microbial infections in human subjects and animal models. J Epidemiol 1999; 9: S84-S92.

16. Goettsch W, Garssen J, Timmerman HH, Dortant P. Kuper F, De Gruijl FR, Van Loveren $\mathrm{H}$. Systemic effects of UVB irradiation on basal immune parameters in the 
rat. In: Biological Effects of Light 1993 (Jung EG, Holick MF, eds). Berlin: Walter de Gruyter, 1993: 637-641.

17. Bouwes Bavinck JN, Vermeer BJ, Van der Woude FJ, Vandenbroucke JP, Schreuder GMT, Thorogood J, Persijn GG, Claas FHJ. Relation between skin cancer and HLA antigens in renal-transplant recipients. N Engl J Med 1991: 325: 843-848.

18. Diffey BL. Larkö O. Clinical climatology. Photodermatol 1984; 1: 30-7.

19. Hollander AAMJ, Hene RJ, Hermans J, Van Es LA, Van der Woude FJ. Late prednisone withdrawal in cyclosporine-treated kidney transplant patients: a randomized study. J Am Soc Nephrol 1997: 8: 294-301.

20. Virgili A, Zampino MR, La Malfa V, Strumia R, Bedani PL. Prevalence of superficial dermatomycoses in 73 renal transplant recipients. Dermatology 1999: 199: 31-34.

21. Vincenti F, Amend W, Feduska NJ, Duca RM, Salvatierra O. Improved outcome following renal transplantation with reduction in the immunosuppression therapy for rejection episodes. Am J Med 1980: 69: 107-112.

22. Romano G, Moretti G, DiBenedetto A, Giofre C, DiCesare E, Russo G, Califano

L, Cucinotta D. Skin lesions in diabetes mellitus: prevalence and clinical correlations. Diabetes Res Clin Pract 1998: 39: 101-106.

23. Trilla A, Miro JM. Identifying high risk patients for Staphylococcus aureus infections: skin and soft tissue infections. J Chemother 1995: 7: S37-S43.

24. Taylor JR, Schmieder GJ, Shimizu T, Tie C, Streilein JW. Interrelationship between ultraviolet light and recurrent herpes simplex in man. J Dermatol Sci 1994; 224-232.

25. Brandt BM, Mandleblatt J, Asbell PA. Risk factors for herpes simplex-induced keratitis: a case-control study. Ann Ophthalm 1994: 26: 12-16.

26. Liesegang TJ, Melton LJ, Daly PJ, Ilstrup DM. Epidemiology of ocular herpes simplex. Incidence in Rochester, Minn, 1950 through 1982. Arch Ophthalmol 1989: 107: 1155-1159.

27. Davis LE, Redman JC, Skipper BJ, McLaren LC. Natural history of frequent recurrences of herpes simplex labialis. Oral Surg Oral Med Oral Pathol 1988: 66: 558-561.

28. Glynn C, Crockford G, Gavaghan D, Cardno P, Price D, Miller J. Epidemiology of shingles. J R Soc Med 1990: 83: 617-619.

29. Gallerani M. Manfredini R. Seasonal variation in herpes zoster infection. Br J Dermatol 2000: 142: 588 .

30. Brisson M, Edmunds WJ, Law B, Gay NJ, Walld R, Brownell M, Roos L, De Serres G. Epidemiology of varicella zoster virus infection in Canada and the United Kingdom. Epidemiol Infect 2001: 127: 305-314.

31. Lévi FA, Canon C, Touitou Y, Reinberg A, Mathé G. Seasonal modulation of the circadian time structure of circulating $\mathrm{T}$ and natural killer lymphocyte subsets from healthy subjects. J Clin Invest 1988: 81: 407-413.

32. El-Ghor AA, Norval M. The effect of chronic treatment of mice with urocanic acid isomers. Photochem Photobiol 1997; 65: 866-872.

33. Sleijffers A, Garssen J, Van Loveren H. Chronic low dose UVB exposure can prevent UVB-induced suppression of DTH in a mouse model for hepatitis B vaccination, but not suppression of CHS responses. Submitted, 2003.

34. Sontag Y, Guikers CLH, Vink AA .De Gruijl FR, Van Loveren H, Garssen J, Roza L. Kripke ML. Van der Leun JC, Van Vloten WA. Cells with UV-specific 
DNA damage are present in murine lymph nodes after in vivo UV irradiation. J Invest Dermatol 1995: 104: 734-738.

35. Garssen J, van Steeg H, De Gruijl FR, De Boer J, Van der Horst GTJ, Van Kranen H, Van Loveren H, Van Dijk M, Fluitman A, Weeda G, Hoeijmakers JHJ. Transcription-coupled and global genome repair differentially influence UV-Binduced acute skin effects and systemic immunosuppression. J Immunol 2000; 164 : 6199-6205.

36. Fisher MS, Kripke ML. Further studies on tumor-specific suppressor cells induced by ultraviolet radiation. J Immunol 1978; 121: 1139-1144.

37. Norval M, El-Ghorr AA. UV-induced immunosuppression in virus infections. Mutation Res 1998; 422: 131-138.

38. De Gruijl FR. Ultraviolet radiation and tumor immunity. Methods 2002; 28: $122-$ 129.

39. Cooper KD, Oberhelman L, Hamilton TA, Baadsgaard O, Terhune M, LeVee G, Anderson T, Koren $\mathrm{H}$. UV exposure reduces immunization rates and promotes tolerance to epicutaneous antigens in humans: Relationship to dose, CDla-DR+ epidermal macrophage induction, and Langerhans cell depletion. Proc Natl Acad Sci USA 1992; 89: 8497-8501.

40. Jansen C, Leszczynski D, Pastila R, Koulu L, Laihia J et al. Immunosuppressive, carcinogenic and metastase-related effects of solar UV radiation. Publications of The Finnish Research Programme on Environmental Health, SYTTY 2000: 1: 241-247.

41. Kelly DA, Young AR, McGregor JM, Seed PT, Potten CS, Walker SL. Sensitivity to sunburn is associated with susceptibility to ultraviolet radiation-induced suppression of cutaneous cell-mediated immunity. J Exp Med 2000; 191: 561-566. 

Chapter 3 Amsterdam Cohort Study on HIV and AIDS: impact of exposure to UVR as estimated by means of a 2-year retrospective questionnaire on immune parameters in HIV-positive males

J. Maas' , F. Termorshuizen ${ }^{2}$, R.B. Geskus ${ }^{1}$, W. Goettsch ${ }^{2}$, R.A. Coutinho ${ }^{1.4}$, F. Miedema $^{3}$, H. van Loveren ${ }^{2}$

'The Amsterdam Cohort Study, Municipal Health Service, University of Amsterdam, Amsterdam, The Netherlands; ${ }^{2}$ Laboratory for Toxicology, Pathology, and Genetics, National Institute of Public Health and the Environment (RIVM), Bilthoven, The Netherlands; ${ }^{3}$ The Netherlands Red Cross Blood Transfusion Service, Amsterdam, The Netherlands; ${ }^{4}$ Department of Human Retrovirology, The Academic Medical Center, University of Amsterdam, Amsterdam, The Netherlands. 


\section{Summary}

We investigated whether greater exposure to sunlight is associated with a less favourable course of some important immunological parameters in a group of HIVinfected homosexual men who participated in the Amsterdam Cohort Study on HIV and AIDS. This was done because ultraviolet radiation (UVR) is potentially harmful to the cellular immunity and may enhance viral replication.

The exposure to UVR was estimated by means of a 2-year retrospective questionnaire in 1997. Both a 2-year cumulative estimate and estimates by 3-monthly episodes were calculated. The associations with $\mathrm{CD}^{+} \mathrm{T}$-cell count, $\mathrm{CD} 4^{+} / \mathrm{CD}^{+} \mathrm{T}$-cell ratio, and T-cell reactivity were investigated. At first, the associations between the cumulative estimate and the individual slopes of these parameters during the 2 years covered by the questionnaire were explored by means of a linear regression analysis. Secondly, the short-term association with an estimate by episode was examined by means of a linear mixed-effect model for repeated measurements (LME).

No statistically significant associations with the cumulative estimate were found. Although a trend to lower values of the immunological parameters studied after short-term greater exposure was observed in the LME, the differences were not statistical significant either. These findings suggest that exposure to sunlight does not have a suppressive effect on the above-mentioned immunological parameters in HIVinfected persons.

\section{Introduction}

It has been shown that ultraviolet radiation (UVR) may enhance the replication of viruses, such as labial herpes simplex virus and HIV [ $\left.\begin{array}{lll}1 & 2 & 3\end{array}\right]$. Furthermore, UVR exposure may cause a systemic suppression of various immunological parameters. Reduced numbers of $\mathrm{CD}^{+} \mathrm{T}$-helper cells, decreased $\mathrm{CD} 4^{+} / \mathrm{CD}^{+} \mathrm{T}$-cell ratios, reduced degrees of contact sensitization, diminished lymphocyte responses to mitogens, and reduced cytotoxic activity of natural killer cells upon exposure to UVR have been reported [4-8]. The deleterious effect of UVR on the disease progression of HIV infection might therefore be clinically identifiable, because UVR-associated impairment of the immune system may lead to an increased HIV replication and accelerate the course of HIV infection [9]. This is potentially a matter of concern, because of the sun-seeking behaviour of many people in western countries and because of the phototherapy that is sometimes used for treating HIV-associated cutaneous disorders [2 910$]$.

In various clinical studies, it appeared that UVR as used in phototherapy had no adverse effects on HIV-infected individuals [2]. The number of participants in these studies, however, was often small ( $n=6$ to 10). In a large longitudinal HIV cohort study $(n=496)$, no adverse immunological association with the cumulative exposure to UVR during HIV infection (due to outdoor activities and/or due to the use of tanning beds) was found [9]. However, data from both animal and human experimental studies suggest that UVR may have short-term and possibly reversible suppressive effects on the immune system [4 5 11]. For this reason, it is important to assess the exposure by episode and to explore whether a short-term alteration in immunological parameters can be established.

In the Amsterdam Cohort Study on HIV and AIDS, we estimated the individual exposure of homosexual men to sunlight by means of a 2-year retrospective 
questionnaire. This questionnaire provided us with an estimate of the 2-year cumulative exposure as well as an estimate of exposure by episode (eg, a sunny holiday abroad) [12]. Hence, we were able to explore the association with relevant immunological parameters with both a 2-year cumulative estimate and a short-term estimate of UVR exposure.

\section{Methods}

\section{Study group}

Since October 1984, HIV-seronegative and seropositive homosexual men have been enrolled in the Amsterdam Cohort Study on the natural history of HIV and AIDS [13]. All HIV-1 seropositive participants were seen at 3-monthly consultations, at which a medical history was taken, a physical examination was done, and blood was drawn for various virological and immunological tests. Informed consent was obtained from all participants.

\section{Exposure assessment}

In the period January through May 1997, a 2-year retrospective questionnaire was handed out to the HIV-infected participants who visited the Municipal Health Service at that time. The UVR exposure was estimated on the basis of a self-reported approximation of the daily number of outdoor hours during holidays, vocational, and non-vocational activities. Furthermore, items as sunburn were asked for. The effects of clothing, kind of outdoor activity (eg, walking, gardening, etc.), latitude, and season on the UVR dose were taken into account by coupling data from the literature and data on ambient levels of UVR to the self-reported data on outdoor behaviour [14 15 16]. Exposure to UVR from tanning beds was estimated by assuming that each visit to the solarium is equivalent to one MED $\left(200 \mathrm{~J} / \mathrm{m}^{2}\right.$ at wavelength $\left.297 \mathrm{~nm}\right)$. The exposure assessment has already been described in detail elsewhere [12].

We examined whether there was an association between the 2-year cumulative number of weighted hours and/ or number of weighted hours by episode on the one hand and the changes of $\mathrm{CD}^{+} \mathrm{T}$-cell count, $\mathrm{CD} 4^{+} / \mathrm{CD} 8^{+} \mathrm{T}$-cell ratio, and $\mathrm{T}$-cell reactivity after stimulation with monoclonal CD3 antibodies (CD3 mAb) on the other hand. CD3 mAb-induced T-cell reactivity is known to be a sensitive marker of cellular immunity that can be impaired early in the HIV infection [17 18].

\section{Statistical analysis}

\section{Association with the 2-year cumulative estimate of exposure}

Individual slopes of the immunological parameters in the course of the 2 years covered by the questionnaire were calculated by means of a regression analysis (the least-square method). Next, we examined whether there was a linear correlation between the individual 2-year cumulative estimate of UVR on the one hand (secondroot transformed) and the individual slope of an immunological parameters during the same 2 years on the other hand. This was done in a linear regression analysis. Subjects who had started Highly Active Anti-Retroviral Treatment (HAART) in July 1996 or thereafter were excluded from this analysis, as this statistical model does not enable the inclusion of HAART time dependently [19]. 


\section{Association with the short-term estimate of exposure}

In the second analysis, the short-term UVR effect on the immunological parameters was examined by means of a linear mixed-effect model for repeated measurements (LME) [20]. In this model, the statistical dependence of correlated observations (ie, the immunological parameter assessments belonging to the same person) was taken into account by modelling the individual deviations from the average time course of an immunological parameter. At first, the individual association between the immunological parameter and the calendar time was modelled. To achieve an optimal fit of the LME model, the immunological data had to be third, fourth, or fifth root transformed. In the next step, the individual short-term UVR exposure by episode was included in the model. The short-term exposure during a 3-month interval prior to the immunological parameter assessment was categorised in four quartiles, and for every exposure category a yes/no variable ('dummy') was introduced separately. The lowest exposure category was chosen as the reference category. The $\beta$ parameter that was estimated for each exposure category indicated the deviation from the baseline intercept. We expected that a more intense exposure during the 3-month interval would be associated with a greater and negative deviation from the intercept value for the $\mathrm{CD}^{+} \mathrm{T}$-helper count, $\mathrm{CD} 4^{+} / \mathrm{CD}^{+} \mathrm{T}$-cell ratio, and the T-cell reactivity. The effect of HAART was taken into account by including the use of this treatment (yes/no) in the model as a time-dependent co-variable [19].

\section{Results}

\section{Description}

Sixty-seven questionnaires out of the 106 questionnaires that were handed out were returned. No differences regarding mean $\mathrm{CD}^{+} \mathrm{T}$-helper count were found between those who returned the questionnaires $(n=67)$ and those who did not $(n=39)$. One subject was excluded from the analysis because he returned a blank questionnaire. Nine of the remaining 66 HIV-infected asymptomatic subjects had recently started HAART. The median $\mathrm{CD} 4^{+} \mathrm{T}$-cell count at the beginning of the period covered by the questionnaire was $480 \times 10^{6} / 1$ [interquartile range (IQR): 320-613]. The median number of visits (and the number of serial immunological parameter assessments) was 8 (IQR: 6-12), with a median study interval of 2.0 years (IQR: 1.4-2.0). The median number of weighted hours exposed over the 2 years was 1052 (IQR: 537-1803) or 1.4 hours per day (IQR: 0.7-2.5). By January 1998, one person out of the 57 untreated HIV-infected participants had developed AIDS (Candida oesophagitis).

\section{Association with the 2-year cumulative estimate of exposure}

In the linear regression analysis, no associations between the 2-year cumulative estimate of exposure and the individual changes of the immunological parameters could be established (Table 1). An association beween having been sunburnt during the two years and the investigated parameters could not be found either (data not shown).

\section{Association with the short-term estimate of exposure ( $L M E)$}

For this analysis, 573 immunological assessments from 66 participants could be included. The $\mathrm{CD} 4^{+} \mathrm{T}$-cell count and $\mathrm{T}$-cell reactivity gradually decreased in time, whereas the $\mathrm{CD}^{+} / \mathrm{CD}^{+} \mathrm{T}$-cell ratio increased very slowly (Table 2 ). Higher levels of UVR exposure appeared to be associated with a trend to negative deviations from the 
baseline value. Neither these differences between the 3-month exposure categories (Table 2) nor the ones between the 1-week and 2-week exposure categories were statistically significant (data not shown). (By "exposure" here, we mean exposure during 1 week or 2 weeks prior to the immunological parameter assessment). As expected, a statistically significant effect of HAART was found. HAART was associated with favourable changes of the $\mathrm{CD} 4^{+} \mathrm{T}$-cell count, $\mathrm{CD} 4^{+} / \mathrm{CD} 8^{+} \mathrm{T}$-cell ratio, and $\mathrm{T}$-cell reactivity.

Table 1. Associations between the 2-year cumulative estimate of UVR exposure (number of weighted hours exposed) and the individual course of $C D 4^{+} T$-cell count, $C D 4^{+} / C D 8^{+} T$-cell ratio, and $T$-cell reactivity $(n=57)$.

\section{Immunological}

parameter

\begin{tabular}{llll}
\hline & Slope & $95 \%-\mathrm{CI}^{\mathrm{a}}$ & $\mathrm{P}$ value \\
$\mathrm{CD} 4^{+\mathrm{b}}$ & -0.05 & -1.17 to 1.06 & 0.93 \\
$\mathrm{CD}^{+} / \mathrm{CD}^{+c}$ & 0.001 & -0.004 to 0.006 & 0.66 \\
T-cell reactivity $^{d}$ & 0.003 & -0.008 to 0.01 & 0.61 \\
\hline
\end{tabular}

${ }^{2} 95 \%$-confidence interval

${ }^{\mathrm{b}}$ Unit: $100 \times 10^{6}$ cells/year

'Unit: percent/year

${ }^{d}$ Unit: percent/year

Table 2. Association between the 3-month cumulative estimate of UVR exposure and the deviation from the intercept for $C D 4^{+} T$-cell count, the $C D 4^{+} / C D 8^{+} T$-cell ratio, and the $T$-cell reactivity $(L M E, n=66)$.

\begin{tabular}{|c|c|c|c|c|c|c|}
\hline & \multicolumn{6}{|c|}{ Immunological parameter } \\
\hline & \multirow[t]{2}{*}{$\mathrm{CD}^{+\mathrm{a}}$} & \multicolumn{3}{|c|}{$\mathrm{CD}^{+} / \mathrm{CD}^{+}{ }^{+b}$} & \multicolumn{2}{|c|}{ T-cell reactivity ${ }^{c}$} \\
\hline & & $\mathrm{P}$ value $^{\mathrm{c}}$ & & $P$ value $^{f}$ & & $\mathrm{P}$ value ${ }^{\mathrm{g}}$ \\
\hline Intercept & 2.60 & $<0.0001$ & 3.46 & $<0.0001$ & 2.21 & $<0.0001$ \\
\hline Time (year) & -0.003 & 0.03 & 0.003 & 0.37 & -0.001 & 0.63 \\
\hline UVR quartiles & deviation $^{\mathrm{d}}$ : & & deviation $^{\text {d : }}$ & & deviatio & \\
\hline $0-0.5$ hours & 0 & - & 0 & - & 0 & - \\
\hline $0.5-13.6$ hours & 0.009 & 0.44 & -0.011 & 0.55 & 0.022 & 0.45 \\
\hline 13.6-54.3 hours & -0.008 & 0.19 & -0.004 & 0.68 & -0.021 & 0.20 \\
\hline 54.3-795 hours & -0.005 & 0.18 & -0.010 & 0.11 & -0.010 & 0.33 \\
\hline HAART $^{b}$ & 0.03 & 0.06 & 0.06 & 0.03 & 0.08 & 0.05 \\
\hline
\end{tabular}

${ }^{\mathrm{a}} \mathrm{CD} 4^{+} \mathrm{T}$-cell count, fourth root transformed; ${ }^{\mathrm{b}} \mathrm{CD} 4^{+} / \mathrm{CD} 8^{+} \mathrm{T}$-cell ratio , third root transformed; ${ }^{\mathrm{C}} \mathrm{T}$-cell reactivity after stimulation with $\mathrm{CD} 3$ antibodies, fifth root transformed; ${ }^{d}$ Deviation of the intercept from baseline; ${ }^{\mathrm{C}}$ Overall statistic for UVR exposure: $\mathrm{P}=0.39 ;{ }^{\mathrm{f}}$ Overall statistic for UVR exposure: $\mathrm{P}=0.22 ;{ }^{\mathrm{g}}$ Overall statistic for UVR exposure: $\mathrm{P}=0.33 ;{ }^{\mathrm{h}}$ HAART: Highly Active Anti-Retroviral Treatment 


\section{Discussion}

Higher levels of UVR exposure appeared to be associated with a trend to negative deviations from the baseline intercept values of the $\mathrm{CD}^{+} \mathrm{T}$-cell count, the $\mathrm{CD} 4^{+} / \mathrm{CD} 8^{+} \mathrm{T}$-cell ratios, and the T-cell reactivity. However, these differences did not reach statistical significance, and no associations with a 2-year cumulative estimate of exposure were found. Even with higher exposures as evidenced by sunburn, no effect of solar exposure that might be indicative of UVR-induced immunosuppression could be established. Our data do therefore not support the notion that exposure to sunlight may be associated with a deleterious effect on the immunological system in HIVinfected persons [2 9].

We may raise different objections to our study. At first, our study group may have been too small for the establishment of such subtle effects. As many of the participants did not fill out the questionnaire, their data could not be included in the analysis. However, by calculating estimates of exposure by episode, the number of observations for the repeated measurement analysis $(\mathrm{n}=573)$ was much greater than the number of persons $(n=67)$. Secondly, the exposure assessment by means of a retrospective questionnaire has different limitations. It depends on the recall and reporting ability of the participant, which may imply inaccuracy. Furthermore, many details of exposure to solar UVR such as weather conditions, surface reflectance, and use of sunscreens could not be taken into account. Nevertheless, we may assume that the memory of a special and joyful event such as a holiday, both with respect to geographical location and season, is reasonably good. As much of the exposure in the western world occurs during holidays, the questionnaire is probably sufficient for the establishment of short periods of great exposure [21]. These periods are probably the most relevant ones for examining the effects of UVR on the human immune system in an observational study design [4 5 7].

Furthermore, we may question whether systemic immune parameters were the most adequate read-out for effects of UVR in HIV infection. In a recent study among HIV-infected patients with UVR-treatable skin diseases, it was found that UVR irradiation led to a 6-10-fold increase in the number of HIV in the skin [3]. In this study, it was demonstrated for the first time that HIV activation might occur in vivo in the skin of HIV-seropositive persons. The HIV activation in the skin, however, does not necessarily lead to a clinically relevant increase in plasma HIV and/or an impairment of systemic immune parameters, as was searched for in our study. The numbers of HIV in the skin, even after treatment with UVR, are low in comparison with the numbers of HIV in other tissues, and T lymphocytes, which are the principal reservoir for HIV, are preferentially destructed by UVR irradiation [3].

In conclusion, our findings do not indicate a suppressive effect of exposure to sunlight on a number of systemic immunological parameters that are known to be important in HIV-infected persons. Still, subtle effects of solar exposure on these immune parameters may have been missed.

\section{Acknowledgments}

This study was supported by the Dutch Foundation for Preventive Medicine (Grant No. 28-2370) as an initiative of the Dutch Program Committee for AIDS Research (PccAo), by EU Project ENV4-CT96-0192, and by the Dutch National Research Programme on Global Air Pollution and Climate Change (NOP, Project 952276). This 
study was performed as part of the Amsterdam Cohort study on HIV infection and AIDS, a collaboration between the Municipal Health Service, the University Medical Centre Amsterdam, the Central Laboratory of the Netherlands Red Cross Bloodtransfusion Service (CLB), the Sanquin Blood Supply Foundation and the Laboratory for Experimental and Clinical Immunology, Amsterdam. The Netherlands. We would like to thank N. Albrecht and M. Dekker for the daily organisation of the cohort study. Most of all, we are indebted to the men in the cohort for participating so willingly and so long.

\section{References}

1. Rooney JF, Bryson Y, Mannix ML, Dillon M, Wohlenberg CR, Banks S, Wallington CJ, Notkins AL, Straus SE. Prevention of ultraviolet-light-induced herpes labialis by sunscreen. Lancet 1991; 338: 1419-1422.

2. Akaraphanth R, Lim HW HIV, UV and immunosuppression. Photodermatol

Photoimmunol Photomed 1999; 15: 28-31.

3. Breuer-McHam J, Simpson E, Dougherty I, Bonkobara M, Ariizumi K, Lewis DE, Dawson DB, Duvic M, Cruz PD. Activation of HIV in human skin by ultraviolet B radiation and its inhibition by NFאB blocking agents. Photochem Photobiol 2001: 74: $805-810$.

4. Hersey P, Hasic E, Edwards A, Bradley M, Haran G, McCarthy WH. Immunological effects of solarium exposure. Lancet 1983: I: 545-548.

5. Hersey P, Haran G, Hasic E, Edwards A. Alteration of T cell subsets and induction of supressor $\mathrm{T}$ Cell activity in normal subjects after exposure to sunlight. $\mathrm{J}$ Immunol 1983; 31: 171-174.

6. Morison WL, Parrish JA, Bloch KJ, Krugler JI. In vivo effects of UVB on lymphocyte function. Br J Dermatol 1979; 101: 513-519.

7. Falkenbach A, Sedlmeyer A. Travel to sunny countries is associated with changes in immunological parameters. Photodermatol Photoimmunol Photomed 1997; 13 : 139-142.

8. Garssen J, Norval M, El-Ghorr A, Gibbs NK, Jones CD, Cerimele D, De Simone C, Caffieri S, Dall'Acqua F De Gruijl FR, Sontag Y, Van Loveren H. Estimation of the effect of increasing UVB exposure on the human immune system and related resistance to infectious diseases and tumours. J Photochem Photobiol B: Biology 1998; 42: 167-179.

9. Saah AJ, Horn TD, Hoover DR, Chen C, Whitmore SE, Flynn C, Wesch J, Detels R. Anderson R. Solar ultraviolet radiation exposure does not appear to exacerbate HIV infection in homosexual men. AIDS 1997; 11: 1773-1778.

10. Flegg PJ. Potential risks of ultraviolet radiation in HIV infection. Int J Std AIDS 1990; 1: 46-48.

11. Goettsch W, Garssen J, Timmerman HH, Dortant P, Kuper F, De Gruijl FR, Van Loveren H. Systemic effects of UVB irradiation on basal immune parameters in the rat. In: Biological Effects of Light 1993 (Jung EG, Holick MF, eds). Berlin: Walter de Gruyter, 1993: 637-641.

12. Termorshuizen F, Garssen J, Maas JJ, Goettsch WG, Matthijssen J, Houweling H, Van Loveren H. UVB and infectious diseases: exposure assessment by means of a retrospective questionnaire for an epidemiological study. Report 640300.001 . National Institute of Public Health and the Environment. Bilthoven, 1999. 
13. De Wolf F, Lange JM, Houweling JT, Coutinho RA, Schellekens PT, Van der Noordaa J, Goudsmit J. Numbers of CD4+ cells and the levels of core antigens of and antibodies to the human immunodeficiency virus as predictors of AIDS among seropositive homosexual men. J Infect Dis 1988 ; 158: 615-622.

14. Herlihy E, Gies PH, Roy CR. Jones M. Personal dosimetry of solar radiation for different outdoor activities. Photochem Photobiol 1994; 60: 288-294.

15. Pearl DK, Scott EL. The anatomical distribution of skin cancers. Int J Epidemiol 1986; 15: 502-506.

16. Slaper H, Reinen HAJM, Bordewijk JA, Schlamann E. Effective ultraviolet radiation in the Netherlands. Report 610070.002. National Institute of Public Health and the Environment. Bilthoven, 1994.

17. Roos MTL, Miedema F, Koot M, Tersmette M, Schaasberg WP. Coutinho RA, Schellekens PTA. T cell function in vitro is an independent progression marker for AIDS in human immunodeficiency virus-infected asymptomatic subjects. J Infect Dis 1995: 171: 531-536.

18. Schellekens PT, Koot M, Roos MT, Tersmette M, Miedema F. Immunologic and virologic markers determining progression to AIDS. J Acquir Immune Defic Syndr Hum Retrovirol 1995: 10: S62-S66.

19. Borleffs JCC. Esseveld F, Hoepelman IM, Boucher CAB. AIDS; nieuwe ontwikkelingen. II. Behandeling van HIV-infectie. Ned Tijdschr Geneeskd 1997; 141: 1036-1043.

20. Pinheiro JC, Bates DM. Mixed effects models in S and S-plus. Springer-Verlag. Heidelberg, 2000.

21. Slaper H, Eggink GJ. Blootstelling aan ultraviolette straling. Een analyse van het probleemveld. Report 249104.002. National Institute of Public Health and the Environment. Bilthoven, 1991. 
Chapter 4 Seasonal influences on immunological parameters in HIVinfected homosexual men: searching for the immunomodulating effects of sunlight

F. Termorshuizen', R.B. Geskus, M.T. Roos ${ }^{3}$, R.A. Coutinho ${ }^{2}$, H. van Loveren'

'Laboratory for Toxicology, Pathology, and Genetics, National Institute of Public Health and the Environment (RIVM), Bilthoven, The Netherlands; ${ }^{2}$ The Amsterdam Cohort Study, Municipal Health Service, University of Amsterdam, Amsterdam, The Netherlands; ${ }^{3}$ The Central Laboratory of the Netherlands Red Cross Bloodtransfusion Service (CLB), Amsterdam, The Netherlands. 


\section{Summary}

In view of the capacity of ultraviolet radiation (UVR) to induce suppression of various immunological parameters and to enhance the viral replication of HIV, we investigated whether seasonal influences on immunological parameters that are relevant for HIV infection could be identified. As the sunny season is associated with high levels of ambient UVR, a decline of immunological parameters and an increase of the HIV viral load during the summer months might ensue.

We analysed the immunological data of the HIV-infected homosexual men who participated in the Amsterdam Cohort Study on HIV infection and AIDS (19841996; $\mathrm{n}=556$ ). The effect of season on the individual development of various immunological parameters in time was examined by means of a random-effects model for repeated measurements.

Lower levels in the mean number of $\mathrm{CD}^{+}{ }^{+} \mathrm{T}$ cells and the mean $\mathrm{CD} 4^{+} / \mathrm{CD}^{+}$ $\mathrm{T}$-cell ratio were found during summer and spring, respectively $(\mathrm{P}=0.0001 / 0.0001)$. For the $\mathrm{CD}^{+} \mathrm{T}$ cells, high mean values were observed both in April and September ( $\mathrm{P}$ $=0.0001)$. The highest $\mathrm{T}$-cell reactivity values were found during the summer $(\mathrm{P}=$ $0.0001)$. No effect of season on the viral load was established. The seasonal effect on $\mathrm{CD} 4^{+} \mathrm{T}$ cells seemed to be more pronounced at a more advanced stage of the HIV infection.

It is concluded that the lower $\mathrm{CD} 4^{+} \mathrm{T}$-cell counts during summer supports the notion that solar UVR may have a suppressive effect on the cellular immunity of HIVinfected persons. However, whether this observation can be attributed to the effect of ambient UVR only is questionable, as the other immunological parameters follow different seasonal courses and other reports suggest that both internal and environmental factors influence immunological parameters.

\section{Introduction}

It has been shown that ultraviolet radiation (UVR) may enhance the replication of viruses, such as the labial herpes simplex virus and HIV $\left[\begin{array}{lll}1 & 2 & 3\end{array}\right]$. Furthermore, UVR exposure may cause a systemic suppression of various antigen-presenting and immunological functions [4-10]. UVR, when penetrating the skin, causes skin transurocanic acid to isomerise, and cis-urocanic acid suppresses immune responses, most notably T-cell dependent immune responses, both in the skin and systemically. In addition, also UVR-induced DNA damage will lead to suppression of T-cell dependent immune responses [11]. This effect may be especially important for individuals who have a disorder of the immune system, such as those who suffer an HIV infection, especially in the light of T lymphocytes as the target for the virus [12].

We have already investigated whether exposure to solar UVR was associated with a less favourable course of some immunological parameters that are relevant for the HIV disease progression [13]. This was done by means of a 2-year retrospective questionnaire on sunlight exposure that was given to some of the homosexual participants of the Amsterdam Cohort Study (ACS) on HIV infection and AIDS. No suppressive effect of exposure on the immunological parameters could be established. A small decline in the number of $\mathrm{CD} 4^{+} \mathrm{T}$ cells, the $\mathrm{CD} 4^{+} / \mathrm{CD} 8^{+} \mathrm{T}$-cell ratio, and the $\mathrm{T}$-cell reactivity after a short period of great exposure was suggested, but the differences did not reach the level of statistical significance. This result was in accordance with previous reports [2 14]. However, the small study group $(n=57)$ and 
the probable inadequacy of precisely estimating the individual exposure by means of a retrospective questionnaire might have hampered the establishment of subtle effects.

As there is a strong association between season and exposure to solar UVR in northern European countries, we examined in the present study whether there is a seasonal influence on immunological parameters after HIV infection [15]. As no complicated exposure assessment was required, we analysed the data of all HIVinfected homosexual men who were monitored for disease progression in the ACS. In this way, we hoped to find support for our previous finding (ie, no effect) or to establish a subtle effect of ambient UVR, either favourable or deleterious, on immunological parameters that indicate the disease progression after HIV infection.

\section{Materials and methods}

\section{The study group}

From October 1984 onwards, 1677 HIV-seronegative and HIV-seropositive homosexual men were enrolled in the ACS. These men were predominantly Caucasians and lived in Amsterdam. The HIV-seropositive participants were seen at 3-monthly visits, at which a medical history was taken, a physical examination was done, and blood was drawn for various virological and immunological tests [16]. The immunological assessments from July 1996 onwards were excluded, because Highly Active Anti-Retroviral Treatment (HAART) was introduced in the Netherlands at that time, and it is known that this new therapy has a strong influence on immunological parameters [17]. For the present analysis, the data of $556 \mathrm{HIV}$-seropositive participants were included. These men seroconverted before July 1996, and at least one assessment of both their $\mathrm{CD}^{+}$and $\mathrm{CD}^{+} \mathrm{T}$-cell numbers during their HIV infection before July 1996 was available.

\section{The laboratory tests}

Fresh cells were used for testing T-cell subsets. CD4 ${ }^{+}$and $\mathrm{CD} 8^{+} \mathrm{T}$ cells were enumerated by a direct immunofluorescent technique that uses monoclonal antibodies and a flow cytometric system. In time, several changes were introduced in the immunophenotyping procedures. However, no longitudinal retrospective corrections for possible inter-assay variations were necessary [16]. T-cell reactivity to monoclonal CD3 antibodies (CD3 mAb) was measured in whole-blood lymphocyte cultures according to stimulation protocols that varied with time. Adjusted longitudinal test outcomes were calculated to take these inter-assay variations in time into account [16]. The reactivity was expressed as the percentage of median responses detected in concurrently running cultures of five healthy controls. All serological tests were done on fresh sera. Viral load measurements were included in the analysis. Viral load concentration in peripheral blood was assessed by means of HIV RNA PCR. The viral loads were measured with the nucleic acid sequence-based amplification (NASBA) assay, Organon Technika, Boxtel, The Netherlands, (quantification threshold 1000 RNA copies $/ \mathrm{ml}$ ). As the viral load was not measured consistently at each 3-monthly visit, the results of the seasonal analysis on this parameter have to be interpreted with caution.

\section{Statistical analysis}

The development of four immunological parameters (number of $\mathrm{CD}^{+} \mathrm{T}$ cells, CD8 ${ }^{+}$ $\mathrm{T}$ cells, $\mathrm{CD}^{+} / \mathrm{CD}^{+} \mathrm{T}$-cell ratio, $\mathrm{T}$-cell reactivity) in time was investigated in a 
random- effects regression model for repeated measurements. The correlation between observations of an immunological parameter from the same person in the course of follow-up was taken into account by modelling the individual deviations from the mean time course of the immunological parameter under consideration. The intercept ( $\beta_{0}$, the 'baseline value'), a first-order term ( $\beta_{1} *$ time), and a second-order term $(\beta$ $2^{*}$ time $\left.^{2}\right)$ were included as individual random effects in the model. The $\mathrm{CD}^{+} / \mathrm{CD}^{+} \mathrm{T}$ cell ratio was included in the analysis, as it has been reported that this compound immunological parameter may be a sensitive read-out for the effects of UVR on cellular immunity [4 5 7]. T-cell reactivity is known to be a sensitive marker of cellular immunity that can be impaired early in the HIV-1 infection [18 19]. The viral load was modelled via a tobit analysis, in which the cut-off value of the test used was taken into account [20]. The time was the number of years and months since entry into the ACS if the participant was seropositive at entry (a 'seroprevalent') or since seroconversion (a 'seroconverter') if the participant was infected thereafter. For 327 participants, we were able to estimate the date of seroconversion either because they seroconverted for HIV while being in follow-up $(n=126)$ or they were HIV positive at entry into the study between April 1984 and October 1985 and their date of seroconversion was imputed based on marker values at entry [l21 22]. The use of antiretroviral treatment at the time of the immunological assessment and the season of that immunological assessment were introduced as fixed effects. For every month of the year of an immunological assessment separately, a $\beta$ parameter was estimated. Such a $\beta$ parameter ( $\beta_{\text {season, } 1-12}$ ) indicates the deviation from the average time trend by month. As ambient levels of UVR are lowest in January in the northern hemisphere. and, as a consequence, human exposure is at its minimum then, this month was the 'reference exposure month' (ie, $\beta_{\text {season, } 1=0 \text { ). }}$

The data were analysed by means of the PROC MIXED procedure in SAS statistical software, version 6.12 and S-PLUS 3.4 for Unix for the tobit analyses.

\section{Results}

\section{Description}

The date of entry (for seroprevalents) or the approximate date of seroconversion (for seroconverters) varied from October 1984 to June 1996. The mean time of follow-up included in the present analysis was 4.4 years $(0-11.5)$, and the mean number of immunological parameter assessments was 28.4 (range: $1-132$ ). The mean $\mathrm{CD}^{+} \mathrm{T}$ cell count at the start of the follow-up or seroconversion was $525 * 10^{6} / \mathrm{L}$ for the seroprevalents $(n=430)$ and $679 * 10^{6} / \mathrm{L}$ for the seroconverters $(n=126)$. The mean age of the homosexual men at the start of follow-up or seroconversion was 35.4 years (range: $19.3-58.0$ ).

\section{The random-effects regression model}

The results of the regression analysis on sixth-square-root-transformed immunological parameters are presented in Table 1. Seasonal differences were observed for the CD4 ${ }^{+}$ $\mathrm{T}$-cell count, the $\mathrm{CD} 8^{+} \mathrm{T}$-cell count, the $\mathrm{CD}^{+} / \mathrm{CD}^{+} \mathrm{T}$-cell ratio, and the $\mathrm{T}$-cell reactivity. The lowest seasonal parameter value for the $\mathrm{CD}^{+} \mathrm{T}$-cell count was found in the month of July $\left(\beta_{\text {season, } 7=-0.0200}\right)$. For the $\mathrm{CD}^{+} \mathrm{T}$-cell count, low seasonal parameter values were found both in July $\left(\beta_{\text {season, } 7}=-0.0125\right)$ and in February $(\beta$ season, $2=-0.0078)$. For the $\mathrm{CD}^{+} / \mathrm{CD}^{+} \mathrm{T}$-cell ratio, the lowest values were found in 
April and May. For the T-cell reactivity, the highest value was found in July. The monthly differences in the $\mathrm{CD} 4^{+} \mathrm{T}$-cell count, the $\mathrm{CD} 8^{+} \mathrm{T}$-cell count, the $\mathrm{CD} 4^{+} / \mathrm{CD}^{+}$ $\mathrm{T}$-cell ratio, and the $\mathrm{T}$-cell reactivity reached the level of statistical significance when an overall test (Type III) for the effect of season was performed ( $\mathrm{P}$ values $<0.0001$ ). On the other hand, no significant seasonal effect on the viral load could be established $(\mathrm{P}=0.5000)$. Restricting these analyses to those for whom a date of seroconversion was estimated ( $n=327$ ) did not modify the results.

The seasonal parameter value for the CD4 ${ }^{+} \mathrm{T}$-cell count for July $\left(\beta_{\text {season, } 7}\right)$ in untransformed data was $-27.4 * 10^{6} / \mathrm{L}$, which indicates the average decline in the $\mathrm{CD}^{+} \mathrm{T}$-cell count in July in comparison with January. The stage of HIV disease progression was taken into account to examine the relevance of our finding for various stages of the HIV infection. A significant seasonal influence was found in a low range of $\mathrm{CD}^{+} \mathrm{T}$-cell numbers $\left(<300 * 10^{6} / \mathrm{L}\right)$ : $\beta_{\text {season, } 7}=-6.588 * 10^{6} / \mathrm{L}$ (data not transformed) $/ \mathrm{P}=0.0328$ (season overall/Type III, sixth-square-root-transformed data, $\mathrm{n}=375$ ). At higher ranges of $\mathrm{CD}^{+} \mathrm{T}$-cell numbers, no statistically significant seasonal influences could be established: $\beta_{\text {season, } 7}=+2.397 * 10^{6} / \mathrm{L}$ (data not transformed) $/ \mathrm{P}$ $=0.1179$ (season overall/Type III, sixth-square-root-transformed data, $n=464$ ) and $\beta$ season. $7=-3.471 * 10^{6} / \mathrm{L}$ (data not transformed) $/ \mathrm{P}=0.2337$ (season overall $/$ Type III, sixth-square-root-transformed data, $\mathrm{n}=432)$ for intermediate $\left(\geq 300-500 * 10^{6} / \mathrm{L}\right)$ and high $\left(\geq 500 * 10^{6} / \mathrm{L}\right)$ ranges, respectively (data not shown).

In addition, longitudinal data on $\mathrm{CD}^{+}$and $\mathrm{CD} 8^{+} \mathrm{T}$-cell numbers from a small sample of HIV-negative males in the ACS $(n=78)$ were available. In a random-effects model with season as fixed effect, no significant differences in the $\mathrm{CD} 4^{+} \mathrm{T}$-cell numbers by month of immune parameter assessment were found: $\beta_{\text {season, } 7}=+32.555$ $* 10^{6} / \mathrm{L}$ (data not transformed) $/ \mathrm{P}=0.6264$ (season overall/ Type III, sixth-squareroot-transformed data). For the $\mathrm{CD}^{+} \mathrm{T}$-cell numbers and the $\mathrm{CD} 4^{+} / \mathrm{CD} 8^{+} \mathrm{T}$-cell ratio, no significant differences were found either $(\mathrm{P}=0.9474$ and 0.3200 , respectively).

\section{Discussion}

We found small, but statistically significant, differences by season in the CD4 ${ }^{+} \mathrm{T}$-cell count, the $\mathrm{CD}^{+} \mathrm{T}$-cell count, the $\mathrm{CD}^{+} / \mathrm{CD}^{+} \mathrm{T}$-cell ratio, and the $\mathrm{T}$-cell reactivity in a cohort of HIV-infected homosexual men. The average lesser CD4 ${ }^{+} \mathrm{T}$-cell number in July in itself is in accordance with our hypothesis, which was based on the potential of UVR to induce immunosuppression. To our knowledge, this analysis is the first study in which a seasonal fluctuation in the immunological parameters for HIV-infected patients is examined.

Daily cycles in $\mathrm{CD}^{+} \mathrm{T}$ cells in HIV patients have already been studied. It was found that these cycles might be disrupted at an early stage of the disease [23 24]. In contrast, our data suggest that the seasonal differences in $\mathrm{CD} 4^{+} \mathrm{T}$ cells were more pronounced at a more advanced stage of the HIV infection. Furthermore, we could not establish seasonal effects on immune parameters in a small sample of HIV noninfected participants of the ACS from whom longitudinal data were available.

Seasonal modulation of immune responses has already been studied before in vitro, in animal experiments, and in healthy human volunteers [25-29]. In the study of Lévi et al., small values for both $\mathrm{CD}^{+}$and $\mathrm{CD}^{+}{ }^{+} \mathrm{T}$-cell numbers in five healthy men in the sunny season were found, which agrees with our findings among HIVinfected persons. In the study of Pati et al., high values for the murine lymphocyte 
responsiveness in April to June in the data from 356 mice collected over 5 years were found, which globally coincides with our finding of maximum values of the T-cell reactivity during sunny season. However, these mice were kept in standardised indoor conditions throughout the year. Hence, the seasonal effects might be due to endogenous physiological rhythms [26 30]. Furthermore, our data and studies of others indicate 6-monthly cycles and/or 3-monthly cycles, in addition to the yearly cycles [ $\left[\begin{array}{lll}26 & 27 & 30\end{array}\right]$. Although it has been observed that seasonally associated factors like ambient UVR, photoperiod, and temperature may have a strong influence on the immune system, sub-yearly cycles are hard to attribute to the seasonal fluctuation of these factors only [ $4 \begin{aligned} & 4 \\ & 5\end{aligned} 910313233$ ]. Many factors, both endogenous and environmental, may influence the immune system concomitantly along the yearly scale.

No seasonal effect on the viral load was established in the present analysis. In a recent study among HIV-infected patients with UVR-treatable skin diseases, it was found that UVR irradiation led to a 6-10-fold increase of the HIV load in the skin [3]. In this study, it was demonstrated for the first time that HIV activation might occur in vivo in the skin of seropositive persons. The HIV activation in the skin, however, does not necessarily lead to a clinically relevant increase in plasma HIV, as was searched for in our study. The load of HIV in the skin, even after treatment with UVR, is low in comparison with the load of HIV in other tissues, and T lymphocytes, which are the principal reservoir for HIV, are preferentially destructed by UVR irradiation [3].

In conclusion, our finding of lower $\mathrm{CD}^{+} \mathrm{T}$-cell numbers in the sunny season supports the notion that solar UVR may have a suppressive effect on immunological parameters. especially in HIV-infected patients with advanced immunosuppression. Besides the seasonal fluctuation of ambient UVR, other as yet undefined internal and environmental factors may also influence immunological parameters along the yearly scale.

\section{Acknowledgements}

This study was supported by the Dutch National Research Programme on Global Air Pollution and Climate Change (NOP, Project 952276). This study was performed as part of the Amsterdam Cohort study on HIV infection and AIDS, a collaboration between the Municipal Health Service, the Academic Medical Centre Amsterdam, the Central Laboratory of the Netherlands Red Cross Bloodtransfusion Service (CLB), the Sanquin Blood Supply Foundation and the Laboratory for Experimental and Clinical Immunology, Amsterdam, The Netherlands. We would like to thank N. Albrecht and M. Dekker for the daily organisation of the cohort study. Most of all, we are indebted to the men in the cohort for participating so willingly and so long. 
Table 1. Results of the random-effects regression model.

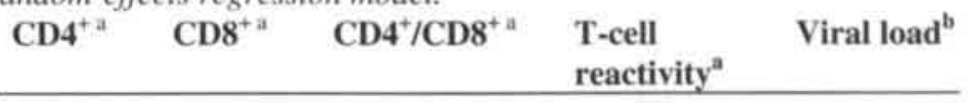

$\mathrm{N}$ (persons)

$\mathrm{N}$ (observations)

$\begin{array}{ccccc}556 & 556 & 556 & 475 & 522 \\ 11412 & 11412 & 11412 & 8219 & 3498\end{array}$

$\beta$ parameters

Intercept

\begin{tabular}{ccccc}
$\beta$ & $\beta$ & $\beta$ & $\beta$ & $\beta$ \\
\hline 1.9437 & 2.0626 & 0.9479 & 1.9166 & 4.0073 \\
-0.0276 & 0.0126 & -0.0237 & -0.0624 & 0.1916 \\
-0.0101 & -0.0012 & -0.0026 & -0.0010 & 0.0047
\end{tabular}

${\text { (years since entry })^{2}}^{2}$

Season

$\begin{array}{rccccc}\text { January } & 0.0000 & 0.0000 & 0.0000 & 0.0000 & 0.0000 \\ \text { February } & -0.0064 & -0.0078 & 0.0006 & 0.0462 & 0.1141 \\ \text { March } & 0.0023 & 0.0054 & -0.0009 & 0.0081 & 0.0016 \\ \text { April } & -0.0104 & 0.0086 & -0.0084 & 0.0355 & 0.0898 \\ \text { May } & -0.0044 & 0.0100 & -0.0060 & 0.0292 & 0.1644 \\ \text { June } & -0.0097 & -0.0037 & -0.0030 & 0.0499 & 0.0972 \\ \text { July } & -0.0200 & -0.0125 & -0.0039 & 0.0603 & -0.0525 \\ \text { August } & -0.0056 & 0.0039 & -0.0041 & 0.0445 & 0.0119 \\ \text { September } & 0.0037 & 0.0077 & -0.0009 & 0.0198 & 0.0503 \\ \text { October } & 0.0018 & 0.0033 & 0.0005 & 0.0167 & 0.1510 \\ \text { November } & 0.0030 & 0.0022 & 0.0006 & 0.0361 & 0.0587 \\ \text { December } & 0.0057 & -0.0032 & 0.0043 & 0.0040 & -0.0675\end{array}$

Anti-retroviral

treatment

$\begin{array}{cccccc}\text { Yes } & 0.0362 & 0.0054 & 0.0145 & 0.0658 & -0.7831 \\ \text { No } & 0.0000 & 0.0000 & 0.0000 & 0.0000 & 0.0000\end{array}$

Type III statistics

Years since entry

(years since entry) ${ }^{2}$

Season

Anti-retroviral

treatment

\begin{tabular}{ccccc}
$\mathbf{P}$ & $\mathbf{P}$ & $\mathbf{P}$ & $\mathbf{P}$ & $\mathbf{P}$ \\
\hline 0.0001 & 0.0002 & 0.0001 & 0.0001 & 0.0001 \\
0.0001 & 0.0086 & 0.0001 & 0.2740 & 0.3414 \\
0.0001 & 0.0001 & 0.0001 & 0.0001 & 0.5000
\end{tabular}

${ }^{a}$ Data were sixth-root transformed to obtain an approximation of a normal distribution of the residuals 'bixth-root transformed; the effect of low values that were registered with the cut-off value of 1000 was taken into account (tobit analysis) [20]. 


\section{References}

1. Rooney JF, Bryson Y, Mannix ML, Dillon M, Wohlenberg CR, Banks S, Wallington CJ, Notkins AL, Straus SE. Prevention of ultraviolet-light-induced herpes labialis by sunscreen. Lancet $1991 ; 338: 1419-1422$.

2. Akaraphanth R, Lim HW HIV, UV and immunosuppression. Photodermatol Photoimmunol Photomed 1999; 15: 28-31.

3. Breuer-McHam J, Simpson E, Dougherty I, Bonkobara M, Ariizumi K, Lewis DE, Dawson DB, Duvic M, Cruz PD. Activation of HIV in human skin by ultraviolet B radiation and its inhibition by NFKB blocking agents. Photochem Photobiol 2001; 74: 805-810.

4. Hersey P. Hasic E, Edwards A, Bradley M, Haran G, McCarthy WH. Immunological effects of solarium exposure. Lancet 1983; I: 545-548.

5. Hersey P, Haran G, Hasic E. Edwards A. Alteration of T cell subsets and induction of supressor T Cell activity in normal subjects after exposure to sunlight. J Immunol 1983; 31: 171-174.

6. Morison WL, Parrish JA, Bloch KJ, Krugler JI. In vivo effects of UVB on lymphocyte function. Br J Dermatol 1979; 101: 513-519.

7. Falkenbach A, Sedlmeyer A. Travel to sunny countries is associated with changes in immunological parameters. Photodermatol Photoimmunol Photomed 1997: 13: 139-142.

8. Garssen J, Norval M, El-Ghorr A, Gibbs NK, Jones CD, Cerimele D, De Simone C, Caffieri S, Dall'Acqua F De Gruijl FR, Sontag Y, Van Loveren H. Estimation of the effect of increasing UVB exposure on the human immune system and related resistance to infectious diseases and tumours. J Photochem Photobiol B: Biology 1998; 42: 167-179.

9. Whitmore SE, Morison WL. The effect of suntan parlor exposure on delayed and contact hypersensitivity. Photochem Photobiol 2000; 71: 700-705.

10. Kelly DA, Walker SL, McGregor JM. Young AR. A single exposure of solar simulated radiation suppresses contact hypersensitivity responses both locally and systemically in humans: quantitative studies with high-frequency ultrasound. J Photochem Photobiol B: Biology 1998; 44: 130-142.

1I. Termorshuizen F, Garssen J, Norval M, Koulu L, Laihia J, Leino L, Jansen CT, De Gruijl FR, Gibbs NK, De Simone C, Van Loveren H. A review of studies on the effects of ultraviolet irradiation on the resistance to infections: evidence from rodent infection models and verification by experimental and observational human studies. Int Immunopharm 2002; 2: 263-275.

12. Flegg PJ. Potential risks of ultraviolet radiation in HIV infection. Int J Std AIDS 1990: 1: 46-48.

13. Maas J. Termorshuizen F. Geskus RB, Goettsch W. Coutinho RA. Miedema F, van Loveren H. Amsterdam Cohort Study on HIV and AIDS: impact of exposure to UVR as estimated by means of a 2-year retrospective questionnaire on immune parameters in HIV positive males. Int J Hyg Environ Health 2002: 205: 373-377.

14. Saah AJ, Horn TD, Hoover DR, Chen C, Whitmore SE, Flynn C, Wesch J, Detels R. Anderson R. Solar ultraviolet radiation exposure does not appear to exacerbate HIV infection in homosexual men. AIDS 1997; 11: 1773-1778.

15. Diffey BL. Human exposure to ultraviolet radiation. Semin Dermatol 1990; 9: 210. 
16. Maas JJ. Markers of HIV-1 infection and its pathogenesis [PhD Thesis]. Amsterdam, University of Amsterdam, 2000.

17. De Wolf F, Goudsmit J. AIDS; nieuwe ontwikkelingen. III. Voorspellende waarde van de hoeveelheid HIV-RNA voor het beloop van de HIV-infectie en het effect van de behandeling. Ned Tijdschr Geneeskd 1997; 141: 1043-1050.

18. Roos MTL, Miedema F, Koot M, Tersmette M, Schaasberg WP, Coutinho RA, Schellekens PTA. T cell function in vitro is an independent progression marker for AIDS in human immunodeficiency virus-infected asymptomatic subjects. J Infect Dis 1995; 171: 531-536.

19. Schellekens PT, Koot M, Roos MT, Tersmette M, Miedema F. Immunologic and virologic markers determining progression to AIDS. J Acquir Immune Defic Syndr Hum Retrovirol 1995; 10: S62-S66.

20. Hughes JP. Mixed Effects Models with Censored Data, with Application to HIV RNA Levels. Biometrics 1999; 55: 625-629.

21. Geskus RB. On the inclusion of prevalent cases in HIV/AIDS natural history studies through a marker-based estimate of time since seroconversion. Stat Med 2000; 19: 1753-1769.

22. Geskus RB. Methods for estimating the AIDS incubation time distribution when date of seroconversion is censored. Stat Med 2001; 20: 795-812.

23. Malone JL, Simms TE, Gray GC, Wagner KF, Burge JR, Burke DS. Sources of variability in repeated $\mathrm{T}$-helper lymphocyte counts from human immunodeficiency virus type 1-infected patients: total lymphocyte count fluctuations and diurnal cycle are important. J Acq Immun Def Synd 1989; 2 : 114-124.

24. Martini E, Muller JY, Doinel C, Gastal C, Roquin H, Douay L, Salmon C.

Disappearance of CD4-lymphocyte circadian cycles in HIV-infected patients: early event during asymptomatic infection. AIDS 1988; 2: 133-134.

25. Munch-Petersen B, Wallevik K. Faber M. Seasonal variations in UVR-induced DNA synthesis and in UVR inhibition of phytohaemagglutinin-stimulated proliferation of human lymphocytes. Scan J Clin Lab Invest 1985; 45: 37-44.

26. Pati AK, Florentin I, Chung V, De Sousa M, Levi F, Mathe G. Circannual rhythm in natural killer activity and mitogen responsiveness of murine splenocytes. Cell Immunol 1987; 108: 227-234.

27. Lévi FA, Canon C, Touitou Y, Reinberg A, Mathé G. Seasonal modulation of the circadian time structure of circulating $\mathrm{T}$ and natural killer lymphocyte subsets from healthy subjects. J Clin Invest 1988; 81: 407-413.

28. Fennerty AG, Jones KP. Davies BH. Lymphocytes are rhythmic: is this important? Br Med J 1985; 290: 152-153.

29. Edman B. Seasonal influence on patch test results. Contact Dermatitis 1989; 20: 226.

30. Brock MA. Seasonal rhythmicity in lymphocyte blastogenic responses of mice persist in a constant environment. J Immunol 1983: 130: 2586-2588.

31. Roberts JE. Visible light induced changes in the immune response through an eyebrain mechanism (photoneuroimmunology). J Photochem Photobiol B: Biology 1995; 29: 3-15.

32. Nelson RJ, Demas GE, Klein SL, Kriegsfeld LJ. The influence of season, photoperiod and pineal melatonin on immune fuction. J Pineal Res 1995; 19: 149 165. 
33. Rosenthal NE, Brown C, Oren DA, Galetto G, Schwartz PJ. Malley JD. Effects of light on T-cells in HIV-infected subjects are not dependent on history of seasonal affective disorder. Photochem Photobiol 1994; 59: 314-319. 
Chapter 5 Vaccine-induced antibody responses in relation to season An analysis on hepatitis B, rubella and measles

F. Termorshuizen', A. Sleijffers ${ }^{2}$, S. van den $\mathrm{Hof}^{3}$, H. de Melker ${ }^{3}$, J. Garssen', G.J.

Boland $^{4}$, J. van Hattum ${ }^{4}$, F.R. de Gruijl $1^{2}$, H. van Loveren ${ }^{1 *}$

${ }^{1}$ Laboratory for Toxicology, Pathology, and Genetics, National Institute of Public Health and the Environment (RIVM), Bilthoven, The Netherlands; ${ }^{2}$ Department of Dermatology, University Medical Centre Utrecht, Utrecht. The Netherlands;

${ }^{3}$ Department of Infectious Diseases Epidemiology, National Institute of Public Health and the Environment (RIVM), Bilthoven, The Netherlands; ${ }^{4}$ Department of Gastroenterology, University Medical Centre Utrecht, Utrecht, The Netherlands. 


\section{Summary}

In view of the immunosuppressive effects of ultraviolet radiation (UVR), especially the B-waveband, it was investigated whether a seasonal effect on the antibody response following vaccination might be detectable.

IgG assessments and dates of vaccination were available 1 . from a survey on the formation of anti-HB antibodies (anti-HBs) during the vaccination procedure to hepatitis B $(\mathrm{HB})$ in paramedical students in Utrecht $(\mathrm{n}=522)$ and 2. from a crosssectional serosurveillance study on vaccination to measles and rubella in children aged 2-7 years who had received their mumps-, measles-, rubella-vaccination at 14 months of age $(n=719)$.

The data from the survey among paramedical students indicated a slightly retarded antibody response during vaccination procedures that were started in a sunny season. However, at the end of the procedure equal levels of anti-HBs were found. In the survey on rubella and measles, no seasonal influences on the formation of antibodies could be established.

The slightly retarded antibody response in the survey on hepatitis B may indicate that season and the related exposure to ambient UVR does have a biological significant effect on the immune system. However, these data do not support a reduced immunoprotection due to high ambient UVR during sunny season in the general population.

\section{Introduction}

Experimental animal data show that ultraviolet radiation (UVR, 280-400 nm), especially the B-waveband (UVB, 280-315 nm) at doses that are relevant to outdoor exposure may affect specific and non-specific immune responses and increase the susceptibility to viral, bacterial and parasitic pathogens [ [ 12 2]. Effects of artificial UVR and sunlight on immune parameters have also been shown in humans [3-7].

However, it is still an unresolved issue whether increases in UVR exposure due to ozone depletion and sun-seeking behaviour are associated with increasing incidences of infectious diseases in the human situation [8 9].

Measurement of vaccine responses in terms of antibody titres has been recommended as a great opportunity to monitor the suppression of immune function due to immunotoxic influences on the population level [ $\left.8 \begin{array}{lll}8 & 11 & 11\end{array}\right]$. In experimental studies in rodents, it has been shown that the antibody response to sheep erytrocytes is an adequate indicator for immunotoxicity, as major components of the immune system are involved. In addition, alterations in the response to sheep erythrocytes appeared to correlate well with the resistance to experimentally induced infections [12 13]. The advantage of using antibody responses to vaccination as read-out in humans is that the effect of immunotoxic agents on the protection against infections may be ascertained without the need to induce infections experimentally or to wait for actual infections to develop. Even when it is not possible to extrapolate the vigour of an antibody response to protection to the pathogen at which a certain vaccination was aimed, this immune response may still serve as a model for effects of exposure on immune responses in general [10].

Animal data show that UVR may reduce the antibody response following immunization with a T-cell dependent antigen [14 15 16]. For example, in the recent study by Sleijffers et al. (2002), it was found that exposure to broadband UVB prior to vaccination with a recombinant hepatitis B surface antigen ( $\mathrm{HBs} A g)$ impaired both 
the antigen-specific delayed type hypersensitivity response and the formation of antiHBsAg antibodies (anti-HBs), especially those of the IgG2a subclass [16]. It was demonstrated in humans that short-term exposure to UVR from solarium treatment or from sunbathing may cause a decrease in the $\mathrm{CD} 4^{+} / \mathrm{CD}^{+} \mathrm{T}$-cell ratio, and an increase in the suppressor $\mathrm{T}$-cell activity leading to impaired $\mathrm{IgG}$ production in vitro [3 4]. In view of these experimental findings, it may be hypothesized that vaccinations given in summer are associated with lower immune responses than vaccinations given in winter. As UVR may exert a short-term effect on the cellular immune responses that are induced immediately after the first encounter with an antigen, we regarded the season of the first vaccine as indicative of the exposure to UVR that might be of relevance for the formation of protective antibodies. For hepatitis B, rubella, and measles vaccinations we analysed pre-existing data on antibody levels and examined whether a seasonal influence actually could be established.

\section{Methods}

\section{Hepatitis $B$}

\section{Study population \& vaccination}

Data on antibody responses during and after a hepatitis $B(\mathrm{HB})$ vaccination procedure were available from 522 students of two paramedical colleges in Utrecht, the Netherlands (nurses, dental hygienists, speech trainers). These students received their first dose HBsAg vaccine (Engerix-B, Glaxo Smith Kline Biologicals, 20 $\mu \mathrm{g}$ ) in January $1994(n=25)$, October $1995(n=24)$, February $1996(n=19)$, September 1996 $(n=77)$, August $1997(n=68)$, September $1997(n=2)$, April $1998(n=33)$, August 1998 $(n=19)$, January $1999(n=19)$, May $1999(n=20)$, June $1999(n=1)$, September 1999 $(n=54)$, October $1999(n=27)$, January $2000(n=22)$, February $2000(n=2)$, or March $2000(n=110)$. A standard immunization procedure was applied with 3 vaccinations (I: 0. II: month 1. III: month 6) and with injection in the deltoid muscle. The young and healthy students were predominantly female and 17-20 years of age. All participants gave written informed consent.

\section{Laboratory test}

Serological assessment was done in blood taken at the time of the first vaccination. 3 and 7 days thereafter, at the time of the second vaccination, 3.7 and/ or 14 or 30 days thereafter, at the time of the third vaccination and 1 month thereafter. The concentration of IgG antibody to HBsAg (anti-HBs) was assessed by means of an enzyme-linked immunosorbent assay (AUSAB, Abbott, Chicago, IL), performed on the IMx. An anti-HBs titre of $\geq 1000$ IU/I was registered as ' 1000 ', which implies that evaluation of differences in the highest levels was limited. The cut-off values for protection were assumed to be $10 \mathrm{IU} / \mathrm{l}$ (level of low protection), $100 \mathrm{IU} / \mathrm{l}$ (level of high protection), and $1000 \mathrm{IU} / \mathrm{l}$ (level of high and lasting protection).

\section{Statistical analysis}

Mean titre by season The geometric mean titre (GMT, ${ }^{10} \log$-transformation) and $95 \%$ confidence interval $(95 \%-\mathrm{CI})$ were calculated by quarter of first vaccine $(1-4)$ and calendar year and for every time point of blood sampling in the course of the immunization procedure separately. We considered subjects who started the vaccination procedure in spring or summer (quarter 2; April through June, quarter 3: July through September) to be exposed to relatively high doses of ambient UVR at the time of the first vaccine $(n=274)$. We considered persons who started the vaccination 
sampling. No statistically significant differences or a consistent trend that might indicate a seasonal fluctuation in either anti-measles or anti-rubella IgG could be established.

\section{Discussion}

In the present study, it was investigated whether a seasonal influence on the formation of antibodies after vaccination to hepatitis B, measles or rubella could be established. It was hypothesized that sunny season might be associated with a reduced antibody formation. The postulated seasonal influence on immune responses due to UVR might be observed especially in those countries that experience a strong seasonal fluctuation in ambient UVR like Northern-European countries [22]. The establishment of such a seasonal influence is important as it may support the notion that (ambient) UVR influences the human immune system and the related susceptibility to infections and for practical reasons may indicate a better efficiency of vaccinations given in winter. In this study, no clear and consistent influence of sunny season, either favourable or deleterious, on the antibody response after vaccination was found. In the sero-survey on hepatitis B, the data indicated a slightly retarded immune response when the first vaccine was given in a sunny season. However, no consistent and significant seasonal difference in the level of protective antibodies was found at the end of the vaccination procedure. This suggests that season has an effect on immune responses, but no seasonal effect on the level of clinical protection, which is acquired at the end of the immunization procedure, is present. This was supported by our findings from the sero-survey on measles and rubella, in which an effect of season at the time of vaccination on the protective antibody levels as were assessed a number of months to years thereafter could not be established.

Some remarks on our study design are required. Seasonal data on human immune parameters and the protection to infections have to be interpreted with caution. Sunny season is associated with high levels of ambient UVR. but also with higher ambient temperature and longer days. It has been reported that temperature and photoperiod also influences the immune system [23 24]. Furthermore, yearly rhythms in immunological parameters that are independent of environmental influences have been described [ 2526 ]. It is hard to disentangle the effects of different factors that have a seasonal association in common. In a study in human volunteers by Kelly et al. (2000), it was found that UVR at a dose relevant to solar exposure prior to sensitization considerably suppressed the contact hypersensitivity response to DNCB 1 . In contrast, it was also found that the contact hypersensitivity response in the same volunteers was comparatively high in sunny season, which suggests that the effects of experimental UVR and season on the human immune system may be not in a direct line with each other [27]. For this reason, a study design, in which season is regarded as a confounder and in which fluctuations in personal exposure to solar UVR due to the effect of clouding or to the effect of differences in outdoor behaviour are measured, may be advocated.

Our results on hepatitis B are in accordance with a recent experimental study in human volunteers on the effect of UVR on anti-HBs formation by Sleijffers et al. (2002). As this study was carried out during winter season, the possible confounding effect of varying levels of ambient UVR was ruled out. Irradiation with 1 MED of broadband UVR on 5 consecutive days prior to a standard vaccination with Engerix-B

\footnotetext{
'1-chloro-2.4-dinitrobenzene
} 
did not influence the formation of anti-HBs [28]. In contrast, natural killer cell activity and contact hypersensitivity response to $\mathrm{DCP}^{2}$ were significantly suppressed in the experimental group. One possible reason for this lack of a detectable influence on antibody formation in humans is that the standard doses of the vaccins studied were too high for detection of an immunomodulatory effect of UVR. Immune suppression by UVR may be more easily detected at lower doses of antigen [27 28 29]. Another possible reason is that UVR may affect especially Th-1-skewed immunity, leaving Th-2 immune responses that are particular responsible for the formation of antibodies unaltered. Such a changed Th-1-Th-2 balance may explain observations on the recurrences of systemic lupus erythematosis and the latitude gradient for the incidence of multiple sclerosis [ 3031 ]. However, in different studies it has been shown that UVR may affect both Th-1 and Th-2 responses [1 15 l 163233 3.

It may be argued that the possible subtle immunosuppressive effect of UVR is hard to establish from a bird's eye view as we tried by searching after this effect in the human population as a whole. Differences in susceptibility to UVR-induced immunosuppression like differences in sensitivity to sunburn exist in humans [27]. Furthermore, the immunosuppressive effects of UVR in humans may appear only at personal doses that are associated with local erythema or sunburn [34]. This means that in our study a suppressive effect on the antibody formation might be measurable only in persons who suffer from erythema/ sunburn at the time of their vaccination. This implies that data on personal exposure at the time of vaccination at a detailed level are required.

We conclude that the presented data show slight effects of season on the immune system, but do not indicate a reduced immunoprotection in vaccinations that are given in sunny season. Therefore, an advice for the general population to avoid the starting of an immunization procedure in summer seems unneccesary. UVR-induced immunomulation will possibly come to light more clearly in a study in which the personal exposure to sunlight is recorded in detail and differences in susceptibility to UVR are taken into account.

\section{Acknowledgements}

This study was supported by the Dutch National Research Programme on Global Air Pollution and Climate Change (NOP, Project 952276).

\footnotetext{
${ }^{2}$ diphenylcyclopropenone
} 


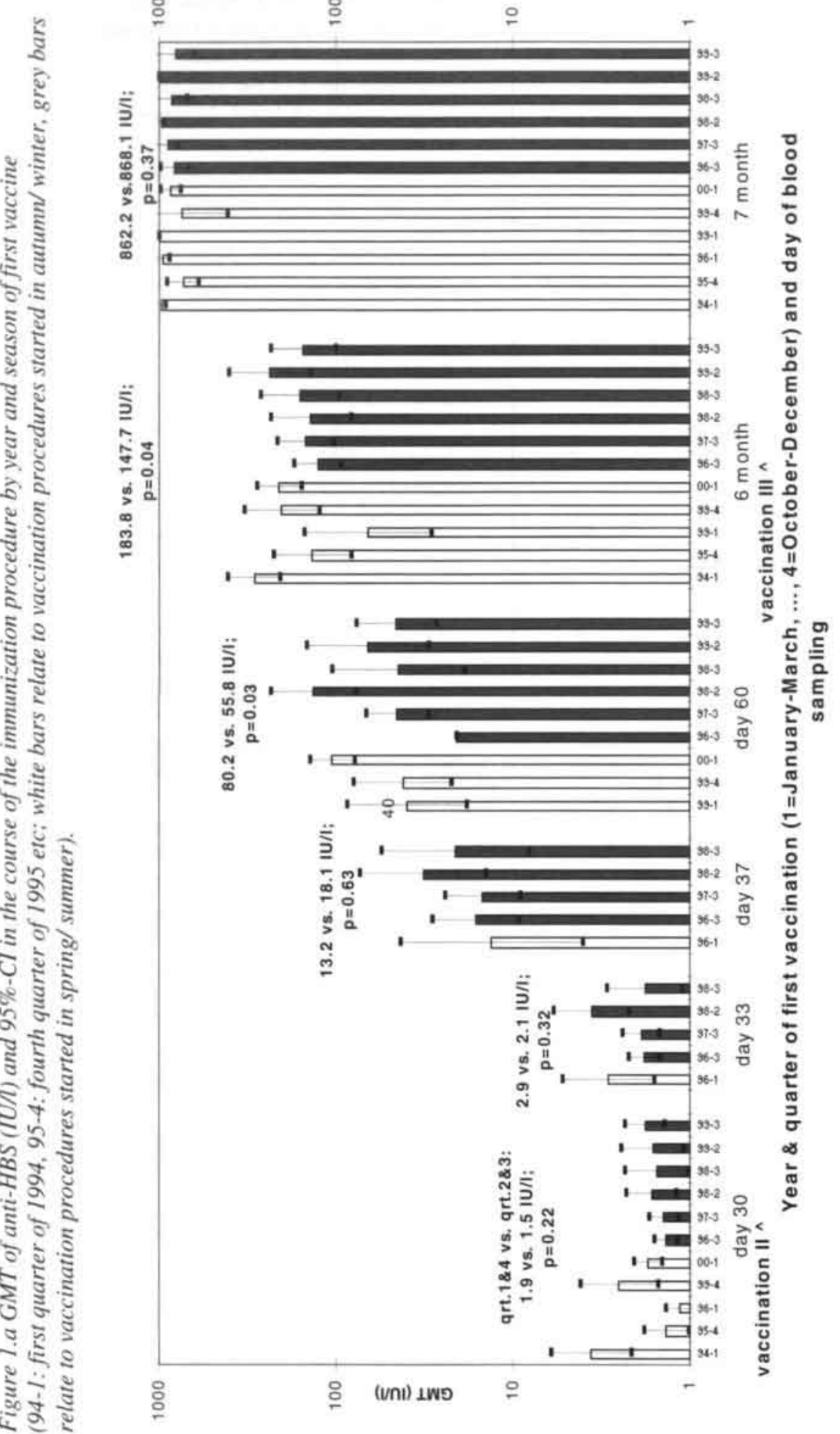


Figure 1.b Percentage of participants with ami-HBs at the appropriate cut-off level or higher $(<\geq 10 .<\geq 100,<\geq 1000 \mathrm{IU} / \mathrm{l})$ and $95 \%$-Cl in the course of the immunization procedure by year and season of first vaccine (see Figure l.a)

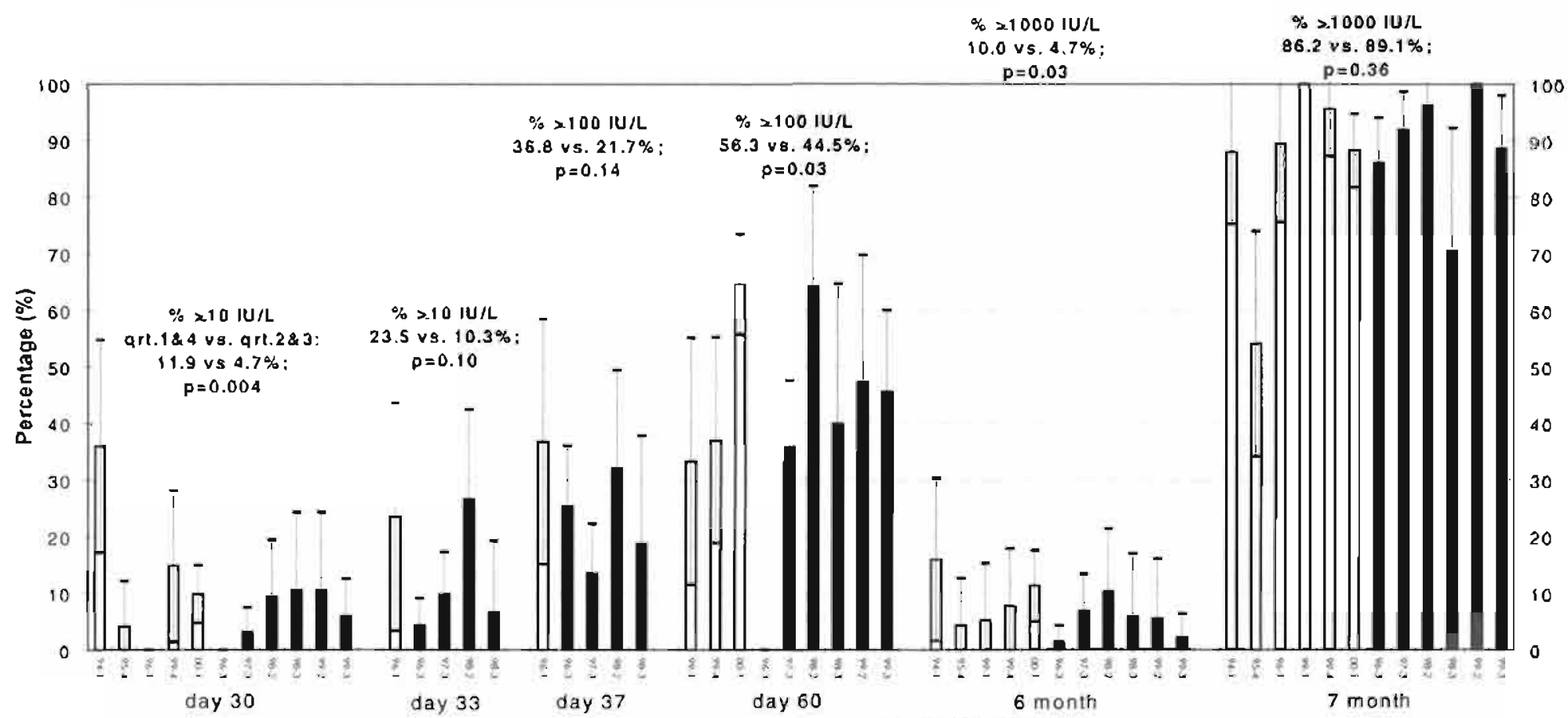

vacclnation II"

Year \& quarter of flist vaccination (1 = January-March

vaceination III $\wedge$

sampling 
Figure 2 Percentage of children with anti-measles $\operatorname{IgG}$ at the cut-off level or higher $(</ \geq 0.2$ IUII) and $95 \%-C I$ by season of first vaccine (MMR-1) and age of blood sampling.

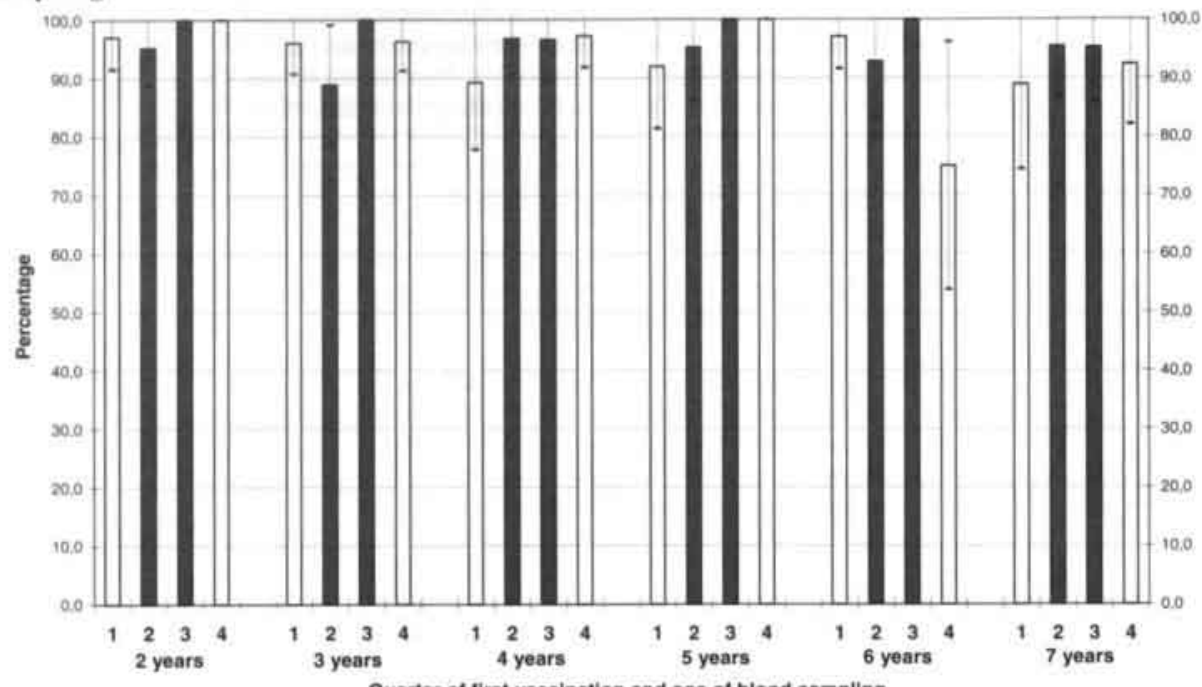

Figure 3. Percentage of children with anti-rubella IgG at the cut-off level or higher $(<1 \geq I 0 I U /)$ and $95 \%-C I$ by season of first vaccine (MMR-1) and age of blood sampling.

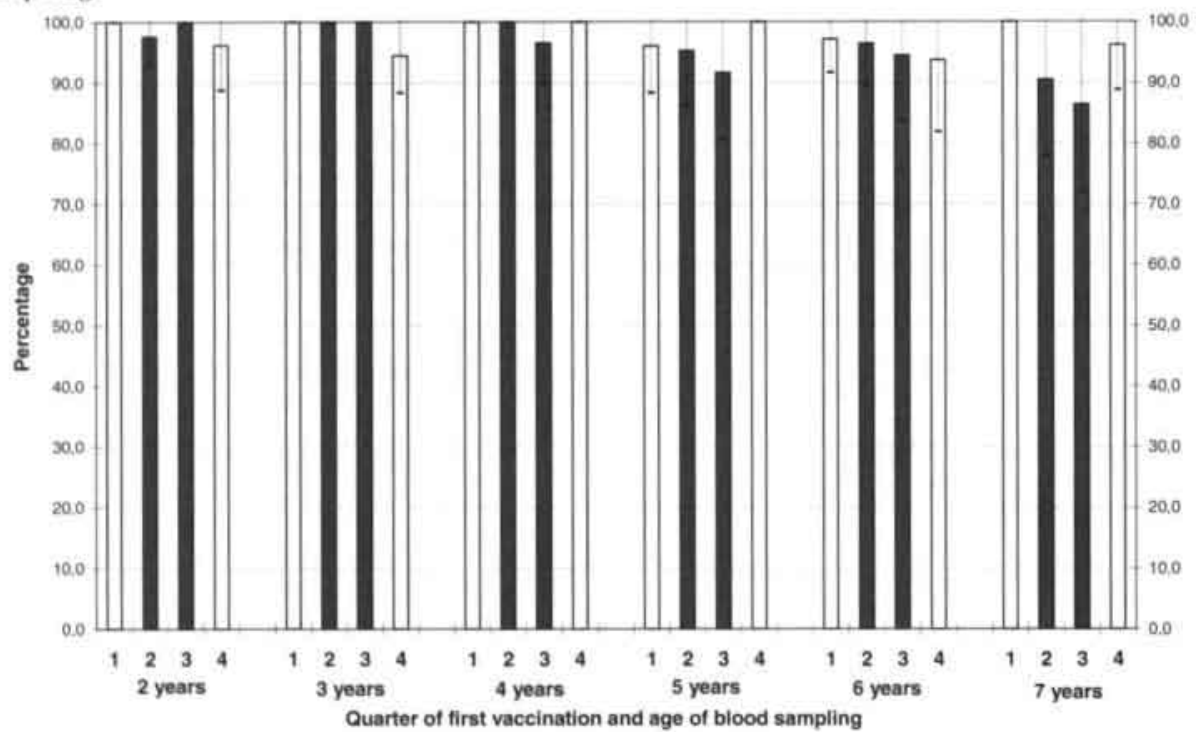




\section{References}

1. Goettsch W, Garssen J, Slob W, De Gruijl FR, van Loveren H. Risk assessment for the harmful effects of UVB radiation on the immunological resistance to infectious diseases. Environ Health Perspect 1998; 106: 71-76.

2. Garssen J, Norval M, El-Ghorr A, Gibbs NK, Jones CD, Cerimele D, De Simone C, Caffieri S, Dall'Acqua F, de Gruijl FR, Sontag Y, van Loveren H. Estimation of the effect of increasing UVB exposure on the human immune system and related resistance to infectious diseases and tumours. J Photochem Photobiol B: Biology $1998 ; 42: 167-179$.

3. Hersey P, Hasic E, Edwards A, Bradley M, Haran G, McCarthy WH. Immunological effects of solarium exposure. Lancet 1983; I: 545-548.

4. Hersey P, Haran G, Hasic E, Edwards A. Alteration of T cell subsets and induction of suppressor $\mathrm{T}$ cell activity in normal subjects after exposure to sunlight. J Immunol 1983; 31: 171-174.

5. Falkenbach A, Sedlmeyer A. Travel to sunny countries is associated with changes in immunological parameters. Photodermatol Photoimmunol Photomed 1997;13: 139-142.

6. Whitmore SE, Morison WL. The effect of suntan parlor exposure on delayed and contact hypersensitivity. Photochem Photobiol 2000; 71: 700-705.

7. Kelly DA, Walker SL, McGregor JM, Young AR. A single exposure of solar simulated radiation suppresses contact hypersensitivity responses both locally and systemically in humans: quantitative studies with high-frequency ultrasound. J Photochem Photobiol B: Biology 1998; 44: 130-142.

8. Chapman RS, Cooper KD, De Fabo EC et al. Solar ultraviolet radiation and the risk of infectious disease: summary of a workshop. Photochem Photobiol 1995; 61: 223247.

9. Norval M, Garssen J, Van Loveren H, El-Ghor AA. UV-induced changes in the immune response to microbial infections in human subjects and animal models. J Epidemiol 1999; 9: S84-S92.

10. Van Loveren H, Van Amsterdam JGC, Vandebriel RJ, Kimman TG, Rümke HC, Steerenberg PS, Vos JG. Vaccine-induced antibody responses as parameters of the influence of endogenous and environmental factors. Environ Health Persp 2001; 109: 757-764.

11. Van Loveren H, Germolec D, Koren HS, Luster MI, Nolan C, Repetto R, Smith E, Vos JG, Vogt RF. Report of the Bilthoven Symposium: Advancement of epidemiological studies in assessing the human health effects of immunotoxic agents in the environment and the workplace. Biomarkers 1999; 4: 135-157.

12. Luster MI, Portier C, Pait DG, White KL, Gennings C, Munson AE, Rosenthal GJ. Risk assessment in immunotoxicology. I. Sensitivity and predictability of immune tests. Fundam Appl Toxicol 1992; 18: 200-210.

13. Luster MI, Portier C, Pait DG, Rosenthal GJ, Germolec DR, Corsini E, Blaylock BL, Pollock P, Kouchi Y, Craig W, Munson AE, White KL. Risk assessment in immunotoxicology. II. Relationship between immune and host resistance tests. Fundam Appl Toxicol 1993; 21: 71-82.

14. Boonstra A, van Oudenaarden A, Barendregt B, An L, Savelkoul HFJ. Effect of short-term UVB irradiation on humoral immunity. Photochem Photobiol 1999; 69: 98S. 
15. Garssen J, Vandebriel RJ, De Gruijl FR, Wolvers DAW, Van Dijk M, Fluitman A, Van Loveren H. UVB exposure-induced systemic modulation of Th1 - and Th2mediated immune responses. Immunology 1999; 97: 506-514.

16. Sleijffers A, Garssen J, De Gruijl FR, Boland GJ, Van Hattum J, Van Vloten WA, Van Loveren H. UVB Exposure impairs immune responses after hepatitis B vaccination in two different mouse strains. Photochem Photobiol 2002; 75: 541-546.

17. De Melker HE, Conyn-van Spaendonck MAE. Immunosurveillance and the evaluation of national immunisation programmes: a population based approach. Epidemiol Infect 1998; 121: 637-43.

18. Van den Hof S, Berbers GAM, de Melker HE, Conyn-van Spaendonck MAE. Sero-epidemiology of measles antibodies in the Netherlands, a cross-sectional study in a national sample and in communities with low vaccine coverage. Vaccine 2000; 18: 931-940.

19. De Haas R, Van de Hof S, Berbers GAM, De Melker HE, Conyn-van Spaendonck. Prevalence of antibodies against rubella virus in the Netherlands 9 years after changing from selective to mass vaccination. Epidemiol Infect 1999; 123: 263-270.

20. Chen RT, Markowitz LE, Albrecht P. Stewart JA, Mofenson LM, Preblud SR, Orenstein WA. Measles antibody: re-evaluation of protective titers. J Infect Dis 1990; 162: 1036-1042.

21. Skendzel LP. Rubella Immunity. Defining the level of protective antibody. Am J Clin Pathol 1996; 106: 170-4.

22. Diffey BL. Human exposure to ultraviolet radiation. Seminars in Dermatology Semin Dermatol 1990; 9: 2-10.

23. Demas GE, Nelson RJ. Photoperiod and temperature interact to affect immune parameters in adult male deer mice (Peromyscus maniculatus). J Biol Rhythms 1996; 11: 94-102.

24. Nelson RJ, Demas GE, Klein SL, Kriegsfeld LJ. The influence of season, photoperiod and pineal melatonin on immune fuction. J Pineal Res 1995; 19 : 149 165.

25. Pati AK, Florentin I, Chung V, De Sousa M, Levi F, Mathe G. Circannual rhythm in natural killer activity and mitogen responsiveness of murine splenocytes. Cell Immunol 1987; 108: 227-234.

26. Brock MN. Seasonal rhythmicity in lymphocyte blastogenic responses of mice persisit in a constant environment. J Immunol 1983; 130: 2586-2588.

27. Kelly DA, Young AR, McGregor JM, Seed PT, Potten CS, Walker SL. Sensitivity to sunburn is associated with susceptibility to ultraviolet radiation-induced suppression of cutaneous cell-mediated immunity. J Exp Med 2000; 191: 561-566.

28. Sleijffers A, Garssen J, De Gruijl FR, Boland GJ, Van Hattum J, Van Vloten WA, Van Loveren $\mathrm{H}$. Influence of Ultraviolet B exposure on immune responses following Hepatitis B vaccination in human volunteers. J Invest Dermatol 2001: 117: 1144 1150.

29. Miyauchi H. Horio T. Ultraviolet B-induced local suppresion of contact hypersensitivity is modulated by ultraviolet irradiation and hapten application. J Invest Dermatol 1995: 104: 364-369.

30. Vila LM, Mayor AM, Valentin AH, Rodriguez SI, Reyes ML, Acosta E, Vila S. Association of sunlight exposure and photoprotection measures with clinical outcome in systemic lupus erythematosus. P R Health Sci J 1999; 18: 89-94. 
31. McMichael AJ, Hall AJ. Does immunosuppressive ultraviolet radiation explain the latitude gradient for multiple sclerosis? Epidemiology 1997; 8: 642-645.

32. Van Loveren H, Boonstra A, Van Dijk M, Fluitman A, Savelkoul HBJ, Garssen J. UV exposure alters respiratory allergic responses in mice. Photochem Photobiol 2000; 72: 253-259.

33. Goettsch W, Garssen J, Deijns A, De Gruijl FR, Van Loveren H. UVB exposure impairs resistance to infections with Trichinella spiralis. Environ Health Perspect 1994; 102: 298-301.

34. Jansen C, Leszczynski D, Pastila R, Koulu L, Laihia J et al. Immunosuppressive, carcinogenic and metastase-related effects of solar UV radiation. Publications of The Finnish Research Programme on Environmental Health, SYTTY 2000; 1: 241-247. 

Chapter 6 Exposure to solar ultraviolet radiation in young Dutch children: assessment by means of a six-week retrospective questionnaire

F. Termorshuizen', A. Wijga ${ }^{2}$, J.Garssen', P.N. den Outer $^{3}$, H. Slaper ${ }^{3}$, H. van Loveren'

' Laboratory for Toxicology, Pathology, and Genetics; ${ }^{2}$ Department for Chronic Diseases Epidemiology; ${ }^{3}$ Laboratory for Radiation Research, National Institute of Public Health and the Environment (RIVM), Bilthoven, The Netherlands. 


\section{Summary}

We designed a 6-week retrospective questionnaire on sunlight exposure. Estimation of the short-term exposure to sunlight is important for observational human studies concerning the effects of ultraviolet radiation (UVR) on the human immune system and related resistance to infections. This questionnaire was given to the parents of 16721 -year-old children in the Netherlands who participate in a birth-cohort study. We evaluated the questionnaire and estimated the personal 6-week cumulative exposure to solar UVR.

Only 910 questionnaires $(54.4 \%)$ were filled out completely and consistently. This suggests that reporting data on the child's outdoor exposure, even for the recent past, is often difficult. The data from these questionnaires indicated that the crude number of reported outdoor hours was enough to obtain a relative estimate of the individual exposure to ambient UVR, but that weighting for the effect of clothing was essential for the classification of the systemic UVR dose received. Sunny weeks in the Netherlands in 1998, as were established by independent measurements of the levels of ambient UVR, vacations abroad, and sunburn were associated with a comparatively high mean estimated exposure. These results support the suitability of the questionnaire for classifying the participants with respect to their short-term exposure to solar UVR.

(Abbreviations: C, (the effect of) clothing as reported (on the UVR dose); L\&S, (the effect of) latitude and season (on the UVR dose); PSB, polysulfone film badges; SCC, Spearman Correlation Coefficient; WCq, (the effect of) weather conditions, as reported in the questionnaire (on the UVR dose); UVR, Ultraviolet radiation)

\section{Introduction}

Investigators have often resorted to the use of questionnaires for examining the correlation between exposure to ambient ultraviolet radiation (UVR) and diseases in human populations. For studies on skin cancer and cataracts, questionnaires were designed to give a relative estimate of the cumulative exposure of the participant in the preceding decades $\left[\begin{array}{lll}1 & 2 & 3\end{array}\right]$. It appears from experimental studies (both animal and human) that UVR has short-term and reversible suppressive effects on the immune system [4 5]. Whether this UVR-induced immunomodulation will lead to impaired resistance to infectious diseases in human populations is still an unresolved issue [6]. As many infections have a high incidence in human populations and exposure to solar UVR is ubiquitous, the establishment of such an effect may be of importance for public health. Assessment of the short-term exposure to UVR and outcome variables that indicate immunosuppression or impaired resistance to infections is crucial to obtain supporting evidence for the immunomodulating capacities of UVR in humans [7].

In various studies, personal dosimetry such as UVR-sensitive polysulfone film badges (PSB) was used for assessment of short-term exposure to UVR [8-12] Personal dosimetry may yield a precise estimate of the encountered levels of ambient UVR. However, the required laboratory facilities, the difficulties with the logistics, and, above all, the dependence on the compliance of the participants to renew their badges every day during several weeks make it less suitable for large-scale epidemiological studies. We assessed the exposure to solar UVR by means of a 6- 
week retrospective questionnaire. This questionnaire was given to the parents of 1 year-old children who participate in a birth-cohort study on asthma, allergy, and respiratory tract infections in the Netherlands. We evaluated the ability of the parents to fill out this questionnaire and investigated what kind of information was essential for classifying the children with respect to their short-term exposure to UVR.

Furthermore, we investigated whether the reported data on outdoor exposure and weather conditions coincided with the levels of ambient UVR, which were measured objectively and independently on a daily basis. In this way, we gain insight into the relevance and limitations of the use of this questionnaire for epidemiological studies on the short-term effects of UVR.

In the future, we will examine whether children with comparatively high exposure to solar UVR have a greater risk of respiratory tract infections at the time of. or shortly after, exposure.

\section{Methods}

\section{The cohort study and the questionnaire on sunlight exposure}

In the cohort study, the children are followed from birth until the age of 8 years. At the time of each birthday, they receive a questionnaire on complaints indicating asthma, allergy, and respiratory tract infections and many possible determinants. This cohort study offers an excellent opportunity to examine the effects of UVR on infections in humans, as both the outcome and many possible confounding factors are recorded for a large group of humans recruited from the general population in the Netherlands.

A supplementary 6-week retrospective questionnaire on sunlight exposure was handed out to the parents of the participating children $(n=1672)$ in the months April through September 1998 at the time of the child's first birthday. The parents were requested to report each child's daily number of outdoor hours in the daytime, the clothing, and the weather conditions during different periods within the preceding 6 weeks (see Appendix 1). The parents were asked to define these different periods on the basis of their experience of weather conditions in the Netherlands or vacations abroad (eg, two rainy weeks at home, three sunny weeks in Spain, and one sunny week at home again). Clothing and weather conditions at the time of outdoor exposure were asked for in broad categories and for every self-defined period separately. Furthermore, a few questions about sunburn and protection (such as use of sunscreen or a hat) during the 6 weeks were added (see Appendix 2).

\section{Personal exposure assessment (see Appendix 1)}

An estimate of personal exposure to UVR was calculated on the basis of the reported data [7]. The starting point was the number of reported outdoor hours, To adjust for the effect of latitude and season (L\&S) on the UVR dose, all reported outdoor hours were weighted with factors reflecting differences in the ambient levels of UVR by L\&S. These weighting factors were calculated on the basis of the daily cumulative biologically effective UVR doses received on a horizontal plane in 1998 (CIE weighted, Commission International de l'Eclairage) [13]. These daily UVR doses were calculated for $5^{0}$-latitude zones using an UVR transfer model [14]. Daily values for the zonal mean of the total ozone column, as well as a fixed set of atmospheric parameters were used (TOMS/ NASA: Total Ozone Monitoring System. Data available by anonymous ftp at: toms.gsfc.nasa.gov). For the calculation of weighting factors for L\&S, the effect of clouds was disregarded. The corresponding weighting 
factors for L\&S were applied to all reported outdoor hours. To do this, both the country of exposure (eg, vacation in France) and the dates of the self-defined periods were taken into account.

The clothing determines the extent of the skin area exposed and consequently the dose of UVR that may give a biological effect. We calculated weighting factors for the effect of clothing as reported $(\mathrm{C})$ on the basis of the percentage of skin area exposed per anatomical site [15]. For example, when dressed in shorts and T-shirt, the head and neck, the forearms, the back of the hands, the upperarms, and the legs are exposed. These skin areas represent approximately $9 \%, 6 \%, 3 \%, 6 \%$, and $30 \%$ of total body area, respectively. This yields a weighing factor of $54 \%(0.54)$. The other weighting factors for $\mathrm{C}$ were calculated likewise: 0.87 (nude or swimming trunks only), and 0.12 (completely dressed).

Next, all reported outdoor hours were weighted for the effect of weather conditions, as reported in the questionnaire (WCq). A cloudy sky may reduce the ambient UVR by as much as $80 \%$ (see Figure 2.h) [12 16 17]. The weighting factors for the effect of weather conditions on the UVR dose were chosen by approximation at 1.0 (bright sky), 0.8 (mostly sunny, sometimes clouded), 0.6 (sometimes sunny, sometimes cloudy and rainy), 0.4 (mostly cloudy, sometimes sunny), and 0.2 (clouded sky).

The weighting factors for L\&S, C, and WCq were divided by the mean weighting factor applied for L\&S, C, and WCq, respectively, to give a 'scaled weighting factor'. This means that the mean weighting factor that was applied equals 1. In this way the various estimates of exposure (ie, with and without the weighting factors) could be compared with each other on the same scale.

\section{Influence of the various weighting factors on the range and the ranking of the participants}

We studied whether introducing the weighting factors in the exposure assessment influenced the range of exposure estimates ( $5 \%-95 \%$ quantiles). Enlargement of the $5 \%-95 \%$ quantile indicates that the contrast in exposure estimates between the participants increases due to the introduction of the weighting factors in the calculation of the exposure. As 'scaled weighting factors' were used in the analysis (see before), this (possible) enlargement is not caused by the ranges of the different weighting factors.

Furthermore, we evaluated the relevance of introducing the weighting factors for ranking the participating children's exposure to UVR. Correlations between the 6week cumulative number of outdoor hours as reported on the one hand and the same number after weighting for the different effects ( $L \& S, C, W C q)$ on the other hand were established. This was done by means of the Spearman Correlation Coefficient (SCC).

\section{Comparison of the estimated exposure in the Netherlands with the estimated exposure abroad and with the independently measured levels of ambient UVR}

In this analysis, the data from the questionnaire, the weighting factors applied, and the estimated exposure were considered on the group level $(n=910)$. The daily median number of reported outdoor hours, the daily mean weighting factors for L\&S, C, and WCq, and the daily median number of weighted hours were calculated separately for days spent in the Netherlands and days spent abroad. In this way, we compared the median estimated exposure in the Netherlands with (a) the median estimated exposure 
abroad and (b) the objectively measured levels of ambient UVR in the Netherlands in 1998. Daily cumulative biologically effective doses of ambient UVR were obtained by objective measurements. The levels of ambient UVR in the Netherlands have been measured since 1994 at the Dutch National Institute of Public Health and the Environment (RIVM) UVR monitoring site. The RIVM records spectrally resolved UVR received on a horizontal plane every 12 minutes from sunrise to sunset using a DILOR XY spectroradiometer. The ratio of the measured daily dose of UVR and a modelled clear sky value, which we refer to as the UVR ratio, indicates the weather conditions of that day and ranges from 1.0 (cloudless sky all day long) to approximately 0.2 (clouded all day long) (Figure 2.h). Total ozone column data for the Netherlands were used in the model calculation to obtain the clear sky values. We focussed on days or weeks with sunny weather conditions in the Netherlands in 1998 , as indicated by a high UVR ratio, to check if these days were associated with a high daily median exposure in the Netherlands, as estimated on the basis of the questionnaires. We also checked whether the reported weather conditions during outdoor hours in the Netherlands coincided approximately with the observed course of the UVR ratio.

\section{Correlation with sunburn}

We investigated whether the sunburnt children's estimated exposure to sunlight was greater, on average, than that of children for whom no sunburn was reported.

Furthermore, we tested whether the weighting factors applied influenced the difference in estimated exposure between children with and children without sunburn. Differences were tested by means of the non-parametric Wilcoxon test for continuous data. A two-sided $\mathrm{P}$ value of 0.05 or less was regarded as statistically significant.

\section{Results}

\section{The questionnaire on sunlight exposure}

Of the 1672 questionnaires handed out, 1529 (91.4\%) were returned (Table 1). In 503 cases $(30.1 \%)$, the parents were not able to define short periods within the 6 weeks, as the dates were missing or did not link up with each other. In 110 questionnaires

\section{Table I. Facts about the questionnaires}

\begin{tabular}{lcc}
\hline & Number & Percentage \\
\hline Questionnaires handed out & 1672 & $100.0 \%$ \\
Questionnaires not returned & 143 & $8.6 \%$ \\
& & \\
\hline Blank questionnaires & 6 & \\
Or one or more dates missing & +229 & \\
Or self-defined periods do not link up & +274 & \\
Or number of outdoor hours missing & +45 & \\
Or country missing & +62 & \\
Or clothing data missing & +1 & \\
Or weather conditions data missing & +2 & \\
\hline Questionnaires with missing information & 619 & $37.0 \%$ \\
& & \\
Questionnaires filled out completely and consistently & $\mathbf{9 1 0}$ & $54.4 \%$
\end{tabular}


$(6.5 \%)$, the parents were able to define short periods, but they did not answer one or more of the other questions on their child's outdoor exposure. The data from the remaining 910 questionnaires $(54.4 \%$ ) were usable for exposure assessment and hence were included in the further analyses.

\section{Personal exposure assessment}

The frequency distribution of the 6-week cumulative number of outdoor hours weighted for L\&S, C, and WCq is shown in Figure 1. The majority of the participating children received an exposure of 120 weighted hours or less; a few received much more exposure, which yielded a non-normal distribution, skewed to low values.

Figure 1. Frequency distribution of the 6-week cumulative number of outdoor hours, weighted for the effect of latitude \& season, clothing, and weather conditions as reported $(n=910)$.

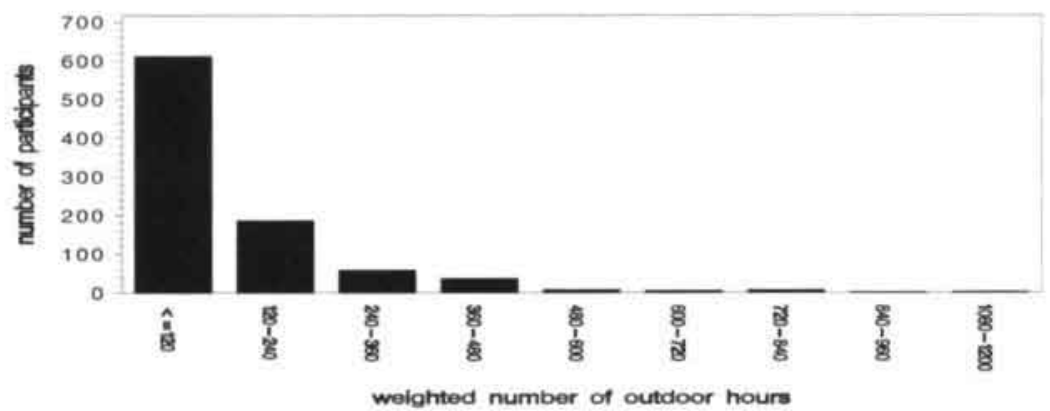

Influence of the weighting factors on the range and the ranking of the participants Introduction of the weighting factors for $\mathrm{L} \& \mathrm{~S}, \mathrm{WCq}$, and especially $\mathrm{C}$ in the personal exposure assessment enlarged the range of the 6-week cumulative estimates (Table 2.a). Introduction of the weighting factors for $\mathrm{L} \& \mathrm{~S}$ and $\mathrm{WCq}$ in the personal exposure

Table 2.a Influence of the weighting factors on the range of individual estimates for exposure $(n=910)$.

Exposure estimated as:

$5 \%-95 \%$ quantiles

The cumulative numbers of outdoor hours

$15.00-150.62$

The cumulative number of outdoor hours after weighting for:

$\begin{array}{lc}\text { L\&S } & 12.2-186.8 \\ C & 7.7-275.9 \\ \text { L\&S and C } & 5.1-325.2 \\ W C q & 13.8-191.8 \\ \text { L\&S and WCq } & 10.7-233.5 \\ C \text { and WCq } & 5.7-317.1 \\ \text { L\&S, C, and WCq } & 3.9-380.5\end{array}$


assessment hardly altered the ranking of the participants with respect to their 6-week cumulative exposure ( $\mathrm{SCC}>0.90$ ). On the contrary, introducing the weighting factors for $\mathrm{C}$ substantially modified this ranking as a lesser SCC $(<0.90)$ was established (Table 2.b).

Table 2.b Influence of the weighting factors on the ranking of the participants $(n=910)$.

Exposure estimated as: SCC with the cumulative number of outdoor hours (95\%-confidence interval)

The cumulative number of outdoor hours
The cumulative number of outdoor hours after weighting for:

\begin{tabular}{lll} 
L\&S & 0.955 & $(0.946-0.965)$ \\
$\mathrm{C}$ & 0.807 & $(0.780-0.835)$ \\
L\&S and C & 0.786 & $(0.758-0.814)$ \\
WCq & 0.938 & $(0.928-0.949)$ \\
L\&S and WCq & 0.906 & $(0.892-0.921)$ \\
C and WCq & 0.764 & $(0.733-0.796)$ \\
L\&S,C, and WCq & 0.751 & $(0.720-0.783)$ \\
\hline
\end{tabular}

Comparison of the estimated exposure in the Netherlands with the estimated exposure abroad and with the measured levels of ambient UVR

Days or weeks spent in the Netherlands were reported in 907 of the 910 questionnaires. The mean number of reported days in the Netherlands was 39.8 (range: 6 - 43 days). Days or weeks spent abroad were reported in 139 questionnaires. The mean number of reported days abroad was 15.4 (range: 3 - 42 days).

The median number of reported outdoor hours is shown by day and country of exposure in Figure 2.a. A small number of the participants contributed to the extreme points of the graph. On average 169 (range: 1-294) persons determined the median estimate of 1 day for exposure in the Netherlands and 10 (range: 1-39) for exposure abroad.

Days abroad were associated with a larger median number of outdoor hours than days spent in the Netherlands (Figure 2.a). Furthermore, outdoor hours abroad were generally associated with higher maximum levels of ambient UVR (Figure 2.b), less C (Figure 2.c), and more favourable weather conditions (Figure 2.d). Hence, the contrast between the estimated exposure in the Netherlands and the estimated exposure abroad (Figure 2.e, f, g) increased by introducing the weighting factors for L\&S (Figure 2.b), C (Figure 2.c), and WCq (Figure 2.d) in the exposure assessment.

The daily UVR ratio in 1998 in the Netherlands is shown in Figure 2.h. For optical reasons only, a smoothing function was applied to these data, as the daily levels of ambient UVR are often very capricious. This smoothing function was not used in the statistical analyses, but enables assessment of periods of days to weeks with favourable weather conditions at first sight. Furthermore, comparison with the data from the questionnaire is facilitated, as these data were reported for longer periods of days to weeks. Sunny weeks in May (days 120-150) and August (days 210240) in 1998 in the Netherlands (Figure 2.h) were associated with a comparatively large daily median number of reported outdoor hours (Figure 2.a). These sunny weeks were also associated with a greater daily mean weighting factor for $\mathrm{C}$ (Figure 2.c) and 
a greater daily mean weighting factor for $\mathrm{WCq}$ (Figure 2.d). This means that the sunny weeks coincided with the reporting of less $\mathrm{C}$ and more favourable weather conditions. As a consequence, these sunny weeks in the Netherlands were associated with a large daily median number of weighted outdoor hours (Figure 2.e, f, g). The SCC between the measured weather conditions in the Netherlands (Figure 2.h, the 'UVR ratio' data without smoothing) and the daily median number of outdoor hours weighted for L\&S, $\mathrm{C}$, and $\mathrm{WCq}$ in the Netherlands (Figure 2.g. line at the bottom) was 0.34 ( $\mathrm{P}=0.0001$ ). When using the daily levels of ambient UVR in the calculation of the SCC (ie, without dividing them by the modelled daily clear-sky value), the SCC increased to $0.718(\mathrm{P}=0.0001)$. For the calculation of these SCC's, the extreme points of the graph were excluded because of the small number of contributing participants.

\section{Correlation with sunburn}

Sunburn was reported for 80 children. For most of them, the parents reported slight sunburn $(n=75)$ without peeling or blisters and sunburn only once during the preceding 6 weeks $(n=60)$. For a large percentage of these children, frequent use of sunscreen $(80 \%)$ and/or other means of protection, such as a hat or shadow $(83.7 \%)$. were reported. These percentages were statistically significantly higher than those for the group of children for whom no sunburn was reported $(58.2 \%$ and $68.6 \%)$.

Figure 3 shows that sunburnt children on average received a higher exposure than children without sunburn, irrespective of the weighting factors applied. Introducing the weighting factors for $\mathrm{L} \& \mathrm{~S}, \mathrm{C}$, and $\mathrm{WCq}$ in the exposure assessment made the difference in estimated exposure even more apparent. All differences were statistically significant.

\section{Discussion}

An estimate of personal exposure to UVR was calculated for a cohort of 1-year-old children on the basis of the parents' data in a 6-week retrospective and selfadministered questionnaire. The starting point of the estimation was the number of reported outdoor hours. These hours were weighted for the effects of L\&S, C, and WCq on the UVR dose received per hour.

The exposure assessment involved a number of sources of inaccuracy.

1. It completely depended on the recall and reporting abilities of the parents, which possibly introduced bias [12]. Many parents did not manage to complete the questionnaire, although details such as the time of the day and kind of outdoor activity were not considered, and the number of outdoor hours, clothing, and weather conditions were asked for in broad categories only. Particularly, the definition of the different periods by weather conditions and/or vacations abroad was often too difficult (Table 1). The ability to complete the questionnaire appeared to be associated with a higher socio-economic status (data not shown), which has to be taken into account when interpreting our results. Asking for the daily number of outdoor hours and $\mathrm{C}$ as an approximation for all 6 weeks at once may facilitate completing the questionnaire, thus increasing the number of usable questionnaires. However, such a simplified questionnaire will yield a very imprecise estimate, as intra-individual differences in exposure due to vacations abroad and/or weather conditions cannot be taken into account by the participant when he/ she fills out the questionnaire. Asking the participants to keep daily records may resolve this dilemma, but would increase the 
burden of participation. Keeping daily records was not feasible in the framework of the birth-cohort study.

2. We were able to weight for important environmental effects such as those of latitude, season, and weather conditions. However, other factors such as time of day, surface reflection, altitude, shade, and humidity were not considered [18 19]. Furthermore, the calculation of the weighting factors for the effect of clothing and weather conditions was based on a rough estimation. Clothing and weather conditions were asked for in broad categories, and the influence of these factors on the UVR dose that was received is hard to quantify exactly on the basis of self-reported data in a retrospective questionnaire.

To obtain a more precise estimate of the daily exposure to UVR, personal dosimetry is needed, as has been done in various studies using UVR-sensitive PSB (see introduction). Personal dosimetry with PSB is often performed with a small number of participants for only a short interval, because close supervision or high compliance of the participants is required. This is often not enough to provide sufficient statistical power for an epidemiological study. Furthermore, questionnaires or diaries are still needed to establish what clothing was worn during outdoor hours, as clothing certainly affects the dose of UVR that penetrates the skin to exert a systemic effect. We wonder whether the greater precision of personal dosimetry is required and whether it is not outweighed by the costs and increased burden of participation [20]. A relative estimate for classifying the participants may be enough for an epidemiological study like the present one. Diaries and personal dosimetry under close supervision should be used only when detailed information on outdoor behaviour is required [20].

It may be argued that personal dosimetry with PSB for a small sample of participants was required to establish the usefulness of the questionnaire. We doubt whether personal dosimetry with PSB is feasible in 1-year-old children without close supervision. The PSB may get easily damaged or lost when attached to young children and hence will not yield a 'gold standard' for validation of the questionnaire. We evaluated the usefulness of the questionnaire by considering the data on the group level. The data from the questionnaires that were filled out completely and consistently confirmed the expectation:

1. The estimated exposure had a non-normal distribution that was skewed to low values (Figure 1). This result coincides with the described distributions in other reports $\left[\begin{array}{lll}1 & 1 & 14\end{array}\right]$.

2 . Both vacations abroad and periods with sunny weather conditions in the Netherlands in 1998 were associated with a comparatively high daily mean exposure as estimated on the basis of the questionnaire (Figure 2). This fulfils the expectation, as sunny weather encourages people to go outdoors in a rainy country such as the Netherlands, and a greater exposure to UVR will ensue. Good correlation between the level of ambient UVR and the mean level of UVR exposure as measured by personal dosimetry in a group of school children was also found in Queensland. Australia [11]. Although these results do not prove the validity of the individual exposure assessment, it supports the suitability of the questionnaire for ranking the participants with respect to their short-term exposure.

3. Furthermore, we examined the association between the estimated 6-week cumulative exposure and sunburn, which is known to be an important biological effect of UVR. The number of reported outdoor hours for sunburnt children was greater, on average, than the number of reported outdoor hours for children without sunburn (Figure 3). The difference in exposure became more apparent when the different 
weighting factors were included in the exposure assessment (Figure 3 ). This observation is as expected, as a large UVR dose per hour is needed to induce sunburn, and indicates that including the weighting factors improved the exposure assessment. However, this approach of the relationship between exposure and sunburn was rather crude (see Appendix 2). Our definition of sunburn was based on the experience and the reporting of the parents, which may imply an underestimation, because erythema is probably often not regarded as sunburn or parents may not be willing to report a sunburn episode of their child. Furthermore, the daily exposure immediately prior to an episode of sunburn is more relevant than an estimate of the 6-week cumulative exposure. Next, the association between exposure and sunburn is modified by the sensitivity of the child's skin to sunlight and the use of sunscreens and/ or other means of protection. As the effect of solar UVR on the immune system and the resistance to infections was our main interest, we did not include the (available) data on skin type in our exposure assessment. It has been shown that the mechanisms of UVR-induced erythema and immunosuppression are different, and that the sensitivity to the acute sunburn effects of UVR are not in a direct line with the sensitivity to the immunosuppressive effects of UVR [21].

For a comparatively great part of the sunburnt children, the use of sunscreens and/ or other means of protection were reported, indicating the tendency of the parents to avoid damage of their child's skin during intense exposure to solar UVR. The association between the child's skin photo-type, outdoor behaviour, sunburn and the tendency of the parents to protect their children against the sun is an important issue, especially for the risk of skin cancer in later life and possibly also for the risk of immunosuppression and the susceptibility to infections. This requires further studies on children's outdoor behaviour and the perceived health risks associated with exposure to solar UVR.

We examined the influence of the inclusion of the weighting factors in the exposure assessment on the range and the ranking of the participants' 6-week cumulative exposure. Introducing the weighting factors for the effects of L\&S, WCq, and especially $\mathrm{C}$ in the exposure assessment was associated with a broadening of the $5 \%-95 \%$ quantile (Table 2.a). This suggests that taking these effects into account would give a better picture of the participants' exposure. Weighting the reported outdoor hours for the effect of environmental factors (L\&S and WCq) on the UVR dose hardly altered the participants' exposure ranking (Table 2.b). This observation suggests that a large number of reported outdoor hours was generally associated with sunny weather conditions during the weeks covered by the questionnaire and, as a consequence, a large UVR dose per outdoor hour. In contrast, a small number of reported outdoor hours was generally associated with cold weather, leading to a small UVR dose per outdoor hour. This is again in line with the general feeling that sunny weather encourages people to go outdoors. This result implies that, within a group of children that is homogeneous with respect to age, the crude number of outdoor hours may give a relative estimate that is valid for exposure to ambient UVR. However, taking the weighting factors for the effect of clothing into account modified the children's ranking considerably (Table 2.b). This finding implies that, besides the number of outdoor hours, data on clothing worn may be important for obtaining a valid classification with respect to the UVR dose that eventually gives a systemic effect.

In conclusion, we estimated the individual short-term UVR exposure in a selected group of 1-year-old children by means of a retrospective questionnaire. The 
questionnaire was probably suited to determining someone's short-term exposure, because vacations abroad, sunny weeks in the Netherlands, and sunburn were associated with a high mean estimated exposure. However, validation studies, preferably in adults, are still needed to gain insight into the reliability of self-reported data on outdoor exposure at an individual level. Such studies will also be helpful to explore whether the questionnaire may be simplified, as was suggested by our results, in order to obtain a higher number of filled-out questionnaires usable for the estimation of the personal exposure.

\section{Acknowledgement}

We thank Dr ir W.G. Goettsch for his support in setting up this study and the design of the questionnaire, Dr ir H.A. Smit and Ir D.J.M. Houthuijs for critically reviewing this manuscript. This study was supported by the Dutch National Research Programme on Global Air Pollution and Climate Change (NOP, Project 952276) and Project ENV4-CT96-0192 of the Programme Environment of the EU. 


\section{Figures 2 and 3}

Figure 2. (next page) Comparison of the median daily exposure in the Netherlands with the median daily exposure abroad (2.a, e, f. g) and with the daily levels of ambient UVR as measured in Bilthoven (2.h), March-September $1998(n=910)$.

2.a Daily median number of reported outdoor hours

2.b Daily mean weighting factor for latitude \& season (L\&S)

2.c Daily mean weighting factor for clothing $(C)$

2.d Daily mean weighting factor for weather conditions as reported (WCq)

2.e Daily median number of outdoor hours weighted for $L \& S$

2.f Daily median number of outdoor hours weighted for $L \& S$ and $C$

2.g Daily median number of outdoor hours weighted for $L \& S, C$, and WCq

2.h Weather conditions in 1998 in Bilthoven (The Netherlands) 


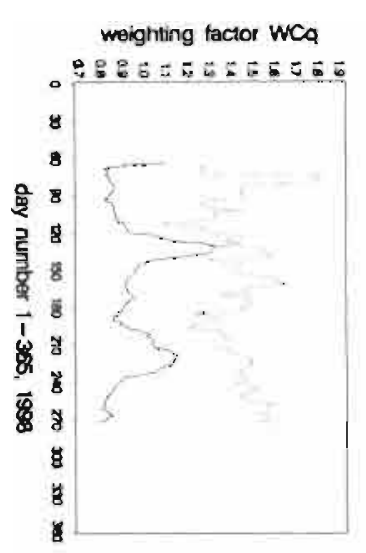

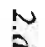

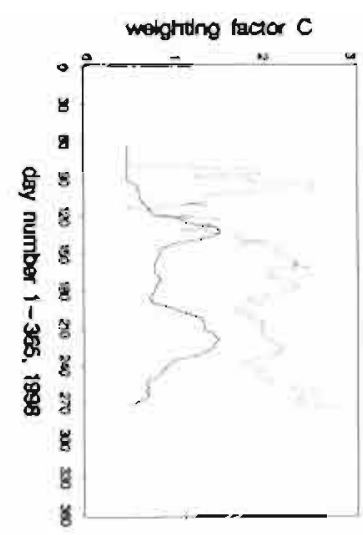

U - raso

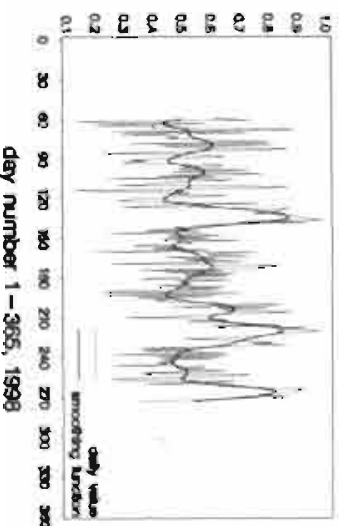

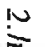

$n$
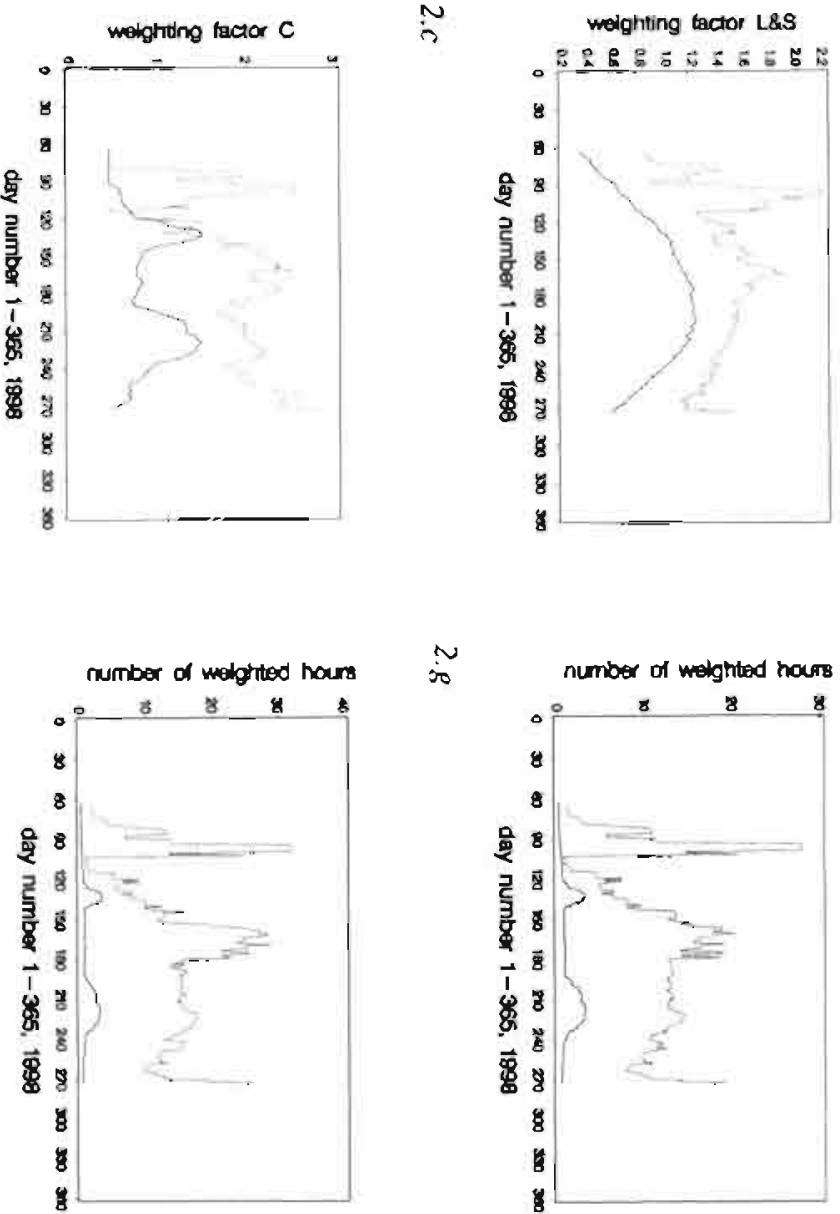

$N$

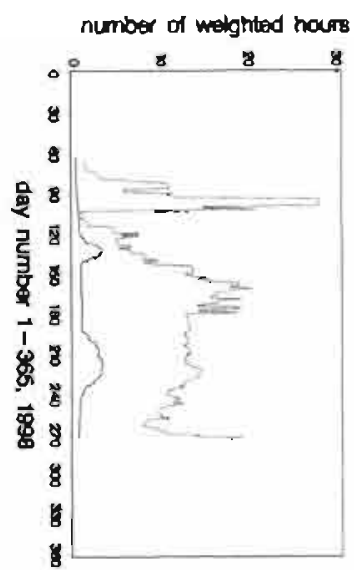

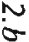

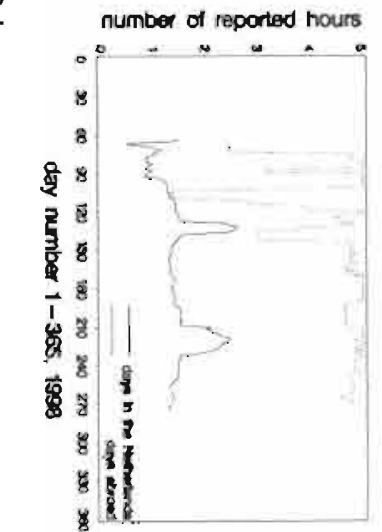

$\stackrel{1}{2}$

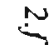

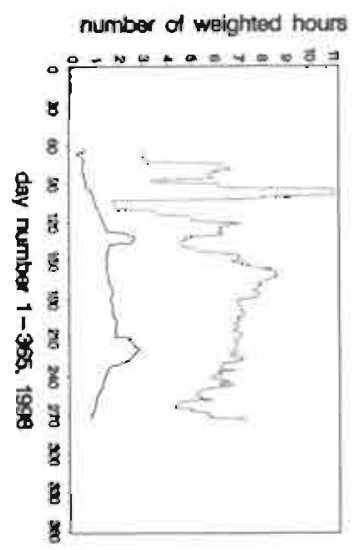


Figure 3. Six-week cumulative exposure: I. Number of reported outdoor hours, II.-IV. after weighting for successively L\&S, - and C, - and WCq, mean and 95\%-confidence interval, by reported sunburn (yes/no)

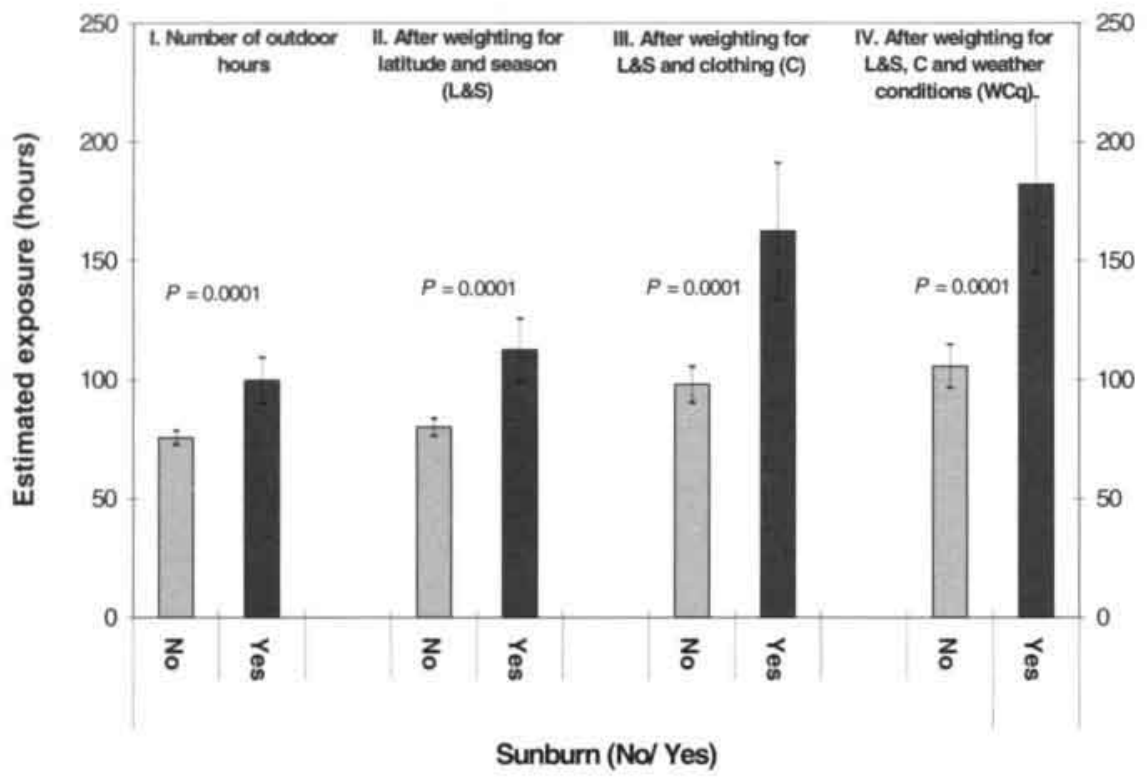




\section{Appendix 1 Key questions on exposure (English translation) and estimation equation}

\section{Questions on exposure}

Date of filling out the questionnaire: (day) (month) 1998

Self-defined period I.

a. Where did you stay during the first days/ weeks of the preceding 6 weeks (for example at home in the Netherlands or on holiday in France)?

b. Can you please give the dates of beginning and end of this period?

c. On how many days did your child go out of the house during the daytime?

d. What was the average number of daily outdoor hours during daylight?

e. How was your child generally clothed during these outdoor hours?

b.1 from _ (day) _ (month) 1998
b. 2 till $\_$(day) _ (month) 1998
days

' 1 hour or less

${ }^{2}$ - 1 - 2 hours

${ }^{3} \cdot 2$ - 4 hours

$\sqrt[4]{ } 4$ hours or more

' $\mathrm{J}$ (swimming) shorts or nude

${ }^{2} \mathrm{~J}$ shorts and T-shirt

${ }^{3} \mathrm{~J}$ completely dressed

$\left.{ }^{4}\right]$ other clothing: please

clarify:

f. Please, can you indicate the weather conditions, which were generally experienced during the outdoor ' $\square$ always a radiant sky

$\left.{ }^{2}\right]$ mostly radiant, sometimes cloudy hours of your child?

${ }^{3}$ both cloudy and sunny moments

[ mostly cloudy, sometimes sunny

${ }^{5} \square$ always cloudy and rainy

If the first period for which you filled in these questions covered the preceding 6 weeks at once, you may skip the next 3 pages (Period II. Period III. Period IV) and continue at page number... .

Estimation equation for exposure:

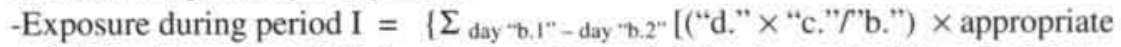
weighting factor for L\&S $\}$ × \{appropriate weighting factor for $\mathrm{C}$ (see "e.") $\} \times$ \{appropriate weighting factor for WCq (see "f.")\}*

(*"b.1", "b.2", "c." etc. refer to the answers given to the questions b.1, b.2, c. etc) -6 -week cumulative exposure $=$ Exposure during period $\mathrm{I}+\ldots \mathrm{II}+\ldots \mathrm{III}+\ldots \mathrm{IV}$. 


\section{Appendix 2 Questions on sunburn and protection}

\section{Questions on sunburn}

1.a. Did your child have been sunburnt in the preceding 6 weeks?

b. If yes, the total number of times

ID No

${ }^{2}$ Yes

c. If yes, the degree of burning

\footnotetext{
$1]$ severe burning with blisters

$\left.{ }^{2}\right]$ painful burning followed by peeling

${ }^{3} \mathrm{a}$ light burning followed by a $\tan$
}

Questions on the use of sunscreen

2.a. Did you embrocate your child's skin with sunscreen during outdoor hours in the preceding 6 weeks?

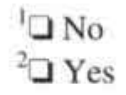

b. If yes, how often did you give sunscreen when the sun was shining?

c. If yes, what was the protection factor of the sunscreen (the number on the flacon)
' (almost) never during sunny outdoor hours ${ }^{2} \mathrm{a}$ sometimes
${ }^{3} \square$ almost half the time
$\left.{ }^{4}\right]$ more than half the time
${ }^{5} \square$ (almost) always during sunny outdoor hours factor:

\section{Question on other ways of protection}

3.a. Did you protect your child against the sun in other ways in the preceding 6 weeks?

b. If yes, how did you do (more answers possible)?

b. If yes, how often did you do that when the sun was shining?

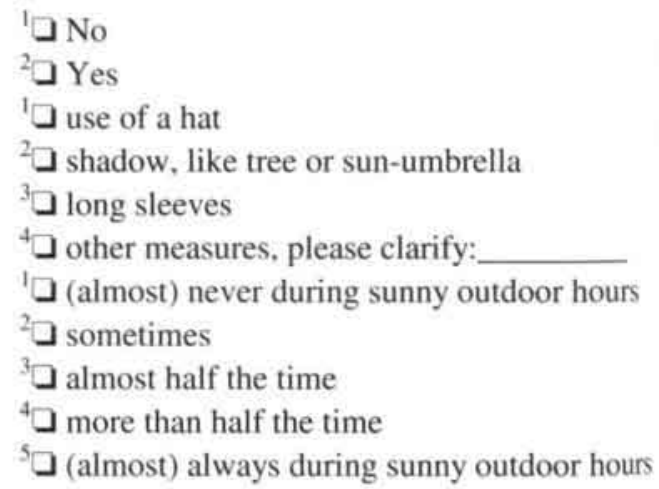




\section{References}

1. Bouwes Bavinck JN, De Boer A, Vermeer BJ, Hartevelt MM, Van der Woude FJ, Claas FHJ, Wolterbeek R, Vandenbroucke JP. Sunlight, keratotic skin lesions and skin cancer in renal transplant recipients. Br J Dermatol 1993; 129: 242-249.

2. Rosmini F, Stazi MA, Milton RC, Sperduto RD, Pasquini P, Maraini G, and the Italian-American Cataract Study Group. A dose-response effect between a sunlight index and age-related cataracts. Ann Epidemiol 1994; 4: 266-270.

3. Duncan DD, Munoz B, Bandeen-Roche K, West SK, and the Salisbury Eye Evaluation Project Team. Assessment of ocular exposure to ultraviolet-B for population studies. Photochem Photobiol 1997; 66: 701-709.

4. Hersey P, Hasic E, Edwards A, Bradley M, Haran G, McCarthy WH. Immunological effects of solarium exposure. Lancet 1983; I: 545-548.

5. Goettsch W, Garssen J, Timmerman HH, Dortant P. Kuper F, De Gruijl FR, Van Loveren H. Systemic effects of UVB irradiation on basal immune parameters in the rat. In: Biological Effects of Light 1993 (Jung EG, Holick MF, eds). Berlin: Walter de Gruyter, 1993: 637-641.

6. Garssen J, Norval M, Van Loveren H. UVB-induced immunomodulation: a health risk. Polar Research 1999; 18: 339-343.

7. Termorshuizen F, Garssen J, Maas JJ, Goettsch WG, Matthijssen J, Houweling H, Van Loveren H. UVB and infectious diseases: exposure assessment by means of a retrospective questionnaire for an epidemiological study. Report 640300.001 . National Institute of Public Health and the Environment. Bilthoven. 1999.

8. Rosenthal FS, Lew RA, Rouleau LJ, Thomson M. Ultraviolet exposure to children from sunlight: a study using personal dosimetry. Photodermatol Photoimmunol Photomed 1990; 7: 77-81.

9. Herlihy E, Gies PH, Roy CR, Jones M. Personal dosimetry of solar radiation for different outdoor activities. Photochem Photobiol 1994; 60: 288-294.

10. Diffey BL, Gibson CJ, Haylock R, McKinlay AF, Outdoor ultraviolet exposure of children and adolescents. Br J Dermatol 1996; 134:1030-1034.

11. Gies P, Roy C, Toomey S, MacLennan R, Watson M. Solar UVR exposure of primary school children at three locations in Queensland. Photochem Photobiol 1998; 68: 78-83.

12. Moise AF, Gies HP, Harrison SL. Estimation of the annual solar UVR exposure dose of infants and small children in tropical Queensland, Australia. Photochem Photobiol 1999; 69:457-463.

13. Commission International de I'Eclairage. Research note: a reference action spectrum for ultraviolet induced erythema in human skin. CIEJ 1987; 6:17-22.

14. Slaper H, Reinen HAJM, Bordewijk JA, Schlamann E. Effective ultraviolet radiation in the Netherlands. Report 610070.002. National Institute of Public Health and the Environment. Bilthoven, 1994.

15. Pearl DK, Scott EL. The anatomical distribution of skin cancers. Int J Epidemiol 1986; 15: 502-506.

16. Borderwijk JA, Slaper H, Reinen HAJM, Schlamann E. Total solar radiation and the influence of clouds on the biologically effective UV. Geophys Res Lett 1995; 22:2151-2154.

17. Bodeker GE, McKenzie RL. An algorithm for inferring surface UV irradiance including cloud effects. J Appl Meteorol 1996; 35:1860-1877.

18. Diffey BL, Larkö O. Clinical climatology. Photodermatol 1984; 1:30-37. 
19. Parisi AV, Kimlin MG. Comparison of the spectral biologically effective solar ultraviolet in adjacent tree shade and sun. Phys Med Biol 1999; 44: 2071-2080.

20. Brandberg Y, Sjödén PO, Rosdahl I. Assessment of sun-related behaviour in individuals with dysplastic naevus syndrome: a comparison between diary recordings and questionnaire responses. Melanoma Res 1997: 7: 347-351.

21. Garssen J, van Steeg H, De Gruijl FR, De Boer J, Van der Horst GTJ, Van Kranen H, Van Loveren H, Van Dijk M, Fluitman A, Weeda G, Hoeijmakers JHJ. Transcription-coupled and global genome repair differentially influence UV-Binduced acute skin effects and systemic immunosuppression. J Immunol 2000; 164: 6199-6205. 


\title{
Chapter 7 Exposure to solar ultraviolet radiation and respiratory tract symptoms in 1-year-old children
}

\author{
F. Termorshuizen' ${ }^{1}$, A. Wijga ${ }^{2}$, J. Gerritsen ${ }^{3}$, H.J. Neijens ${ }^{4}$, H. van Loveren'
}

${ }^{1}$ Laboratory for Toxicology, Pathology, and Genetics, and ${ }^{2}$ Department of Chronic Disease Epidemiology, National Institute of Public Health and the Environment (RIVM), Bilthoven, the Netherlands; ${ }^{3}$ Department of Paediatric Respiratory medicine. Beatrix Children's Hospital, University Hospital of Groningen, University of Groningen, the Netherlands; ${ }^{4}$ Department of Paediatrics, Sophia Kinderziekenhuis, Rotterdam, the Netherlands. 


\section{Summary}

In view of the immunosuppressive effects of ultraviolet radiation (UVR) and resulting impaired resistance to infections, as demonstrated in experimental studies, we examined whether exposure to sunlight was associated with an increased risk of respiratory tract symptoms in children aged 1 year.

In a birth-cohort study, the exposure to solar UVR was estimated by means of a 6-week retrospective questionnaire in the months April through September 1998. In addition, ambient levels of UVR were established during this same period. For 785 children, these data on exposure were coupled to the reported information on respiratory tract symptoms during the preceding 4 weeks.

Slight sunburn appeared to be statistically significantly associated with a higher risk of earache/ runny ear. No consistent and significant association between the exposure during the 2 weeks prior to the 4-week period and the occurrence of respiratory tract symptoms thereafter could be established. In contrast, significantly less symptoms of coughing and runny nose were reported during the 4-week period prior to the establishment of the symptoms for children with a comparatively high exposure to solar UVR during the same 4 weeks.

The results indicate that UVR may impair the resistance to infections, especially at doses inducing (slight) sunburn, but that at sub-erythemal doses an adverse effect on resistance to infections cannot be detected. The postulated acute immunosuppressive effect of solar UVR is possibly subtle at sub-erythemal doses and hence may have been overruled by other factors determining the incidence of respiratory tract symptoms.

\section{Introduction}

It has been shown in experimental studies that ultraviolet radiation (UVR), especially the B-waveband, at doses relevant to outdoor exposure can affect specific as well as non-specific cellular immune responses. Reduced immune responses are held responsible for impaired resistance to viral, bacterial, and parasitic agents, which was observed in experimental animal studies [ 12 2]. Such infectious agents include those that have no skin component, such as Trichinella spiralis and influenza virus [3 4]. Immunosuppressive effects of artificial UVR and sunlight have also been shown in humans [5-9]. In addition, UVR is known to activate labial herpes simplex infections in humans [10]. However, it is still unclear to what extent this activation can be attributed to suppression of immune responses to the virus [11]. It is still an unresolved issue whether acute UVR-induced immunosuppression is associated with an increased incidence and/ or severity of infections in human populations $\left[\begin{array}{lll}11 & 12 & 13\end{array}\right]$. Different factors hamper the extrapolation from experimental data to the real human situation. For example, different spectral distributions may have differential biological effects (ie, the spectral distribution of sunlight as opposed to those of artificial UVR sources), and physiological adaptation to the immunosuppressive effects of UVR when exposed for longer periods of weeks has been reported [14 15 16].

Assessment of the short-term exposure to UVR and outcome variables that indicate impaired resistance to infections is crucial to get supporting evidence for an effect of UVR on infections in humans. In a birth-cohort study on asthma and mite allergy, we assessed the short-term exposure to sunlight in 1-year-old children by means of a 6-week retrospective questionnaire [ $\left[\begin{array}{lll}17 & 18 & 19\end{array}\right]$. We examined whether the 
estimated exposure was associated with the occurrence of symptoms of respiratory tract infections. It has been shown that exposure to immunotoxic agents may lead to a higher susceptibility to respiratory tract infections [20-23]. We hypothesized that exposure to solar UVR likewise may lead to a higher susceptibility to and, as a consequence, a higher incidence of respiratory tract infections. As respiratory tract infections have a very high incidence in human populations and exposure to solar UVR is ubiquitous, the establishment of such an effect may be of importance for public health.

\section{Methods}

\section{The birth-cohort study}

Data were used from a Dutch birth-cohort study, a part of which aims to identify risk factors for the development of asthma and allergy ('natural history part'). Pregnant women were recruited from the general population with the help of 52 midwife practices and obstetric clinics in three different regions of the Netherlands. Written informed consent to participate in the natural history part of the study was obtained from 3291 pregnant women (response $56 \%$ ). Their children were born between July 1996 and October 1997 and will be followed until they are at least 8 years old. At the age of 3 months and next every year at the time of the birthday, a questionnaire was/ is sent to the parents by mail. The parents were/ are requested to report about symptoms of their child that indicate asthma, allergy, or respiratory tract infections during the previous year and about the presence of many possible determinants. At the age of one year, 3243 children ( $98.5 \%$ of the baseline population) were still participating in the study. The study design and the baseline data from the 3-month questionnaires have been described in detail elsewhere [17 18].

\section{The assessment of solar UVR \\ Personal exposure}

A supplementary 6-week retrospective questionnaire on sunlight exposure was handed out to a part of the participating children in the months April through September 1998 at the time of their first birthday $(n=1672)$. These months of the year are associated with comparatively high levels of ambient UVR in the Netherlands, and differences in outdoor behaviour may lead to differences in personal exposure to solar UVR. The parents were asked to report their child's daily number of outdoor hours during the daytime, the child's clothing, and the experienced weather conditions during these hours. This was done for weeks that were spent in the Netherlands and for a holiday abroad, if any, separately. Questions about sunburn and protection (such as sunscreen and hats) were added. We calculated for each child on the basis of these reported data a cumulative number of reported outdoor hours weighted for the effect of latitude, season, clothing, and weather conditions on the UVR dose. The questionnaire, the method of exposure assessment, and the relationship with the independently measured levels of ambient UVR have been described in detail elsewhere [19]. The reporting of data on the child's outdoor exposure was often hard to accomplish. Nine-hundredand-ten out of the 1672 questionnaires were filled out complete and consistent enough to enable exposure assessment. 


\section{Ambient UVR}

In addition to estimating the personal UVR exposure by questionnaires, we have also established the daily cumulative biologically effective doses of ambient UVR in the study period (CIE weighted, Commission International de l'Eclairage) [24]. Ambient UVR levels were measured by recording the spectrally resolved UVR received on a horizontal plane (DILOR XY spectroradiometer). These measurements have been done since 1994 at the Dutch National Institute of Public Health and the Environment (RIVM) UVR monitoring site. For each participant, a cumulative dose of ambient UVR was established by adding up the daily doses that were measured during the 6 weeks that were covered by the sunlight questionnaire. A high 6-week cumulative dose of ambient UVR indicates favourable weather conditions in the Netherlands during these weeks and hence a high potential personal exposure. As this holds true only when the participating child stayed in the Netherlands during these weeks, the analyses with the independently measured levels of ambient UVR were restricted to those children who stayed in the Netherlands during the 6-week period. It should be noted that individual behaviour interferes with the actual individual exposure.

\section{The health outcome}

In the large yearly questionnaire, the parents were asked to report whether their child had coughs and/ or a runny nose and/or earache/ runny ear in the preceding 4 weeks. Furthermore, they were asked to report whether their child had a fever during these weeks, and whether he/ she had been seen by a doctor for this fever and/ or for one of the above-mentioned symptoms. A symptom was regarded as probably more severe when the parents reported that a doctor had seen the child because of this symptom or the child had a fever during these weeks. The parents were also asked to report more severe respiratory tract diseases that were diagnosed by a doctor, required medication, or even hospital admission during the last 12 months (flu, otitis media, bronchitis, pneumonia, and whooping cough).

\section{Statistical analysis}

The estimated cumulative number of weighted outdoor hours was categorised in tertiles (low/ intermediate/ high exposure). Differences in percentage of children with respiratory tract symptoms were tested by means of the $\chi^{2}$-statistic for categorised data. A distinction between mild and severe symptoms was made.

In a multivariable logistic regression analysis, the effects of other determinants of respiratory tract symptoms were taken into account [25-33]. Odds ratios (OR) and the $95 \%$-confidence intervals $(95 \%-\mathrm{CI})$ were calculated. The lowest exposure category was defined as the reference category $(\mathrm{OR}=1.0)$. In the multivariate analysis, the 6-week cumulative estimate of personal exposure was subdivided in an estimate referring to the first 2 weeks and an estimate referring to the last 4 weeks. These 4 weeks coincided with the 4 weeks for which the occurrence of respiratory tract symptoms was reported. In this way, we were able to characterise the exposure that was probably received prior to the appearance of respiratory tract symptoms and, as a consequence, could not have been influenced by the suffering from these symptoms [34]. Next, the association between the reported symptoms and the independently measured levels of ambient UVR during the weeks covered by the questionnaire (ie, without inclusion of the questionnaire-based estimates) was explored, as the levels of ambient UVR are not influenced by the child's health status. Furthermore, it was examined whether restricting the analysis to mild symptoms modified the association 
between exposure and outcome. This was done because mild respiratory tract symptoms do probably not lead or do so to a lesser extent to staying indoors and, as a consequence, diminished personal exposure.

\section{Results}

\section{Description}

The data of 785 children were included in the analysis, as their reported data on outdoor behaviour in the sunlight questionnaire were complete and consistent to enable exposure assessment and the dates of filling out of both questionnaires matched up. Compared to the excluded children $(n=876)$, less respiratory tract symptoms were reported for these children (coughs: $44.0 \%$ vs. $46.4 \%, \mathrm{P}=0.34$; runny nose: $53.7 \%$ vs. $59.2 \%, \mathrm{P}=0.03$; earache/ runny ear $12.2 \%$ vs. $15.5 \%, \mathrm{P}=0.054$ ). For these children, a higher educational level of the parents, less smoking at home, less frequent contacts with other children at home, but more frequent contacts in day-care centres were reported (data not shown).

Table 1. The number and percentage of children with respiratory tract symptoms in the 4 weeks preceding the questionnaire by personal exposure to solar UVR.

6-week cumulative number of weighted outdoor hours

\begin{tabular}{lllllllll} 
& \multicolumn{3}{c}{$<30.9$} & \multicolumn{2}{c}{$30.9-121.4$} & \multicolumn{1}{c}{$121.4-1121$} & \multicolumn{2}{c}{ Total } \\
\cline { 2 - 9 } 1. coughing & $\mathrm{N}$ & $\%^{\mathrm{b}}$ & $\mathrm{N}$ & $\%^{\mathrm{b}}$ & $\mathrm{N}$ & $\%^{\mathrm{b}}$ & $\mathrm{N}$ & $\%^{\mathrm{b}}$ \\
No & 130 & 49.6 & 138 & 52.9 & 169 & 64.5 & 437 & 55.7 \\
Yes, but mild & 47 & 17.9 & 52 & 19.9 & 42 & 16.0 & 141 & 18.0 \\
Yes, severe $^{\mathrm{a}}$ & 83 & 31.7 & 69 & 26.4 & 50 & 19.1 & 202 & 25.7 \\
Unknown & 2 & 0.8 & 2 & 0.8 & 1 & 0.4 & 5 & 0.6
\end{tabular}

2. runny nose $e^{d}$

$\begin{array}{lllllllll}\text { No } & 98 & 37.4 & 112 & 42.9 & 152 & 58.0 & 362 & 46.1 \\ \text { Yes, but mild } & 74 & 28.2 & 75 & 28.7 & 58 & 22.1 & 207 & 26.4 \\ \text { Yes, severe }^{\mathrm{a}} & 89 & 34.0 & 73 & 28.0 & 51 & 19.5 & 213 & 27.1 \\ \text { Unknown }^{1} & 1 & 0.4 & 1 & 0.4 & 1 & 0.4 & 3 & 0.4\end{array}$

3. earache/ runny ear ${ }^{e}$

\begin{tabular}{lllllllll} 
No & 220 & 84.0 & 232 & 88.9 & 234 & 89.3 & 686 & 87.4 \\
Yes, but mild & 4 & 1.5 & 8 & 3.1 & 6 & 2.3 & 18 & 2.3 \\
Yes, severe $^{\mathrm{a}}$ & 36 & 13.7 & 20 & 7.7 & 21 & 8.0 & 77 & 9.8 \\
Unknown $^{\text {Untal }}$ & 2 & 0.8 & 1 & 0.4 & 1 & 0.4 & 4 & 0.5 \\
\cline { 2 - 9 } Total & 262 & $100 \%$ & 261 & $100 \%$ & 262 & $100 \%$ & 785 & $100 \%$
\end{tabular}

a A symptom was regarded as more severe when the parent reported that the child had been seen by a doctor because of this symptom or the child had a fever possibly associated with this symptom during the last 4 weeks.

${ }^{b}$ All percentages are column percentages.

${ }^{\mathrm{c}} \mathrm{P}=0.005\left(\chi^{2}\right.$;cells with 'unknown' were excluded $)$

${ }^{\mathrm{d}} \mathrm{P}=0.001\left(\chi^{2}\right.$;cells with 'unknown' were excluded $)$

${ }^{c} \mathrm{P}=0.088\left(\chi^{2}\right.$;cells with 'unknown' were excluded $)$ 


\section{Respiratory tract symptoms in relation to UVR exposure and sunburn}

For 68 children, one or more episodes of slight sunburn during the 6-week period were reported in the sunlight questionnaire. No associations between the reporting of sunburn and the reporting of 'coughing' $(P=0.78)$ or 'runny nose' $(P=0.97)$ were found. However, a higher percentage of children with reported symptoms of 'earache/ runny ear' was found among those for whom an episode of sunburn was reported, compared to children without reported sunburn $(23.5 \%$ vs. $11.2 \%, \mathrm{P}=0.01)$.

If sunburn was left out of consideration, children who were classified in the highest category of sunlight exposure ( $\geq 121.4$ weighted hours) showed a lower number of respiratory tract symptoms (Table 1). For the symptoms 'coughing' and 'runny nose', the differences by exposure category reached the level of statistical significance. The lowest percentage of children with one or more respiratory tract symptoms was found among those for whom the questionnaire was filled out in August 1998 (Figure 1, dark bars). The tendency towards a lower percentage of reported symptoms in children with a higher personal exposure to sunlight was also observed after breaking down the data by month of filling out the questionnaire (Figure 1, grey bars). Excluding the children for whom a holiday period abroad was reported $(\mathrm{n}=126)$ did not modify these results (data not shown).

Figure 1. The percentage (and 95\%-CI) of children with one or more reported respiratory tract symptom(s) in the 4 weeks preceding the questionnaire, by 6-week cumulative personal exposure (low: $<30.9$, intermediate: $30.9-121.4$, high: $>121.4$ weighted hours) and month of filling out the questionnaire $(n=782)$.

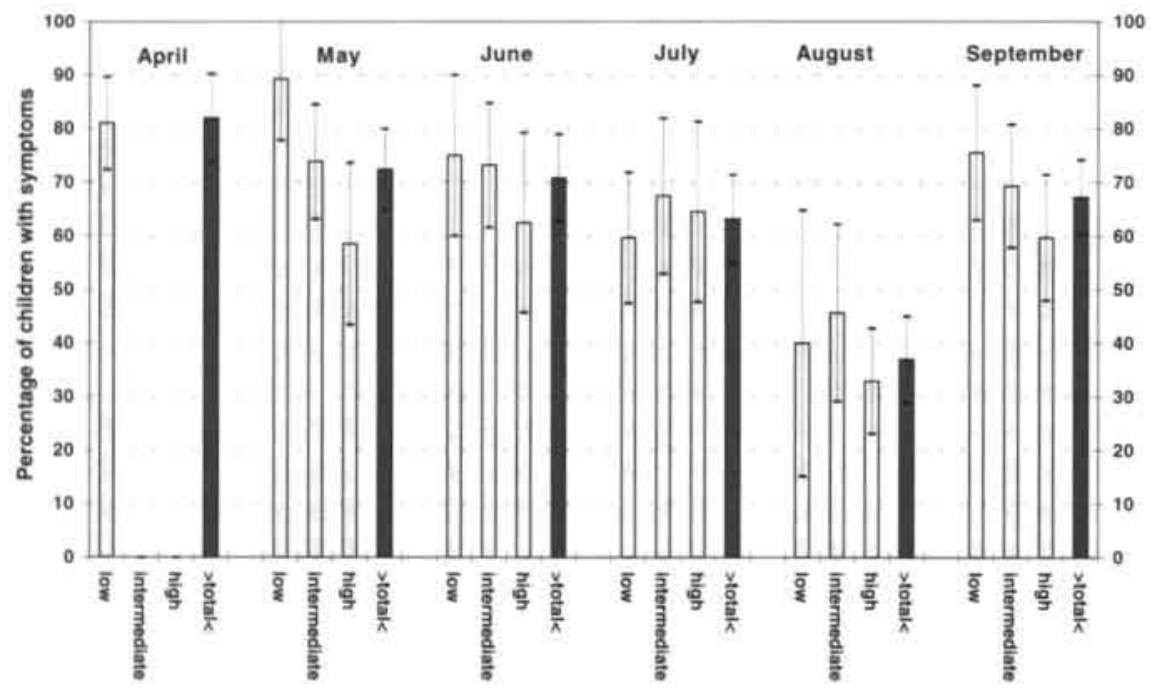

6-week cumulative number of weighted hours (low/ intermediate/ high)

The multivariable logistic regression analysis

The OR's in the models shown in Table 2 are adjusted for each other and for the effects of male gender, presence of other children in the household, and contacts with other children at day care centres. These factors appeared to be associated 
independently with a higher risk of respiratory tract symptoms (data not shown). Furthermore, seasonal fluctuations in the prevalence of respiratory tract symptoms were taken into account by including the month of filling out the questionnaire as a covariate. A positive correlation between symptoms and reported sunburn was suggested (Table 2.a \& 2.b). For 'earache/ runny ear', this association reached the level of statistical significance (Table 2.a). No statistically significant associations with the estimated cumulative exposure during the 2 weeks prior to the 4 -week period. or with the independently measured ambient UVR levels during these 2 weeks were found (Table 2.a \& 2.b). In contrast, a comparatively high exposure to sunlight during the 4 weeks prior to the filling out of the questionnaire appeared to be independently and statistically significantly associated with a lower risk of 'coughing' and 'runny nose' during that same period $(\mathrm{OR}<1)$. These associations were found both with the questionnaire-based estimate of personal exposure (Table 2.a) and with the independently measured levels of ambient UVR (Table 2.b). The tendency towards a lower risk of 'coughing' and 'runny nose' $(O R<1)$ when higher exposed in the 4week period was also found when restricting the analysis to mild symptoms and to the data of those children for whom no severe respiratory tract diseases during their first year of life were reported. The OR of one or more respiratory tract symptoms for the intermediate exposure category, compared with the low exposure category, was 0.37 (95\%-CI: $0.14-0.97)$, and the OR for the high exposure category was 0.27 (95\%-CI: $0.09-0.81)(n=216)$.

Table $2 a-b$. The multivariable logistic regression analysis on symptoms of respiratory tract infections in children who stayed in the Netherlands.

2. a Models with the questionnaire-based estimate of personal exposure

\begin{tabular}{|c|c|c|c|c|c|c|}
\hline & \multicolumn{2}{|c|}{$\begin{array}{l}\text { 1. Coughs } \\
(\mathrm{N}=637)\end{array}$} & \multicolumn{2}{|c|}{$\begin{array}{l}\text { 2. Runny nose } \\
(\mathrm{N}=639)\end{array}$} & \multicolumn{2}{|c|}{$\begin{array}{l}\text { 3. Runny ear } \\
(\mathrm{N}=638)\end{array}$} \\
\hline & OR & $95 \%-\mathrm{CI}$ & OR & $95 \%-\mathrm{Cl}$ & OR & $95 \%-\mathrm{Cl}$ \\
\hline \multicolumn{7}{|c|}{ Personal exposure, first 2 weeks (cumulative) } \\
\hline$<4.5$ weighted hours & 1.00 & . & 1.00 & $\sigma^{\circ}$ & 1.00 & . \\
\hline $4.5-25.8$ wght hrs. & 0.88 & $0.54-1.44$ & 1.16 & $0.70-1.90$ & 1.11 & $0.54-2.29$ \\
\hline $25.8-419$ wght hrs. & 0.86 & $0.49-1.50$ & 1.24 & $0.70-2.18$ & 0.65 & $0.28-1.54$ \\
\hline
\end{tabular}

Personal exposure, last 4 weeks (cumulative)

$\begin{array}{rlllllll}<16.7 \text { weighted hours } & 1.00 & & 1.00 & & 1.00 & \\ 16.7-85.8 \text { wght hrs, } & 1.06 & 0.66-1.71 & 0.72 & 0.44-1.17 & 0.85 & 0.41-1.74 \\ 85.80-1095 \text { wght hrs. } & \mathbf{0 . 4 6} & \mathbf{0 . 2 6 - 0 . 8 1} & \mathbf{0 . 3 3} & \mathbf{0 . 1 9 - 0 . 5 9} & 1.03 & 0.45-2.39\end{array}$

The reporting of sunburn

\begin{tabular}{rcccccc} 
No & 1.00 & & 1.00 & & 1.00 & \\
Yes & 1.57 & $0.81-3.07$ & 1.49 & $0.76-2.94$ & $\mathbf{2 . 4 4}$ & $\mathbf{1 . 0 5 - 5 . 6 4}$ \\
\hline $\begin{array}{l}\text { Hosmer and Lemeshow } \\
\text { Goodness-of-Fit Test }\end{array}$ & & $p=0.60$ & & $p=0.56$ & & $p=0.88$
\end{tabular}


2.b Models with the independently measured levels of ambient UVR (The Netherlands, 1998)

\begin{tabular}{|c|c|c|c|c|c|c|}
\hline & \multicolumn{2}{|c|}{$\begin{array}{l}\text { 1. Coughs } \\
(\mathrm{N}=637)\end{array}$} & \multicolumn{2}{|c|}{$\begin{array}{l}\text { 2. Runny nose } \\
(\mathrm{N}=639)\end{array}$} & \multicolumn{2}{|c|}{$\begin{array}{l}\text { 3. Runny ear } \\
(\mathrm{N}=638)\end{array}$} \\
\hline & OR & $95 \%-\mathrm{CI}$ & OR & $95 \%-\mathrm{CI}$ & OR & $95 \%-\mathrm{CI}$ \\
\hline \multicolumn{7}{|c|}{ Ambient UVR, first 2 weeks (cumulative) } \\
\hline$<20000 \mathrm{~J} / \mathrm{m}^{2}$ & 1.00 & . & 1.00 & . & 1.00 & $\cdot$ \\
\hline $20000-28400 \mathrm{~J} / \mathrm{m}^{2}$ & 0.67 & $0.26-1.72$ & 1.34 & $0.51-3.55$ & 1.20 & $0.27-5.24$ \\
\hline $28400-41000 \mathrm{~J} / \mathrm{m}^{2}$ & 0.64 & $0.25-1.62$ & 1.28 & $0.49-3.37$ & 0.52 & $0.11-2.51$ \\
\hline \multicolumn{7}{|c|}{ Ambient UVR, last 4 weeks (cumulative) } \\
\hline$<42719.4 \mathrm{~J} / \mathrm{m}^{2}$ & 1.00 & . & 1.00 & . & 1.00 & . \\
\hline $42719-59066 \mathrm{~J} / \mathrm{m}^{2}$ & 0.75 & $0.33-1.70$ & 0.53 & $0.22-1.27$ & 3.23 & $0.62-16.8$ \\
\hline $59066-66202 \mathrm{~J} / \mathrm{m}^{2}$ & 0.51 & $0.20-1.27$ & 0.33 & $0.13-0.88$ & 3.03 & $0.51-17.9$ \\
\hline $66202-69135 \mathrm{~J} / \mathrm{m}^{2}$ & 0.33 & $0.11-0.97$ & 0.22 & $0.07-0.67$ & 3.35 & $0.51-21.8$ \\
\hline $69135-79781 \mathrm{~J} / \mathrm{m}^{2}$ & 0.29 & $0.10-0.88$ & 0.26 & $0.08-0.81$ & 3.55 & $0.57-22.3$ \\
\hline
\end{tabular}

The reporting of sunburn

\begin{tabular}{lcccccc} 
No & 1.00 & & 1.00 & & 1.00 & \\
Yes & 1.40 & $0.73-2.70$ & 1.30 & $0.67-2.53$ & 2.22 & $0.97-5.10$ \\
\hline Hosmer and Lemeshow & & $p=0.91$ & & $p=0.21$ & & $p=0.44$
\end{tabular}

Goodness-of-Fit Test

\section{Discussion}

The study presented herein is one of the few observational human studies in which the effect of solar UVR on the occurrence of infections in humans is examined [12 34 35]. We found in a birth cohort of young children a statistically significantly higher risk of 'earache/ runny ear' in children for whom sunburn was reported. This finding is in line with the hypothesis that exposure to UVR causes reduced immune responses and, as a consequence, may induce a clinically relevant increase of the susceptibility to infections. However, no statistically significant associations of symptoms with the exposure during the 2 weeks prior to the 4-week period for which the symptoms were reported were found. Furthermore, we found inverse associations between the exposure to solar UVR and the occurrence of 'coughing' and 'runny nose' when the entire reporting period was evaluated for both exposure and symptoms.

For the interpretation of these findings, it should be noted that the sequence in time of exposure and symptoms was not established. As a consequence, it may be argued that the design did not enable the establishment of a causal relationship. However, the inverse associations with exposure were found with both a questionnaire-based estimate of personal exposure and with the independently measured levels of ambient UVR. Moreover, excluding children with probably more severe respiratory tract symptoms from the analysis did not modify the results. Hence, the found inverse associations with exposure were probably not due to the possibility that children with respiratory tract symptoms stayed indoors due to sickness and, as a consequence, received a lower dosage of solar UVR. On the other hand, effects of solar UVR, especially at sub-erythemal doses, may have been overruled by other factors that are associated with exposure to sunlight. Exposure to sunlight in the human situation may be accompanied by behavioural changes that influence the 
exposure to the infectious agent. For our study, we may hypothesize that a higher exposure is associated with much time spent outdoors and, as a consequence, a lower exposure to infectious agents that mainly circulate indoors or require intensive personto-person contacts for their transmission. The finding of a higher risk of respiratory tract symptoms in children with intensive contacts with other children, either at home (siblings) or because of day-care attendance, supports this consideration [36]. In addition, sunny weather conditions may diminish the exposure to pathogens, as ambient UVR and dryness are unfavourable conditions for the survival of many pathogens. Furthermore, we did not test various immune functions in the participating children, and hence we do not know whether the found associations with the estimated exposure were due to immune alterations. This also applies to the found association with sunburn.

Our hypothesis of increased incidence of respiratory tract symptoms after exposure to sunlight was based on experimental data that demonstrated local and systemic immunosuppression after relatively low doses of UVR [2 3568 9]. From various studies, however, it also appeared that humans are less sensitive to the immunosuppressive effects of UVR than rodents [1 37]. This may imply that it is hard to demonstrate the effects of UVR on infections in observational human studies, as high exposure levels, possibly beyond a certain threshold, are required. It has been suggested that erythema is a prerequisite for the immunosuppressive effects of UVR in humans, or that there is at least a strong correlation between erythema and immunosuppression [ 38 39]. At low sub-erythemal doses, the beneficial effects of sunlight, for example an increase of vitamin D concentration in skin and serum, may outweigh the unfavourable immunosuppressive effects of UVR [40 41]. Our results seem to support this.

The present study in humans has a number of limitations. A first drawback is that the respiratory tract symptoms are not necessarily caused by infections. It is important to realise that coughing will often be related to asthma-like features, and also nose symptoms can be associated. Micro-organisms are frequently the triggers in these symptoms in young children, but the allergic mucosal and inflammatory host response is different from clear-cut infections. Although micro-organisms are important causes of respiratory tract symptoms in young children, other environmental factors may also play a role, in particular in children who develop allergy and asthma. In a part of the children, exposure to allergens and smoking of the parents may have been relevant factors. UVR-induced suppression of allergic inflammation may lead to a decreased risk of secondary infections [42]. As a consequence, UVR-induced immunomodulation may be associated with opposite effects on the occurrence of respiratory tract symtoms, and this may have attenuated the estimated associations between symptoms and exposure, especially those in relation to runny nose and coughing. Furthermore, even if all symptoms were caused by infections, they were not necessarily caused by the same infections. UVR, and UVR-induced immunosuppression may have different influences on different types of infections [11]. Our way of exposure assessment by means of a retrospective questionnaire can be criticised for different reasons. Quite a number of the parents were not able to fill out the questionnaire. In the exposure assessment, we could not take into account all relevant details, such as use of sunscreen, surface reflectance, differences in human locomotion etc. However, it was found before in the same study group that there was a high correlation between the estimated exposure and the independently measured levels of ambient UVR in the Netherlands [19]. Although children from parents with a 
higher level of education were over-represented in our analysis and, as a consequence. the prevalence of respiratory tract symptoms appeared to be biased downwards [ 26 29], we may assume that level of education does not influence the association between exposure to solar UVR and the risk of respiratory tract symptoms.

In a future study, the data concerning outdoor behaviour, respiratory symptoms, and sunburn should be collected on a daily basis, as this will enable a more precise exposure assessment and a more detailed exploration of the time lag between exposure and outcome. Such a study will also be helpful to further examine whether UVR doses associated with sunburn cause a clinically relevant increase of the susceptibility to certain infections.

\section{Acknowledgement}

We thank Dr ir W.G. Goettsch for his support in setting up this study and the design of the questionnaire, Dr ir H.A. Smit, Ir D.J.M. Houthuijs. Prof. dr B. Brunekreef, and $\operatorname{Dr}$ M.A. Heijnen for critically reviewing this manuscript. This study was supported by the Dutch National Research Programme on Global Air Pollution and Climate Change (NOP, Project 952276) and Project ENV4-CT96-0192 of the Programme

Environment of the EU.

\section{References}

1. Goettsch W, Garssen J, Slob W, De Gruijl FR, Van Loveren H. Risk assessment for the harmful effects of UVB radiation on the immunological resistance to infectious diseases. Environ Health Perspect 1998; 106: 71-76.

2. Garssen J, Norval M, El-Ghorr A, Gibbs NK, Jones CD, Cerimele D, De Simone C, Caffieri S, Dall'Acqua F, De Gruijl FR, Sontag Y, Van Loveren H. Estimation of the effect of increasing UVB exposure on the human immune system and related resistance to infectious diseases and tumours. J Photochem Photobiol B: Biology 1998; 42: 167-179.

3. Goettsch W, Garssen J, Deijns A, de Gruijl F, Van Loveren H. UVB exposure impairs resistance to infections with Trichinella spiralis. Env Health Perspectives 1994; 102: 298-301.

4. Ryan LK, Neldon DL, Bishop LR, Gilmour MI, Daniels MJ, Sailstad DM, Selgrade MJK. Exposure to ultraviolet radiation enhances mortality and pathology associated with influenza virus infection in mice. Photochem Photobiol 2000: 72: 497-507.

5. Hersey P, Hasic E, Edwards A, Bradley M, Haran G, McCarthy WH. Immunological effects of solarium exposure. Lancet 1983; I: 545-548.

6. Hersey P, Haran G, Hasic E, Edwards A. Alteration of T cell subsets and induction of supressor T Cell activity in normal subjects after exposure to sunlight. J Immunol 1983; 31: 171-174.

7. Falkenbach A, Sedlmeyer A. Travel to sunny countries is associated with changes in immunological parameters. Photodermatol Photoimmunol Photomed 1997; 13: 139-142.

8. Kelly DA, Walker SL, McGregor JM, Young AR. A single exposure of solar simulated radiation suppresses contact hypersensitivity responses both locally and systemically in humans: quantitative studies with high-frequency ultrasound. J Photochem Photobiol B: Biology 1998; 44: 130-142. 
9. Whitmore SE, Morison WL. The effect of suntan parlor exposure on delayed and contact hypersensitivity. Photochem Photobiol 2000; 71: 700-705.

10. Rooney JF. Bryson Y, Mannix ML, Dillon M, Wohlenberg CR, Banks S,

Wallington CJ, Notkins AL, Straus SE. Prevention of ultraviolet-light-induced herpes labialis by sunscreen. Lancet 1991; 338: 1419-1422.

11. Norval M, Garssen J, Van Loveren H, El-Ghorr AA. UV-induced changes in the immune response to microbial infections in human subjects and animal models. J Epidemiol 1999; 9: S84-S92.

12. Chapman RS, Cooper KD, De Fabo EC et al. Solar ultraviolet radiation and the risk of infectious disease: summary of a workshop. Photochem Photobiol 1995; 61: 223-247.

13. Selgrade MJK, Repacholi MH, Koren HS. Ultraviolet radiation-induced immune modulation: potential consequences for infectious, allergic, and autoimmune disease. Environ Health Perspect 1997: 105: 332-334.

14. Reeve VE, Bosnic M, Boehm-Wicox C, Nishimura N, Ley RD. Ultraviolet A radiation $(320-400 \mathrm{~nm})$ protects hairless mice from immunosuppression induced by ultraviolet B radiation ( $280-320 \mathrm{~nm}$ ) or cis-urocanic acid. Int Arch Allergy Immunol 1998; 115: 316-322.

15. El-Ghor AA, Norval M. The effect of chronic treatment of mice with urocanic acid isomers. Photochem Photobiol 1997; 65: 866-872.

16. Sleijffers A, Garssen J, Van Loveren H. Chronic low dose UVB exposure can prevent UVB-induced suppression of DTH in a mouse model for hepatitis B vaccination, but not suppression of CHS responses. Submitted, 2003.

17. Wijga A, Smit HA, Brunekreef B, Kerkhof M, Praet I, van Strien R. Werving en samenstelling van de onderzoekspopulatie voor de Natuurlijk Beloop studie van het PLAMA-onderzoek. Report 920001.001. National Institute of Public Health and the Environment. Bilthoven, 1998.

18. Wijga A, Smit HA. Baseline gegevensverzameling in de Natuurlijk Beloop studie van het PIAMA-onderzoek. Report 920001.002. Bilthoven, 1998.

19. Termorshuizen F, Wijga A, Garssen J, den Outer PN, Slaper H. van Loveren H. Exposure to solar ultraviolet radiation in young children: assessment by means of a six-week retrospective questionnaire. J Expo Anal Environ Epidemiol 2002; 12 : 204-213.

20. Chang KJ, Hsieh KH, Lee TP. Tang SY, Tung TC. Immunologic evaluation of patients with polychlorinated biphenyl poisoning: evaluation of delayed-type skin hypersensitive response and its relation to clinical studies. J Toxicol Environ Health 1982; 9: 217-221.

21. Zober A, Ott MG, Messerer P. Morbidity follow up study of BASF employees exposed to 2,3,7,8-tetrachlorodibenzo-p-dioxin (TCDD) after a 1953 chemical reactor incident. Occup Environ Med 1994; 51: 479-486.

22. Yu ML, Hsin JW, Hsu CC, Chan WC, Guo YL The immunological evaluation of the Yucheng children. Chemosphere 1998; 37: 1855-1865.

23. Weisglas-Kuperus N, Patandin S, Berbers GAM, Sas TCJ, Mulder PGH, Sauer PJJ, Hooijkaas H. Immunologic effects of background exposure to Polychlorinarted Biphenyls and dioxins in Dutch preschool children. Environ Health Perspect 2000; 108: $1203-1207$.

24. Commission International de l'Eclairage. Research note: a reference action spectrum for ultraviolet induced erythema in human skin. CIEJ 1987; 6:17-22. 
25. Melia RJ, Florey CD, Altman DG, Swan AV. Association between gas cooking and respiratory disease in children. Br Med J 1977; 2: 149-152.

26. Schenker MB, Samet JM, Speizer FE. Risk factors for childhood respiratory disease. The effect of host factors and home environmental exposures. Am Rev Respir Dis 1983; 128: 1038-1043.

27. Burchfiel CM, Higgins MW, Keller JB, Howatt WF, Butler WJ, Higgins IT. Passive smoking in childhood. respiratory conditions and pulmonary function in Tecumseh, Michigan. Am Rev Respir Dis 1986; 133: 966-973.

28. Rona RJ, Gulliford MC, Chinn S. Effects of prematurity and intrauterin growth on respiratory health and lung function in childhood. BMJ 1993; 306: 817-820.

29. Kolnaar BGM, van den Bosch WJHM, van den Hoogen HJM, van Weel C. The clustering of respiratory diseases in early childhood. Fam Med 1994; 26: 106-110.

30. Flynn MG. Respiratory symptoms, bronchial responsiveness, and atopy in Fijian and Indian children. Am J Respir Crit Care Med 1994; 150: 415-420.

31. Giffin F, Greenough A, Yuksel B. Prediction of respiratory morbidity in the third year of life in children born prematurely. Acta Paediatr 1994; 83: 157-158.

32. Greenough A, Giffin FJ, Yuksel B, Dimitriou G. Respiratory morbidity in young school children born prematurely-chronic lung disease is not a risk factor? Eur J Pediatr 1996; 155: 823-826.

33. Ball TM, Castro-Rodriguez JA, Griffith KA, Holberg C J, Martinez FD, Wright AL. Siblings, day-care attendance, and the risk of asthma and wheezing during childhood. N Engl J Med 2000; 343: 538-543.

34. Saah AJ, Horn TD, Hoover DR, Chen C, Whitmore SE, Flynn C, Wesch J, Detels $\mathrm{R}$, Anderson R. Solar ultraviolet radiation exposure does not appear to exacerbate HIV infection in homosexual men. AIDS 1997; 11: 1773-1778.

35. Schein OD, Vicencio C, Muñoz B, Gelatt KN, Duncan DD, Nethercott J, Honeyman J, Koren HS, West S. Ocular and dermatological health effects of ultraviolet radiation exposure from the ozone hole in Southern Chile. Am J Public Health 1995; 85: 546-550.

36. Koopman LP, Smit HA, Heijnen ML, Wijga A, van Strien RT, Kerkhof M. Gerritsen J, Brunekreef B, de Jongste JC, Neijens HJ. Respiratory infections in infants: interaction of parental allergy, day care, and siblings: The PIAMA study. Pediatrics 2001; 108: 943-948.

37. Garssen J, Norval M, Van Loveren H. UVB-induced immunomodulation: a health risk. Polar Research 1999; 18: 339-343.

38. Jansen C, Leszczynski D, Pastila R, Koulu L, Laihia J et al. Immunosuppressive, carcinogenic and metastase-related effects of solar UV radiation. Publications of The Finnish Research Programme on Environmental Health, SYTTY 2000; 1: 241-247.

39. Kelly DA, Young AR, McGregor JM, Seed PT, Potten CS, Walker SL. Sensitivity to sunburn is associated with susceptibility to ultraviolet radiation-induced suppression of cutaneous cell-mediated immunity. J Exp Med 2000; 191: 561-566. 40. Veldman CM, Cantorna MT. DeLuca HF. Expression of 1,25-dihydroxyvitamin D-3 receptor in the immune system. Arch Biochem Biophys 2000; 374: 334-338. 41. Huff GR, Huff WE. Balog JM, Rath NC. The effect of vitamin D-3 on resistance to stress-related infection in an experimental model of turkey osteomyelitis complex. Poultry Science 2000; 79: 672-679. 
42. Van Loveren H, Boonstra A, Van Dijk M, Fluitman A, Savelkoul HFJ, Garssen J. UV Exposure alters respiratory allergic responses in mice. Photochem Photobiol 2000: 72: 253-259. 



\title{
Chapter 8 Sunlight exposure and (sero)prevalence of epidermodysplasia verruciformis-associated human papillomavirus
}

\author{
F. Termorshuizen ${ }^{1}$, M.C.W. Feltkamp ${ }^{2}$, L. Struijk ${ }^{2}$, F.R. de Gruijl ${ }^{3}$, J.N. Bouwes \\ Bavinck $^{3}$, H. van Loveren ${ }^{14}$
}

'Laboratory for Toxicology, Pathology, and Genetics, National Institute of Public Health and the Environment (RIVM), Bilthoven, The Netherlands; Departments of ${ }^{2}$ Medical Microbiology, Centre of Infectious Diseases, and ${ }^{3}$ Dermatology, Leiden Universitary Medical Centre, Leiden. The Netherlands: ${ }^{4}$ Department of Health Risk Analysis and Toxicology, University of Maastricht, The Netherlands.

J Invest Dermatol 2004 (accepted) 


\section{Summary}

In view of the known relationships between 1. human papillomavirus (HPV), especially epidermodysplasia verruciformis (EV) associated types, and squamous cell carcinoma (SCC), 2. exposure to solar ultraviolet radiation (UVR) in the past and risk of SCC, and 3. exposure to UVR and impaired host resistance to infections and skin tumours, we investigated whether an association between sun exposure and EV-HPV infections could be established.

We evaluated data from 320 healthy controls and 156 patients with a history of SCC, who participated in a case-control study on determinants of skin cancer. Data on exposure to sunlight in the past were collected by means of a lifetime-retrospective questionnaire. As measures of EV-HPV infection, the presence of DNA of HPV types $5,8,15,20,24$, and 38 in plucked eyebrow hair and type-specific seroreactivity were assessed, and analysed in relation to sunlight exposure by means of a multivariate logistic regression model.

After adjustment for age, gender, skin type, and presence of SCC, the odds ratios (OR) of EV-HPV DNA positivity for high and moderate lifetime-cumulative exposure to sunlight, compared with low exposure, were 0.41 (95\%-CI: $0.23-0.74$, $\mathrm{P}<0.01)$ and $0.63(95 \%-\mathrm{CI}: 0.37-1.06, \mathrm{P}<0.10)$, respectively. Painful sunburns at age 13-20 years appeared to be independently associated with an enhanced risk of EVHPV DNA positivity $(\mathrm{OR}=1.54,95 \%-\mathrm{CI}: 1.01-2.37, \mathrm{P}<0.05)$. No significant and consistent associations between sunlight exposure, either as lifetime-cumulative estimate or as reported sunburn, and EV-HPV seropositivity could be established.

These results indicate that UVR at doses causing erythema increases the risk of EV-HPV infection, possibly due to impaired host resistance to HPV and/ or a direct effect of UVR on viral replication. However, the favourable association between lifetime sun exposure and HPV prevalence underscores the enigmatic role of HPV in skin carcinogenesis.

\section{Introduction}

Human papillomaviruses (HPV) are associated with both benign and malignant proliferative skin disorders [1-5]. A quarter of the HPV genotypes that are completely sequenced today belong to the so-called epidermodysplasia verruciformis (EV) associated HPV types [6]. These EV-HPV types have originally been found in skin lesions from patients with EV [7]. EV patients develop multiple skin lesions on sun-exposed sites that often progress into squamous cell carcinoma (SCC). Recent studies indicate that EV-HPV types are not restricted to EV patients. Skin carcinomas in patients from the general population frequently contain EV-HPV [8 9]. In immunosuppressed patients, such as renal transplant recipients, high incidences of skin carcinomas and keratotic skin lesions are found on sun-exposed sites in conjunction with a high percentage of EV-HPV DNA positivity, suggesting that these phenomena are associated with an underlying impairment of the immune system and may be causally linked with each other [10-13].

It is known that exposure to solar ultraviolet radiation (UVR) plays a pivotal role in the genesis of pre-maligant skin lesions and non-melanoma skin cancer. A higher lifetime-cumulative sun exposure is an important risk factor especially for the induction of SCC [ 1014 ]. UVR appears to exert its carcinogenic effects by both mutagenic and immunomodulatory mechanisms. In the study by Fisher and Kripke (1977), for example, it was found that pre-exposure of mice to UVR prevented the 
rejection of transplanted antigenic skin tumour cells [15 16]. UVR exposure resulted in the development of antigen-specific suppressor $\mathrm{T}$ cells and, as a consequence, the UVR-induced high susceptibility to these skin tumour cells was probably long lasting. In the human study by Yoshikawa et al.(1990), it was found that a comparatively high percentage $(92 \%)$ of skin cancer patients showed a suppressed contact hypersensitivity response to $\mathrm{DNCB}^{1}$, which was applied epicutaneously, after exposure to UVR [17]. The immunotoxic effects of UVR may have important consequences for the host resistance to a number of viral, bacterial, fungal, and parasitic infections. This was demonstrated in various animal studies (see review [18]). Immunotoxic effects of UVR, both skin associated and non-skin associated, both at the site of irradiation and at a distant (ie, non-irradiated) skin locus have been demonstrated in humans as well [19-23]. However, the relevance for the susceptibility to infections in humans remains a matter of debate [24].

In view of the capacity of UVR to promote tumour genesis and impair host resistance to infections, and the high prevalence of HPV in non-melanoma skin cancer, it is likely that both UVR and HPV contribute to cutaneous malignancy. HPV may interfere with UVR-induced apoptosis, as has been described for the EV-HPV type 5 and appeared to be mediated by a p53-independent abrogation of the proapoptotic functions of Bak proteins [25]. Furthermore, UVR may increase the risk of HPV infection itself. One possible mechanism may be the direct effect of UVR on HPV replication, as has been described for HIV in human skin [26]. UVR responsiveness has been described for HPV77, and appears to be mediated by a p53dependent stimulation of viral promotor activity [27]. In addition, enhanced viral replication in the epidermis may follow UVR-induced local or systemic immunosuppression, as has been described for herpes simplex virus (HSV) [28 29].

The aim of the present study was to investigate the relationship between exposure to sunlight on the one hand and the presence of DNA of six EV-HPV types (HPV5, 8, 15, 20, 24, 38) in plucked eyebrow hair and the presence of antibodies against these HPV types on the other hand. This was done in the framework of an epidemiological study on risk factors for skin cancer. We hypothesized that a higher lifetime-cumulative sun exposure and sunburn episodes in the past are associated with a higher prevalence of EV-HPV DNA and/ or a higher EV-HPV seroprevalence. This was examined for healthy controls and patients with SCC separately. Presence of SCC may confound the relationship between UVR exposure and HPV, as it is already known that SCC is associated with both a higher lifetime sun exposure and a higher prevalence of HPV.

A positive (ie, unfavourable) association between sun exposure and prevalence of HPV, irrespective of the presence of SCC, would indicate that UVR exposure might have adverse effects on susceptibility to cutaneous HPV infections in humans. Furthermore, such an association between sun exposure and HPV infection would indicate that UVR might promote skin carcinogenesis through an infectious route, in addition to the known mutagenic and immunomodulatory pathways.

\section{Methods}

\section{Study population}

The present study was embedded in the "Leiden Skin Cancer Study" (LSS) that was initiated at the Leiden University Medical Centre (LUMC) in 1997 as a case-control

\footnotetext{
' I-chloro-2.4-dinitrobenzene
} 
study on the causes of skin cancer in the Dutch population. The medical ethical committee approved the protocol and all participants gave informed consent. The design of this study was described earlier by De Hertog et al. (2001) [30]. In short, 580 newly diagnosed cases from 1985 till 1997 with histologically confirmed skin cancer were studied; 161 persons out of these cases were diagnosed with SCC. Controls $(\mathrm{N}=386)$ were recruited at the ophthalmology outpatient clinic. Controls were excluded when they had an intra-ocular melanoma or skin cancer in their history. Furthermore, both cases and controls were excluded when they were transplant recipients or suffered from hereditary skin disorders with an increased risk of skin cancer. Dark-skinned persons (Fitzpatrick skin type classification $\geq$ V) were also excluded, since they very rarely develop skin cancers. For the present study, we selected persons for whom the (sero)prevalence of EV-HPV types 5, 8, 15, 20, 24, and 38 in serum and in plucked hair was assessed, respectively [4 5]. Three-hundredtwenty controls and 156 patients with SCC were eligible for the present analysis.

\section{Data collection}

Participants were sent an invitation for a visit at the Dermatology outpatient clinic. Along with this invitation, a so-called Residence Work Calendar was sent. In this form, every change in residence or working environment during lifetime had to be marked, and this was done to facilitate the assessment of sun exposure in the past during the interview at the outpatient clinic. The visit at the Dermatology outpatient clinic consisted of a standardized interview and a physical examination. Information on propensity to burn rather than tan (skin type) and type and duration of sun exposure was collected during the interview using a standardized questionnaire (obtainable from Dr. Bouwes Bavinck). Hours spent outdoors were recorded for working and non-working days between $9 \mathrm{AM}$ and $5 \mathrm{PM}$ in the months May through September. The whole year was taken into account when people had lived near the equator. Sunburns were asked for by different age periods that corresponded with infancy (2-5 years), primary school (6-12 years), secondary school (13-19 years), and adulthood (20-39 years).

\section{Assessment of EV-HPV DNA in plucked hair}

DNA was isolated form 8-10 plucked eyebrow hairs collected per patient, as described [2]. Within each preparation, EV-HPV DNA was detected by specific polymerase chain reaction (PCR) for EV-HPV types 5, 8, 15, 20, 24 and 38 with primers located in the viral E7 gene using amplitaq Gold DNA polymerase (Applied Biosystems), as recently described [5]. The DNA quality of each sample was ascertained by PCR amplification of the household gene Myb [31].

\section{Assessment of anti-EV-HPV antibodies}

Detection of EV-HPV-reactive IgG antibodies in patient sera was performed by ELISA, as described [4]. To this purpose, LI virus-like particles of EV-HPV types 5, $8,15,20,24$ and 38 were expressed, purified, and coated to Polysorp microtitre plates (Nunc). Patient sera were tested in a 1:100 dilution, and optical densities were measured and corrected, as described. Calculations of the EV-HPV type specific ELISA cut-off values above which a serum is called seropositive were based on the mean reactivity plus $3 x$ SD of a group of 100 randomly selected anonymous LUMC employees, excluding outliers. 


\section{Statistical analysis}

Univariate analyses were performed using the non-parametric one-way Wilcoxon test for continuous data and the $\chi^{2}$ test for categorised data. Presence of EV-HPV DNA and anti-EV-HPV antibodies in relation with sunlight exposure was also analysed in multivariate logistic regression models, in which adjustments were made for age, gender, skin type, and presence of SCC. All calculations were performed with SAS statistical software, version 8.0 for Windows. The statistical contribution of a categorised variable with more than 2 levels was evaluated by individual $95 \%$ confidence intervals $(\mathrm{CI})$ and by one overall-test procedure (Wald $\chi^{2}$ test).

\section{Results}

\section{Population characteristics (Table 1)}

Characteristics of the study population are shown for controls and SCC cases separately in Table 1. The mean age of controls was 59.4 years, which was statistically significantly lower than the mean age of 65.9 years in SCC patients. The percentage of males and participants with skin type I or II ('fair skin') was statistically significantly lower in controls than in SCC patients. Lifetime sun exposure was categorised according to the tertiles of the exposure distribution in the study population as a whole. The majority of control subjects fell in the low and intermediate exposure tertiles, whereas the majority of SCC patients fell in the intermediate and high tertiles. The reporting of painful sunburns in different age periods was more frequent in patients with SCC, especially at young ages (2-12 years).

The majority of participants were infected with at least one of the EV-HPV types $5,8,15,20,24$, or 38 . Among participants with positivity for at least one EVHPV DNA type, infection with multiple EV-HPV types was observed more frequently in SCC patients than in healthy controls $(60.4 \%$ vs. $44.8 \%, \mathrm{P}<0.05)$. With the exception of EV-HPV type 38, the prevalence of EV-HPV DNA positivity for these types in controls was significantly lower than the prevalence of positivity for the same type in SCC patients. The prevalence of anti-HPV antibodies against at least one of the EV-HPV types was low. The prevalence of seropositivity was higher in patients with SCC than in control participants. Statistical significance was reached for HPV type 8,24 , and 38 seropositivity.

\section{EV-HPV DNA positivity (Table 2)}

A higher age and a history of SCC were significantly and independently associated with a higher prevalence of EV-HPV DNA when evaluated for the study population as a whole (Table 2). Male gender appeared to be borderline-significantly associated with a higher EV-HPV prevalence $(\mathrm{P}=0.098)$. In addition, lifetime sun exposure was negatively associated with EV-HPV prevalence. Exposure in the highest $33.3 \%$. category was significantly associated with a lower prevalence $(\mathrm{OR}=0.41,95 \%-\mathrm{CI}$ : $0.23-0.74)$. The lower exposure categories were associated with a higher prevalence, which means that an inverse relationship between lifetime sun exposure and HPV prevalence was found. This inverse association was not substantially modified after excluding history of SCC from the model or when the analyses were performed for controls and SCC patients separately. A statistically significant inverse association between HPV prevalence and lifetime sun exposure was found among controls (Table 
2). Among patients with SCC, an inverse association was suggested with borderline statistical significance (Overall test: $\mathrm{P}=0.092$ ) (Table 2).

Contrary to the inverse association between lifetime sun exposure and the presence of EV-HPV DNA, painful sunburns appeared to be associated with a higher prevalence of EV-HPV DNA (Table 2). The reporting of painful sunburns at age 13 19 years appeared to be significantly associated with a higher HPV prevalence when evaluated for the study population as a whole $(\mathrm{OR}=1.54, \mathrm{P}=0.047)$. This association could also be established when restricting the analysis to control persons $(\mathrm{OR}=1.74$. $\mathrm{P}=0.04)$, but was less and non-significant among participants with $\mathrm{SCC}(\mathrm{OR}=1.18$, $\mathrm{P}=0.68$ ). Adding the reported painful sunburns by age period to the model did not substantially modify the found associations between lifetime-cumulative exposure to sunlight and EV-HPV DNA prevalence. Reporting of sunburn during age period 4059 years was non-significantly associated with a higher risk of EV-HPV DNA positivity $(\mathrm{OR}=1.55,95 \%-\mathrm{CI}: 0.76-3.19)$. As time at risk during this age period depended on the age at the time of study entry, and, as a consequence, a fair comparison is hampered, findings for the reported sunburns during age period 40-59 were not included in Table 2.

The multivariate analyses for the study group as a whole were performed for the different types of EV-HPV separately. A (borderline) significant association with the presence of SCC was found for HPV-5 (OR=1.99, $\mathrm{P}=0.02), \mathrm{HPV}-15(\mathrm{OR}=2.08$, $\mathrm{P}=0.03)$, and HPV $-20(\mathrm{OR}=1.58, \mathrm{P}=0.055)$. A significant association between the reporting of sunburn at age 13-19 years and HPV-DNA positivity was found for HPV$5(\mathrm{OR}=1.88, \mathrm{P}=0.02)$ and $\mathrm{HPV}-15(\mathrm{OR}=1.81, \mathrm{P}=0.06)$. No significant associations between sunburn at age 13-19 and the other HPV types (HPV-8, HPV-20, HPV-24, HPV-38) could be established. With respect to the association with lifetime sun exposure, no single type stood out. Inverse associations with HPV-5, HPV-8, HPV15. HPV -20, HPV-38 were suggested, but did not reach the level of statistical significance (data not shown).

\section{EV-HPV seropositivity (Table 3)}

In $14.2 \%$ of the participants with EV-HPV DNA positivity for any of the abovementioned types. EV-HPV seropositivity could be established. This percentage was not different from the percentage EV-HPV seropositivity in participants who were EV-HPV DNA negative for these types $(15.8 \%, \mathrm{P}=0.64)$. When such differences in EV-HPV seropositivity were evaluated for the EV-HPV types separately, no significant associations between EV-HPV DNA positivity and EV-HPV seropositivity could be established either.

Fair skin type (I/II) was independently correlated with a higher EV-HPV seroprevalence $(\mathrm{OR}=2.10, \mathrm{P}=0.01)$. This correlation was found especially among patients with $\mathrm{SCC}(\mathrm{OR}=3.45, \mathrm{P}=0.02)$. In patients with $\mathrm{SCC}$, higher age and male gender were also borderline-significantly associated with a higher EV-HPV seroprevalence (Table 3). No significant association between lifetime sun exposure and EV-HPV seroprevalence could be established, either in the study group as a whole or in controls and participants with a history of SCC separately (Table 3). No association was found when history of SCC was excluded from the model for the study group as a whole. Furthermore, no significant associations between the reported sunburns by age period and EV-HPV seropositivity could be established. A borderline-significantly higher EV-HPV seropositivity was found in participants with SCC who reported one or more painful sunburns during age period 20-39 years 
$(\mathrm{OR}=2.31, \mathrm{P}=0.056)$. Because of the small numbers, the analyses on EV-HPV seropositivity were not performed for the different EV-HPV types separately.

\section{Discussion}

In view of the known relationship between lifetime sun exposure and sunburns in the past and the occurrence of non-melanoma skin cancer, especially SCC, on the one hand, and the involvement of HPV in non-melanoma skin cancer on the other hand, we investigated whether parallel associations between solar exposure and current or past HPV infection might be established. Current infection with a number EVassociated HPV types was determined by means of DNA positivity in plucked eyebrow hair. Presence of anti-HPV antibodies was measured as an indicator of both present and past infection with HPV. HPV prevalence, either assessed as the presence of EV-HPV DNA or as the presence of EV-HPV-specific antibodies, appeared to be associated with the presence of SCC, as described [4 5]. Furthermore, lifetime sun exposure and painful sunburns in the past, especially at age 2-12 years, were both significantly associated with the presence of SCC, as has been described for the same group of patients and controls before [14]. Painful sunburns in the past, especially at age 13-19, appeared to be associated with an enhanced prevalence of EV-HPV DNA. This finding agrees with our hypothesis of a higher susceptibility to viral skin infections following exposure to solar UVR. Unexpectedly, a statistically significant inverse association between lifetime sun exposure and EV-HPV DNA positivity was found in the present analysis. No significant and consistent association between sunlight exposure, either as lifetime-cumulative estimate or as reported sunburn, and EV-HPV seropositivity could be established.

In the present study, sunlight exposure and number of sunburns were assessed on the basis of self-reported information, which probably has introduced inaccuracy. Skin cancer patients may remember their exposure histories differently from healthy controls. However, we analyzed the relationships between exposure and HPV infection for SCC cases and controls separately. In addition, consciousness of someone's HPV carriership is unlikely, which makes that such 'information bias' is probably not relevant to our results. For the present study, it may be argued that inaccuracy of remembered sun exposure histories may have introduced nonsystematic error, which mostly results in attenuation of the observed associations.

Various studies indicate that UVR, especially at doses causing erythema, may adversely influence the human immune system [ 202323233$]$. For example, in the study by Cooper et al. (1992), a localized moderate sunburn (4 MED) appeared to modulate immunization with a contact sensitizer through a distant, non-irradiated site. Furthermore, in a number of participants who received an erythemagenic dose at the site of sensitization, antigen-specific tolerance was established. This indicates that UVR-induced immunosuppression, which is well timed in relation to the initial sensitization, may be long continued. The importance of UVR for the human immune system and related host resistance is further highlighted by the finding that local sunburn is a known trigger factor for HSV recrudescence [34 35]. UVR may alter certain immune functions in humans at sub-erythemal doses as well. For example, in the study of Kelly et al.(2000), solar-simulated UVR at doses of 0.25-0.50 MED appeared to suppress local contact hypersensitivity response to DNCB in a considerable number of humans with skin type I/II [33]. And in the study of Gilmour et al.(1993) among psoriasis patients, UVR phototherapy caused an impairment of the capacity of epidermal cells to present HSV antigen to autologous T cells [34]. 
However, the possible subtle effect of UVR at sub-erythemal doses on host resistance to infections in humans may be overruled by many other factors associated with outdoor behaviour. As a consequence, this effect may be difficult to establish in retrospective epidemiological studies, especially in those of restricted nature in terms of size, exposure assessment, and adjustments for confounding variables [32].

Although epidemiological and experimental studies overwhelmingly implicate HPV as an important causal agent in cervical cancer, the causal link between HPV and skin carcinogenesis remains a matter of debate [9]. We cannot exclude the possibility that HPV is just "hitching a ride" or has carcinogenic properties in concerted action with other factors only, for example by accumulation of UVRinduced DNA damage in HPV-infected keratinocytes that have lost their capacity for apoptosis [ 25363738 ]. We found a high prevalence of EV-HPV DNA in healthy controls (54\%), which indicates that HPV is ubiquitous. In the study of Antonsson et al. (2000), HPV DNA was detected in at least one of the samples from 5 different body sites from 64 of 80 healthy humans $(80 \%)$ ). Most of the HPV types detected in this study belonged to the EV-associated HPVs. In this study, it was found that HPVDNA prevalence was higher in older persons, which agrees with our recent and previous results [3 5]. In the same study of Antonsson et al. (2000), the prevalence of HPV was high among renal transplant recipients compared to healthy controls and dialysis patients, which indicates that immunosuppression is a risk factor for HPV infection. Furthermore, HPV prevalence was found to be higher on the forehead compared to other (UVR non-exposed) body sites. This suggests a role for UVRinduced local immunosuppression in susceptibility to HPV infection [39].

Our data did not allow an analysis of HPV prevalence by different skin sites, but in a previous study we showed that eyebrow hair has a high yield of EV-HPV in comparison to hair plucked from other body locations [31]. Still, the inverse association between lifetime-cumulative solar exposure and the prevalence of skin EV-HPV DNA throws doubt on the hypothetical causal role of these viruses in UVRassociated skin carcinogenesis.

However, the concomitantly positive (ie, unfavourable) association with sunburn indicates that the relationship between sunlight and human health is not onedimensional and that exposure to sunlight may be associated with both favourable and adverse health consequences. For example, in a recent study by Kaskel et al. (2001) on skin cancer, it was found that outdoor activities in childhood itself might be protective for cutaneous melanoma. In contrast, sunburn in childhood appeared to be an important risk factor for melanoma [40]. This finding of opposite associations was corroborated in an earlier study from our study group [14]. Furthermore, it was found in another study among young children, that a higher short-term exposure to ambient UVR was associated with a statistically significantly lower occurrence of symptoms indicative of respiratory tract symptoms, but, conversely, reported sunburn appeared to be an independent risk factor for these symptoms [32]. Whether the favourable association between lifetime sun exposure and HPV infection is related to melanogenesis and increased thickness of the epidermis, a diminished exposure to micro-organisms that mainly circulate indoors and require intense person-to-person contacts for transmission, or to the reported anti-proliferative and immunological effects of vitamin D, remains to be established [40 41 42]. The idea that "light" or UVR may have a beneficial effect on immunity and infections in humans has a long history [41 43 44]. However, further mechanistic studies, preferentially in human volunteers, are required to establish evidence for a possible favourable influence of 
sunlight (probably UVR over a certain range of low doses) on immunity and related infections.

The finding of a positive association between sunburn and HPV-DNA positivity may also be due to keratinocyte proliferation and associated activation of the HPV life cycle. In the study of Favre et al. (2000), it was found that second-degree burns were associated with a short-term and probably transient generation of antiHPV5 antibodies [45]. The relationship between keratinocyte hyperproliferation and EV-HPV had already been suggested in an earlier study by Favre et al.(1998) among psoriasis patients [46]. Extensive re-epithelization may account for the higher susceptibility to HPV infection or to a higher expression of HPV after a latently established infection, which may enhance the ability of HPV to induce humoral immune responses.

We could not establish significant associations between HPV seropositivity and sunlight exposure or sunburn. This may be explained by the fact that both estimates of UVR exposure relates to exposure in the past and antibodies to HPV develop transitionally, or probably often do not develop at all after exposure to HPV. The found borderline-significant association between painful sunburns at age 20-39 years, which implies a more recent past, and a higher EV-HPV seroprevalence in patients with SCC may support the notion that keratinocyte proliferation is associated with a transient antibody response. However, additional analysis revealed that EVHPV seroprevalence was not related to the time period in between SCC diagnosis and serum collection (data not shown). The discrepancy between virological and serological data indicates that current HPV infection and presence of anti-HPV antibodies show no important association. In addition, suppressive effects of UVR on humoral immunity, both Th-1 and Th- 2 associated, have been described, which further complicates interpretation of the results [47 48]. Erythemal doses of UVR may promote local HPV skin infection and, as a consequence, enhance the ability of HPV to induce humoral immune responses. On the other hand, UVR may concomitantly suppress serological responses. These possible opposite effects on serology associated with UVR exposure are probably hard to disentangle, especially in the observational design of the present study. Mechanistic in-depth studies are required to establish the role of serological responses in host resistance to HPV infection and the suitability of these serological responses as read-out of UVR-induced immunomodulation.

In conclusion, the presented epidemiological data indicate that at suberythemal UVR doses no adverse effects on HPV infection can be detected. The found higher occurrence of HPV DNA in association with sunburn is in accordance with other recent human studies that indicate adverse effects of UVR on immunity, infections, and skin tumour genesis, at least at doses that cause erythema. As no unequivocal relationships between solar exposure in the past and HPV infection could be established, the involvement of HPV in UVR-associated skin cancer remains enigmatic.

\section{Acknowledgement}

This study was supported by European Community grant QLK2-CT-2002-01179, by Dutch Cancer Foundation grant LUMC 99-1913, and by the Dutch National Research Programme on Global Air Pollution and Climate Change (NOP. Project 952276). 
Table I. Characteristics of study population according to presence of squamous cell carcinoma $(S C C)$

\begin{tabular}{|c|c|c|c|}
\hline & $\begin{array}{l}\text { Controls } \\
\mathrm{N}=320\end{array}$ & $\begin{array}{c}\text { Patients with } \\
\text { history of SCC } \\
\mathrm{N}=156\end{array}$ & \\
\hline mean (SD) & $59.4(10.7)$ & $65.9(8.4)$ & *** \\
\hline $5 \%-95 \%$ percentiles & $41.2-74.7$ & $48.4-76.2$ & \\
\hline \multirow[t]{2}{*}{ Gender ( $\mathrm{N}$ and \%) } & $184(57.5 \%)$ & $56(35.9 \%)$ & *** \\
\hline & $136(42.5 \%)$ & $100(64.1 \%)$ & \\
\hline \multirow[t]{2}{*}{ Skin type ( $\mathrm{N}$ and \%) } & $173(54.1 \%)$ & $53(34.0 \%)$ & $* * *$ \\
\hline & $147(45.9 \%)$ & $103(66.0 \%)$ & \\
\hline \multicolumn{4}{|l|}{ EV-HPV DNA positivity ( $\mathrm{N}$ and $\%$ ) } \\
\hline any type $(5,8,15,20,24$, or 38$)$ & $174(54.4 \%)$ & $111(71.2 \%)$ & ** \\
\hline type 5 & $38(11.9 \%)$ & $37(23.7 \%)$ & $* *$ \\
\hline type 8 & $32(10.0 \%)$ & $27(17.4 \%)$ & $*$ \\
\hline type 15 & $26(8.1 \%)$ & $26(16.8 \%)$ & ** \\
\hline type 20 & $73(22.8 \%)$ & $51(32.7 \%)$ & $*$ \\
\hline type 24 & $49(15.3 \%)$ & $39(25.0 \%)$ & $*$ \\
\hline type 38 & $81(25.3 \%)$ & $50(32.3 \%)$ & \\
\hline \multicolumn{4}{|l|}{ EV-HPV seropositivity ( $\mathrm{N}$ and \%) } \\
\hline any type $(5,8,15,20,24$, or 38$)$ & $39(12.5 \%)$ & $30(19.9 \%)$ & * \\
\hline type 5 & $1(0.3 \%)$ & $2(1.3 \%)$ & \\
\hline type 8 & $1(0.3 \%)$ & $5(3.2 \%)$ & $*$ \\
\hline type 15 & $7(2.2 \%)$ & $6(3.9 \%)$ & \\
\hline type 20 & $7(2.2 \%)$ & $7(4.5 \%)$ & \\
\hline type 24 & $22(6.9 \%)$ & $20(12.8 \%)$ & $*$ \\
\hline type 38 & $7(2.2 \%)$ & $9(5.8 \%)$ & $*$ \\
\hline
\end{tabular}

Lifetime sun exposure ( $\mathrm{N}$ and \%)

$$
\begin{array}{rll}
<26,642 \text { hours } & 124(38.8 \%) & 31(19.9 \%) \\
26,642-37,734 \text { hours } & 122(35.0 \%) & 49(31.4 \%) \\
>37,734 \text { hours } & 84(26.2 \%) & 76(48.7 \%)
\end{array}
$$

$* *$

k*

** $*$

*

Painful sunburns at different age periods ( $\mathrm{N}$ and \%)

$\begin{array}{rccc}\text { Age 2-5 years } & 10(3.1 \%) & 11(7.3 \%) & * \\ 6-12 \text { years } & 54(14.1 \%) & 39(25.3 \%) & * * \\ 13-19 \text { years } & 94(29.4 \%) & 52(33.6 \%) & \\ 20-39 \text { years } & 97(30.3 \%) & 55(35.5 \%) & \end{array}$

\footnotetext{
**** $\mathrm{P}<0.0001$

** $\mathrm{P}<0.01$

* $\quad \mathrm{P}<0.05$
}

'One overall-test procedure with $\chi^{2}$ test for categorised data $(\mathrm{df}=2)$ 
Table 2. Association berween lifetime sun exposure, episodes of painful sunburn and the prevalence of EV-HPV DNA (1ype 5. -8. -15. -20, -24. or -38 ).

\begin{tabular}{|c|c|c|c|c|c|c|c|c|}
\hline \multicolumn{3}{|c|}{$\begin{array}{c}\text { Controls and SCC patients } \\
\qquad(n=476)\end{array}$} & \multicolumn{3}{|c|}{ Controls only $(n=320)$} & \multicolumn{3}{|c|}{ SCC patients $(n=156)$} \\
\hline OR & $95 \%-\mathrm{CI}$ & $P$ value & OR & $95 \%-\mathrm{Cl}$ & $\mathrm{P}$ value & OR & $95 \%-\mathrm{Cr}$ & $P$ value \\
\hline 1.03 & $1.01-1.05$ & 0.009 & 1.04 & $1.01-1.06$ & 0.01 & 1.01 & $0.96-1.06$ & 0.63 \\
\hline 1.40 & $0.94-2.08$ & 0.098 & 1.50 & $0.94-2.40$ & 0.092 & 1.16 & $0.54-2.49$ & 0.70 \\
\hline 0.97 & $0.66-1.42$ & 0.86 & 1.04 & $0.66-1.64$ & 0.87 & 0.89 & $0.41-1.91$ & 0.76 \\
\hline 1.96 & $1.25-3.07$ & 0.003 & - & - & & - & - & \\
\hline 0.41 & $0.23-0.74$ & $0.013^{1}$ & 0.45 & $0.22-0.92$ & $0.057^{1}$ & 0.42 & $0.14-1.27$ & $0.092^{1}$ \\
\hline 0.63 & $0.37-1.06$ & & 0.54 & $0.30-0.98$ & & 1.00 & $0.31-3.26$ & \\
\hline 1.00 & & & 1.00 & & & 1.00 & & \\
\hline
\end{tabular}

Painful sunburns al different age periods

\begin{tabular}{rlllllllll}
$2-5$ yTs $($ ref. $=$ no) & 1.63 & $0.60-4.44$ & 0.34 & 1.96 & $0.48 \cdot 7.98$ & 0.35 & 1.31 & $0.31-5.48$ & 0.71 \\
$6-12$ yrs $($ ref. $=$ no) & 1.08 & $0.64-1.82$ & 0.78 & 1.68 & $0.83-3.38$ & 0.15 & 0.54 & $0.24-1.22$ & 0.14 \\
$13-19$ yrs $($ ref. $=$ no) & $\mathbf{1 . 5 4}$ & $\mathbf{1 . 0 1}-\mathbf{2 . 3 7}$ & $\mathbf{0 . 0 4 7}$ & $\mathbf{1 . 7 4}$ & $\mathbf{1 . 0 4 - 2 . 9 1}$ & $\mathbf{0 . 0 4}$ & 1.18 & $0.54-2.60$ & 0.68 \\
$20-39 \mathrm{yrs}(\mathrm{ref} .=110)$ & 1.13 & $0.75-1.71$ & 0.57 & 1.04 & $\mathbf{0 . 6 3 - 1 . 7 2}$ & 0.88 & 1.39 & $0.65-2.98$ & 0.40 \\
\hline
\end{tabular}

'One overall-test procedure with Wald $\chi^{2}$ idf $=2$ ) 
Table 3. Association befween lifetime sun exposure. episodes of painful sunburn and the serorecognition of EV-HPV (19ye 5, -8, -15, -20, -24, or -38 ).

\begin{tabular}{|c|c|c|c|c|c|c|c|c|}
\hline \multicolumn{3}{|c|}{$\begin{array}{l}\text { Controls and SCC patients } \\
\qquad(n=464)\end{array}$} & \multicolumn{3}{|c|}{ Controls only $(n=313)$} & \multicolumn{3}{|c|}{ SCC patients $(n=151)$} \\
\hline OR & $95 \%-\mathrm{CI}$ & $P$ value & OR & $95 \%-\mathrm{Cl}$ & $P$ value & OR & $95 \%-\mathrm{CI}$ & $P$ value \\
\hline
\end{tabular}

Multivariale model: Age (1 year increase)

1.02

$0.99-1.05$

0.27

1.00

Gender (ref. = female)

1.58

$0.91-276$

0.11

$0.96-1.040 .91$

$1.06 \quad 0.99-1.12$

0.08

Skin lype $/ / I$ (ref. = IIVIV)

2.10

$1.18-3.65 \quad 0.01$

$\begin{array}{lll}1.14 & 0.56-2.32 & 0.71\end{array}$

$2.610 .95-7.14$

0.06

Presence of SCC (ref. = no)

1.25
$0.70-2.22$
0.45

Lifeline sun exposure

$>37,734$ hours
$26,642-37,734$ hours
$<26,642$ hours (=ref.)

$\begin{array}{lll}0.95 & 0.44-2.06 & 0.99^{1} \\ 0.95 & 0.46-1.96\end{array}$

$1.68 \quad 0.84-3.36 \quad 0.14$

$3.45 \quad 1.18-10.0$

0.02

$<26,642$ hours (=ref.)

1.00

1.45
1.10
1.00
$0.50-4.16 \quad 0.77^{1}$
$0.44-2.73$

0.65

0.91

1.00
$0.20-2.14 \quad 0.70$
$0.26-3.24$

Painful sunbums al different age periods

\begin{tabular}{rlllllllll}
$2-5$ yrs $($ ref. $=$ no) & 0.92 & $0.25-3.36$ & 0.90 & 0.69 & $0.10-5.76$ & 0.73 & 1.21 & $0.21-6.92$ & 0.83 \\
$6-12$ yrs $($ ref. $=$ no) & 1.41 & $0.75-2.65$ & 0.29 & 1.18 & $0.46-3.01$ & 0.73 & 2.06 & $0.81-5.24$ & 0.13 \\
$13-19$ yrs $($ ref. $=$ no) & 0.68 & $0.37-1.23$ & 0.20 & 0.63 & $0.28-1.41$ & 0.26 & 0.75 & $0.30-1.89$ & 0.54 \\
$20-39$ yrs $($ ref. $=$ no) & 1.29 & $0.75-2.23$ & 0.36 & 0.80 & $0.37-1.73$ & 0.58 & $\underline{\mathbf{2 . 3 1}}$ & $\mathbf{0 . 9 8}-\mathbf{5 . 4 4}$ & $\mathbf{0 . 0 5 6}$ \\
\hline
\end{tabular}

I One overall-test procedure witls Wald $\chi^{2}(d f=2)$ 


\section{References}

1. Zur Hausen H. Papillomaviruses causing cancer: evasion from host-cell control in early events in carcinogenesis. J Natl Cancer Inst 2000; 92: 690-698.

2. Boxman IL, Russell A, Mulder LH, Bavinck JN, Ter Schegget J, Green A. Casecontrol study in a subtropical Australian population to assess the relation between non-melanoma skin cancer and epidermodysplasia verruciformis human papillomavirus DNA in plucked eyebrow hairs. Int J Cancer 2000; 86: 118-121.

3. Boxman IL, Russell A. Mulder LH, Bouwes Bavinck JN, Ter Schegget J, Green A. Association between epidermodysplasia verruciformis-associated human papillomavirus DNA in plucked eyebrow hair and solar keratoses. J Invest Dermatol 2001; 117: 1108-1112.

4. Feltkamp MCW, Broer R, Di Summa FM, Struijk L, Van der Meijden E, Verlaan BPJ, Westendorp RGJ, Ter Schegget J. Spaan WJM, Bouwes Bavinck JN. Seroreactivity to epidermodysplasia verruciformis-related human papillomavirus types is associated with nonmelanoma skin cancer. Cancer Res 2003: 63: 26952700 .

5. Struijk L, Bouwes Bavinck JN, Wanningen P, van der Meijden E, Westendorp RGJ, Ter Schegget J, Feltkamp MCW. Presence of human papillomavirus in plucked eyebrow hairs is associated with a history of cutaneous squamous cell carcinoma. J Invest Dermatol 2003, submitted.

6. De Villiers EM. Taxonomic classification of papillomaviruses. Papillomavirus Report 2001; 12: 57-63.

7. Jablonska S, Orth G. Epidermodysplasia Verruciformis. Clin Dermatol 1985; $3: 83$ 96.

8. Pfister H, Ter Schegget J. Role of HPV in cutaneous premaligant and malignant tumors. Clin Dermatol 1997; 15: 335-347.

9. Harwood CA, Proby CM. Human papillomaviruses and non-melanoma skin cancer. Curr Opin Infect Dis 2002; 15: 101-114.

10. Bouwes Bavinck JN, De Boer A, Vermeer BJ, Hartevelt MM, Van der Woude FJ. Claas FHJ, Wolterbeek R, Vandenbroucke JP. Sunlight, keratotic skin lesions and skin cancer in renal transplant recipients. Br J Dermatol 1993; 129: 242-249.

11. Shamanin V, Glover M. Rausch C. Proby C, Leigh IM, Zur Hausen H, De Villiers EM. Specific types of human papillomavirus found in benign proliferations and carcinomas of the skin in immunosuppressed patients. Cancer Res 1994; 54: 46104613.

12. De Jong-Tieben LM, Berkhout RJ, Smits HL, Bouwes Bavinck JN, Vermeer BJ, Van der Woude FJ, ter Schegget J. High frequency of detection of epidermodysplasia verruciformis-associated human papillomavirus DNA in biopsies from malignant and premalignant skin lesions from renal transplant recipients. J Invest Dermatol 1995; 105: 367-371.

13. Berkhout RJ, Bouwes Bavinck JN, ter Schegget J. Persistence of human papillomavirus DNA in benign and (pre)malignant skin lesions from renal transplant recipients. J Clin Microbiol 2000; 38: 2087-2096.

14. Kennedy C, Bajdik CD, Willemze R, de Gruijl FR, Bouwes Bavinck JN for the members of the Leiden Skin Cancer Study. The influence of painful sunburns and lifetime sun exposure on the risk of actinic keratosis, seborrheic warts, melanocytic nevi, atypical nevi, and skin cancer. J Invest Dermatol 2003; 120: 1087-1093.

15. Fisher MS, Kripke ML. Systemic alteration induced in mice by ultraviolet light irradiation and its relationship to ultraviolet carcinogenesis. Proc Natl Acad Sci USA 1977: 74: 1688-1692. 
16. Kripke ML. Immunological mechanisms in UV radiation carcinogenesis. Adv Cancer Res 1982; 34: 69-106.

17. Yoshikawa T, Rae V, Bruins-Slot W, Van den Berg JW, Taylor JR, Streilein JW. Susceptibility to effects of UVB radiation on induction of contact hypersensitivity as a risk factor for skin cancer in humans. J Invest Dermatol 1990; 95: 530-536.

18. Sleijffers A, Garssen J, Van Loveren H. Ultraviolet radiation, resistance to infectious diseases, and vaccination responses. Methods 2002; 28: 111-121.

19. Hersey P, Haran G, Hasic E, Edwards A. Alteration of T cell subsets and induction of supressor $\mathrm{T}$ cell activity in normal subjects after exposure to sunlight. J Immunol 1983; 31: 171-174.

20. Cooper KD, Oberhelman L, Hamilton TA, Baadsgaard O, Terhune M, LeVee G, Anderson T, Koren H. UV exposure reduces immunization rates and promotes tolerance to epicutaneous antigens in humans: Relationship to dose, CDla-DR+ epidermal macrophage induction, and Langerhans cell depletion. Proc Natl Acad Sci USA 1992; 89: 8497-8501.

21. Kelly DA, Walker SL, McGregor JM, Young AR. A single exposure of solar simulated radiation suppresses contact hypersensitivity responses both locally and systemically in humans: quantitative studies with high-frequency ultrasound. J Photochem Photobiol B: Biology 1998: 44: 130-142.

22. Sleijffers A, Garssen J, De Gruijl FR, Boland GJ, Van Hattum J, Van Vloten WA, Van Loveren $\mathrm{H}$. Influence of Ultraviolet B exposure on immune responses following Hepatitis B vaccination in human volunteers. J Invest Dermatol 2001: 117: 1144 1150.

23. Duthie MS, Kimber I, Norval M. The effects of ultraviolet radiation on the human immune system. Br J Dermatol 1999; 140: 995-1009.

24. Selgrade MJK, Repacholi MH, Koren HS. Ultraviolet radiation-induced immune modulation: potential consequences for infectious, allergic, and autoimmune disease. Environ Health Perspect 1997: 105: 332-334.

25. Jackson S, Harwood C, Thomas M, Banks L, Storey A. Role of Bak in UVinduced apoptosis in skin cancer and abrogation by HPV E6 proteins. Genes Dev 2000: 14: 3065-3073.

26. Breuer-McHam J, Simpson E, Dougherty I, Bonkobara M. Ariizumi K, Lewis DE, Dawson DB, Duvic M, Cruz PD. Activation of HIV in human skin by ultraviolet B radiation and its inhibition by $\mathrm{NF \kappa B}$ blocking agents. Photochem Photobiol 2001; 74: 805-810.

27. Purdie KJ, Pennington J, Proby CM, Khalaf S, de Villiers EM, Leigh IM, Storey A. The promotor of a novel human papillomavirus (HPV-77) associated with skin cancer displays UV responsiveness, which is mediated through aconsensus p53 binding sequence. Eur Mol Biol Org 1999; 18: 5359-5369.

28. Norval M, El-Ghorr AA. UV-induced immunosuppression in virus infections. Mutation Research 1998; 422: 131-138.

29. Taylor JR, Schmieder GJ, Shimizu T, Tie C, Streilein JW. Interrelationship between ultraviolet light and recurrent herpes simplex infections in man. J Dermatol Sci 1994; 8: 224-232.

30. De Hertog SA, Wensveen CA, Bastiaens MT, Kielich CJ, Berkhout MJ, Westendorp RG, Vermeer BJ, Bouwes Bavinck JN. Relation between smoking and skin cancer. J Clin Oncol 2001: 19: 231-238.

31. Boxman IL, Berkhout RJ, Mulder LH, Wolkers MC, Bouwes Bavinck JN, Vermeer BJ. Ter Schegget J. Detection of human papillomavirus DNA in plucked hairs from renal transplant recipients and healthy volunteers. J Invest Dermatol 1997: 108: 712-715. 
32. Termorshuizen F, Garssen J, Norval M, Koulu L, Laihia J, Leino L, Jansen CT, Gruijl FR de, Gibbs NK. Simone C de, Loveren H van. A review of studies on the effects of ultraviolet irradiation on the resistance to infections: evidence from rodent infection models and verification by experimental and observational human studies. Int Immunopharm 2002; 2: 263-275.

33. Kelly DA, Young AR, McGregor JM, Seed PT. Potten CS, Walker SL. Sensitivity to sunburn is associated with susceptibility to ultraviolet radiation-induced suppression of cutaneous cell-mediated immunity. J Exp Med 2000; 191(3): 561566.

34. Gilmour JW, Vestey JP, Norval M. The effect of UV therapy on immune function in patients with psoriasis. Br J Dermatol 1993; 129: 28-38.

35. Neill WA, Halliday KE, Norval M. Differential effect of phototherapy on the activities of human natural killer cells and cytotoxic cells. J Photochem Photobiol B: Biol 1998; 47: 129-135.

36. Jackson S, Storey A. E6 proteins from diverse cutaneous HPV types inhibit apoptosis in response to UV damage. Oncogene 2000; 19: 592-598.

37. Jackson S, Ghali L, Harwood C. Storey A. Reduced apoptotic levels in squamous but not basal cell carcinomas correlates with detection of cutaneous human papillomavirus. Br J Cancer 2002; 87: 319-323.

38. De Gruijl FR. Ultraviolet radiation and tumor immunity. Methods 2002; 28: 122 129.

39. Antonsson A, Forslund O, Ekberg H, Sterner G, Hansson G. The ubiquity and impressive genomic diversity of human skin papilomaviruses suggest a commensalic nature of these viruses. J Virol 2000; 74: 11636-11641.

40. Kaskel P, Sander S, Kron M, Kind P, Peter RU, Krähn G. Outdoor activities in childhood: a protective factor for cutaneous melanoma? Results of a case-control study in 271 matched pairs. Br J Dermatol 2001: 145: 602-609.

41. De Gruijl FR. Health effects from solar UV radiation. Radiation Protection Dosimetry 1997: 72: 177-196.

42. Manolagas SC. Provvedini DM, Tsoukas CD. Interactions of 1,25dihydroxyvitamin D3 and the immune system. Mol Cel Endocrinol 1985; 43: 113 122.

43. Finsen NR. The treatment of Lupus Vulgaris by concentrated chemical rays. In: Phototherapy, pp. 73-75 (London: Edward Arnold), 1901.

44. Barenberg LH, Friedman I, Green D. The effect of ultraviolet irradiation on the health of a group of infants. JAMA 1926; Okt. 2: 1114-1117.

45. Favre M. Majewski S, Noszczyk B, Maienfisch F, Pura A, Orth G, Jablonska S. Antibodies to human papillomavirus Type 5 are generated in epidermal repair processes. J Invest Dermatol 2000; 114:403-407.

46. Favre M, Orth G, Majewski S, Baloul S, Pura A, Jablonska S. Psoriasis: a possible reservoir for human papillomavirus type 5 , the virus associated with skin carcinomas of epidermodysplasia verruciformis. J Invest Dermatol 1998; 110:311-317.

47. Garssen J, Vandebriel RJ, De Gruijl FR, Wolvers D, Van Dijk M. Fluitman A. Van Loveren H. UVB exposure-induced systemic modulation of Th1 and Th2 mediated immune responses. Immunology 1999; 97: 506-514.

48. Sleijffers A, Garssen J. De Gruijl FR, Boland GJ, Van Hattum J, Van Vloten WA, Van Loveren H. Ultraviolet B exposure impairs immune responses following hepatitis B vaccination in two different mouse strains. Photochem Photobiol 2002; 75: 541-546. 

Chapter 9 Summary and general discussion 


\section{Introduction}

In view of the observations that experimental UVR may have adverse effects on immunity and related resistance to infectious diseases in rodent models and on both antigen-specific and non-specific immune parameters in humans, we investigated whether evidence is present that non-experimental exposure to ambient UVR may be associated with an adverse influence on the protection to infections in human populations. We investigated whether solar exposure is associated with the risk of different classes of skin infections in renal graft recipients, the disease progression in $\mathrm{HIV}$ infection, the formation of antibodies following a number of standard vaccinations, and the occurrence of respiratory tract symptoms in young children. In addition, the relation between solar exposure and HPV prevalence was examined, as HPV infection may play an important role in the development of skin cancer, which is known to be strongly associated with lifetime-cumulative exposure to solar UVR. In this chapter, the main results of the previous chapters are described in relation to each other. Furthermore, we will discuss the problems encountered with regard to exposure assessment, measurement of outcome, and interpretation of the results.

\section{Main outcomes and comments}

The results from the renal transplant recipients' study indicated an independent association between sunny season and the occurrence of herpes simplex-, herpes zoster-, and Candida albicans infections (Chapter 2). On the contrary, no effect of the lifetime-cumulative sun exposure on these infections could be established, which is in accordance with the postulated short-term effects of UVR on immunity and infections. Although seasonal differences have to be interpreted with caution, these findings underscore the possibility that sunny season is associated with clinical symptoms in connection with certain infections, and, thus, ambient UVR may have an unfavourable effect on infections in humans. Depressed immune responses in relation to herpes simplex virus and Candida albicans have been demonstrated following experimental UVR exposure in humans [ $\left[\begin{array}{lll}1 & 2 & 3\end{array}\right]$. On the other hand, the lowest rate of bacterial infections was found in summer season, which is not in accordance with the postulated short-term UVR-induced immunomodulation. It is not to be expected that all infections will be affected by UVR similarly, given the differences between microorganisms and the immune responses they elicit in the host. Intracellular viruses and intracellular bacteria (which are a minority among bacterial micro-organisms) stimulate a Th- 1 cellular immune response, which is probably the most affected by UVR. The immunosuppressive effects of UVR might not be apparent in the case of a Th-2 cytokine profile, for example in the parasitic infection with Schistosoma mansoni [1 4].

On the other hand, a higher rate of bacterial infections was found in patients who reported a higher number of painful sunburns in the past. An independent association between sunburn and infections was also suggested in our children's cohort study on higher respiratory tract symptoms (Chapter 7) and in the study on the relationship between sunlight exposure and HPV infection (Chapter 8). In the children's cohort study, recent episodes of slight sunburn were reported and probably preceded the symptoms of respiratory tract infections immediately. The mechanisms underlying the possible relationship between sunburn, either as lifetime-cumulative number or as episode immediately preceding outcome, and infections are poorly 
understood. Effects of UVR on infections in rodent models were found at suberythemal doses. In a study by Garssen et al. (2000) in different knockout mice, it was shown that the mechanisms of erythema and UVR-induced immunosuppression are different, and that the sensitivity to erythema is not associated with the sensitivity to UVR-induced immunosuppression (see also Chapter 1.2) [5]. Furthermore, it was shown that immunosuppression might be induced in humans with deeply pigmented skin as well [6]. In other studies, in was demonstrated that the UVR waveband dependencies might differ for erythema and indicators of immunosuppression like suppression of DTH response, cis-UCA formation, and impaired cytokine production (see also Chapter 1.2)[7 8 9]. In contrast, in the human study of Kelly et al. (2000), a clear association between sensitivity to sunburn and sensitivity to UVR-induced suppression of cellular immune function was established, but exposure with 2 MED resulted in local suppression of CHS in nearly all subjects tested [10]. The results of a study by Jansen et al. (2000) suggested that UVR-induced inflammation (erythema) is required to suppress immune response to a contact sensitizer, either applicated locally (ie, at the site of irradiation) of at a distant locus (ie, systemic immunomodulation) in humans (see also Chapter 1.2) [11]. Systemic immunosuppression following localized sunburn has been observed before in an experimental study design in humans by Cooper et al.(1992) [12] and Kelly et al.(1998) [13]. Our findings on sunburn from the renal transplant recipients study, the children's cohort study, and the HPV study are remarkable and may be in accordance with in-detail studies that indicate an association between the erythema-inducing and immunomodulatory effects of UVR in humans. Studying the effects of sunburn, either as lifetimecumulative number or as episode immediately preceding outcome, may be very fruitful from an epidemiological point of view. Sunburn is probably easily remembered when asked for in a self-administered questionnaire and each reported episode of sunburn may be regarded as a strong and valid indication that a biologically effective dose of solar UVR was received. Furthermore, the possible differential effects of sunburn and exposure to solar UVR without inducing erythema on health outcome may be examined, as was done in the children's cohort study (see below, and Chapter 7) and in the HPV study (see below, and Chapter 8).

In our first study among HIV-infected persons, the exposure to ambient UVR was assessed by means of a 2-years retrospective questionnaire in a small group of HIV-infected homosexual men who participated in the Amsterdam Cohort Study on HIV and AIDS (Chapter 3). No significant effects of the two-year cumulative estimate of exposure on immune parameters were found. A small decline in the number of $\mathrm{CD}^{+} \mathrm{T}$ cells, the $\mathrm{CD}^{+} / \mathrm{CD}^{+} \mathrm{T}$-cell ratio, and the $\mathrm{T}$-cell reactivity after a reported episode of great exposure was suggested, but this was not statistically significant. As the study group was small $(n=57)$ and exposure assessment by means of retrospective questionnaires is probably less precise, we performed a seasonal analysis on immune parameters in a much larger group of HIV-infected homosexual men $(n=556)$ (Chapter 4). A small decline in the $\mathrm{CD}^{+}{ }^{+} \mathrm{T}$-cell number and $\mathrm{CD}^{+} / \mathrm{CD}^{+} \mathrm{T}$-cell ratio during spring and summer was found and this finding itself is in accordance with the hypothesis of depressed cellular immunity in relation with UVR exposure in HIV-infected individuals. However, the T-cell reactivity to monoclonal CD3 antibodies was clearly enhanced during sunny season. This finding is surprising, as it is known that T-cell reactivity is also a sensitive marker of cellular immunity and disease progression in HIV [14]. This finding is the more surprising when realizing that $\mathrm{T}$-cell reactivity was expressed as the percentage of the median response assessed in concurrently running cultures of healthy controls. This indicates 
that the T-cell reactivity in summer season was enhanced in HIV-infected persons in comparison with HIV non-infected persons, suggesting a beneficial effect of HIV infection on UVR-induced immunomodulation. Significant lower $\mathrm{CD}^{+}$and $\mathrm{CD}^{+} \mathrm{T}$ cell numbers in sunny season have been observed in a chronobiological study by Levi et al.(1988), which globally coincides at first sight with our findings [15]. However, the seasonal decline in T-cell numbers in the study by Levi $\left(\mathrm{CD}^{+}:\right.$a decline of approximately -200 cells $/ \mathrm{mm}^{3}$ ) was much greater than the small decline found by us $\left(\mathrm{CD}^{+}:-27\right.$ cells $/ \mathrm{mm}^{3}$ ). Probably more important, the seasonal fluctuations in the study by Levi were found in a very small group of healthy HIV non-infected volunteers. We did not find significant seasonal differences in a greater group of healthy HIV non-infected men $(n=78)$. Furthermore, a beneficial effect of sunny season on T-cell populations was reported in the studies of Roberts (1995) [16]. We could not establish a seasonal effect on HIV viral load in our seasonal analysis. Hence, we may conclude that, the observed small seasonal decline in the $\mathrm{CD}^{+} \mathrm{T}$-cell number notwithstanding, ambient UVR exposure does not seem to have great impact on disease progression in HIV infection. In the study by Breuer-McHam et al. (2001), a significant increase in the number of HIV in skin following UVR exposure was established [17]. On the other hand, our and other studies among HIV-infected persons do not indicate detrimental clinical effects of UVR exposure [18 19]. One possible explanation for this discordance is that UVR-induced HIV activation in the skin does not necessarily lead to an increase in plasma HIV. T lymphocytes in the epidermis may be preferentially destroyed by UVR, and, hence, the local viral activation may have no bearings on the clinical course of HIV infection [17 20].

In the seasonal study on vaccination responses, the initial antibody levels to hepatitis B surface antigen (anti-HBs) were slightly lower, on average, when the hepatitis B immunization procedure was started in summer, ie, when the first encounter with hepatitis B antigen took place in a season with comparatively high ambient UVR (Chapter 5). However, these seasonal differences in anti-HBs early in the immunization procedure were not consistently found when breaking down the anti-HBs titre by calendar year. Probably more important, at the end of the procedure no differences in the mean anti-HBs or the percentage of persons with protective levels against hepatitis B could be established. Furthermore, no effect of season of first vaccination on antibodies to measles and rubella could be established in a crosssectional study in children aged 2-7 years, who had received their first vaccination at 14 months of age. The slightly lower antibody response in the analysis on hepatitis B vaccination may indicate a subtle effect of UVR on the immune system in the general human population. However, other explanations have to be taken into consideration as well. For example, internal melatonin secretion is enhanced during the winter months due to the shorter day length and melatonin has been described to potentiate the primary immunization [21]. Furthermore, it has been described that stress induced by cold temperature in winter may affect preferentially the suppressor T-cell pathways and as a consequence may be associated with enhanced B-cell function [22]. In a recent study by Sleijffers et al. (2001), no effect of experimental exposure to UVR on antibody formation following hepatitis B vaccination in human volunteers (total body, approximately $1 \mathrm{MED}$ ), either shortly after initiation or at later stages of the immunization procedure, could be established [23]. As this study was carried out during winter season, the possible confounding effects of other season-related factors and ambient UVR were ruled out. From our study on seasonal effects on antibody formation, we may conclude that a small and transient seasonal difference on antiHBs occurs, but that no significant and consistent effect of ambient UVR on immune 
responses and related immunoprotection following a vaccination could be established in the general population.

A seasonal difference in the occurrence of respiratory tract symptoms was found in the children's cohort study, which is in accordance with expectation (Chapter 7). The lowest prevalence of respiratory tract symptoms was found in July and August, the highest prevalence was found in March/ April (winter months were left out of consideration for this analysis). The association between personal exposure to solar UVR and respiratory symptoms appeared to be in direct line with this seasonal fluctuation. An adverse effect of exposure to solar UVR itself on the occurrence of respiratory tract symptoms could not be detected. Independently of season, a higher personal exposure, as estimated by means of a 6-week retrospective questionnaire, was associated with a lower incidence of respiratory tract symptoms. This season-adjusted beneficial association with exposure to UVR could be established with the independently measured levels of ambient UVR as well. These levels were measured daily during the same months in the centre of the Netherlands. This indicates that limitations in the reporting of the child's outdoor exposure by the parents in the 6-week retrospective questionnaire and resulting bias in the ranking of the children with respect to their personal outdoor exposure or the possibility that the individual exposure to UVR is influenced by the presence of symptoms did not explain the found relationship (Chapter 6). Whether the found inverse association, which was in contradiction with our hypothesis of UVR-induced immunosuppression, may indicate a beneficial health effect of solar UVR remains to be established.

In contrast, an unfavourable association with sunburn was found. The reporting of (slight) sunburn was independently of season and personal exposure itself statistically significantly associated with symptoms of runny ear. A trend towards a higher prevalence of symptoms of coughing and runny nose with the reporting of slight sunburn was found as well, but did not reach the level of statistical significance. This result suggests that exposure to solar UVR or outdoor behaviour itself may be associated with a beneficial influence, but that at UVR doses causing erythema the beneficial effects will be reversed to their opposite. In a recent study by Kaskel et al, (2001) on skin cancer, it was found that sunburn in childhood is an important risk factor for melanoma. In contrast, outdoor activities in childhood itself were found to be protective for cutaneous melanoma [24]. This study confirms that the effects of sunlight exposure and sunburn on health outcome may be opposite to each other. However, we do not yet know whether the found relationship between outdoor exposure itself and outcome is due to a causal mechanism or to other factors associated with outdoor behaviour. With respect to the induction of skin cancer, we may hypothesize that protective tanning, based on melanogenesis and increased thickness of the epidermis, is the causal mechanism underlying the beneficial effect of outdoor exposure itself [24]. For our study on short-term effects on respiratory tract symptoms, a diminished exposure to micro-organisms that mainly circulate indoors and require intense person-to-person contacts may explain the found inverse association with UVR exposure [25].

Furthermore, the beneficial effects of vitamin D production associated with solar UVR require consideration. Anti-proliferative, anti-cancer and immunological effects of vitamin D have been described [26-30]. Receptors for vitamin $1,25(\mathrm{OH})_{2} \mathrm{D}_{3}$ have been found in immune cells and it has been shown that vitamin $1,25(\mathrm{OH})_{2} \mathrm{D}_{3}$ is able to enhance the IFN- $\gamma$-induced Class II MHC restricted antigen presentation to lymphocytes by monocytes [29]. Furthermore, it has been reported that vitamin D-deficient rickets in humans may be associated with recurrent 
infections, probably due to impaired capacity of leucocytes to phagocytize [29]. We wonder whether these findings are relevant for the results from our children's cohort study. Solar exposure is probably crucial to maintain active vitamin D3 serum levels [28 31]. However, exposure to a third or a half MED for three times a week (a number of minutes at noon in the Netherlands in July) may be enough to maintain proper serum levels of both $25 \mathrm{OH}$-vitD $\mathrm{D}_{3}$ and the active metabolite $1,25(\mathrm{OH})_{2} \mathrm{D}_{3}$ [28]. For this reason, the possible beneficial effect of solar exposure on respiratory tract infections in the children's cohort study might have been expected exclusively at the start of sunny season, immediately following the dark and rainy months. However, the beneficial effect on respiratory tract symptoms associated with a higher personal exposure was also found in August and September. Furthermore, the active vitamin $1,25(\mathrm{OH})_{2} \mathrm{D}_{3}$ may be released slowly into the serum and the level of $1,25(\mathrm{OH})_{2} \mathrm{D}_{3}$ does not appear to differ seasonally as much as $25 \mathrm{OH}$-vitamin $\mathrm{D}_{3}$ does [26]. For this reason, short-term variations in respiratory tract symptoms in association with differences in active vitamin D serum levels due to short-term variations in sunlight exposure are less likely, but this question remains to be settled.

We conclude from the children's cohort study that the postulated adverse effects of exposure to UVR on symptoms of respiratory tract infections cannot be detected at sub-erythemal doses. In contrast, sunburn may be independently associated with a higher occurrence of respiratory tract symptoms.

In the study on HPV infections, it was found that sunburn in the past, especially at age 13-20 years, was independently associated with a higher prevalence of HPV infection as measured by HPV-DNA positivity (Chapter 8). This finding indicates that UVR at doses that cause erythema may have the potential to impair host resistance to HPV, and may promote skin carcinogenesis along an infectious way. However, an inverse (ie, favourable) association between lifetime sun exposure itself and HPV prevalence was also found. This association, which again indicates the presence of favourable effects associated with sunlight exposure, probably at suberythemal doses, could be established with statistical significance among controls $(n=325)$. The same tendency was found with borderline significance in the smaller group of patients with a history of squamous cell carcinoma $(n=155)$. This association between sunlight and HPV infection was a surprising finding, as lifetime sun exposure and HPV are both associated with the occurrence of non-melanoma skin cancer. For this reason, a positive relationship was hypothesized. Thus, this study on HPV gives further evidence that exposure to solar UVR and UVR-induced sunburn may have opposite effects on the occurrence of infections. For further studies, it may be hypothesized that the relationship between sunburn, especially at young age, and the induction of skin cancer is in part due to the adverse effect of sunburn on the susceptibility to HPV infections.

\section{Conclusions and indications for future research}

The results of our observational and epidemiological studies strongly indicate that the relationship between UVR exposure and infections is not simple and straightforward. A clear relationship between herpes simplex recrudescence and solar exposure has been established in humans before and was corroborated in our study on seasonal fluctuations in the occurrence of skin infections in renal graft recipients. However, no unequivocal effects of solar exposure indicative of UVR-induced immunomodulation on disease progression in HIV-infected homosexual men and on antibody responses following a number of standard vaccinations in a sample from the general population 
could be established. For respiratory tract symptoms in young children and for the prevalence of HPV infections in adults, an inverse association with sunlight exposure itself was even found. On the other hand, sunburn appeared to be unfavourably associated with bacterial skin infections in the renal transplant study, respiratory tract symptoms in the children's cohort study, and HPV prevalence in the skin cancer study. These findings support the notion that the relationship between solar exposure to UVR and infections is not one-dimensional and that exposure to UVR may have opposite effects. For further studies on the effects of solar UVR exposure on immunity, infections, and skin tumours, it may be important to distinguish between exposure to sunlight itself and sunburn as separate entities. As sunburn appears to be an important risk factor for skin cancer and -as was indicated by our studies- for certain infections as well, further studies on the mechanisms underlying these effects are warranted. Insight into the health impact of UVR-induced skin damage will further elucidate whether these effects have the same immunological mechanisms in common, and this will be helpful to define safety thresholds for human exposure. With regard to the susceptibility to infections, we have no reason at the moment to give an advice for the human population in general against solar UVR exposure at sub-erythemal doses. UVR exposure at doses causing sunburn has to be regarded as a danger zone for both the induction of skin cancer and the resistance to infections. 


\section{References}

1. Norval M, Garssen J, Van Loveren H, El-Ghorr AA. UV-induced changes in the immune response to microbial infections in human subjects and animal models. J Epidemiol 1999: 9: S84-S92.

2. O'Dell BL, Jessen T, Becker LE, Jackson RT, Smith EB. Diminished immune response in sun-damaged skin. Arch Dermatol 1980; 116: 559-561.

3. Gilmour JW, Vestey JP, Norval M. The effect of UV therapy on immune function in patients with psoriasis. Br J Dermatol 1993; 129: 28-38.

4. Noonan FP, Lewis FA. UVB-induced immune suppression and infection with Schistosoma mansoni. Photochem Photobiol 1995; 61: 99-105.

5. Garssen J, van Steeg H, De Gruijl FR, De Boer J, Van der Horst GTJ, Van Kranen H, Van Loveren H, Van Dijk M, Fluitman A, Weeda G, Hoeijmakers JHJ. Transcription-coupled and global genome repair differentially influence UV-Binduced acute skin effects and systemic immunosuppression. J Immunol 2000; 164: 6199-6205.

6. Vermeer M, Schmieder GJ, Yoshikawa T, Van den Berg JW, Metzman MS, Taylor R, Streilein JW. Effects of ultraviolet B light on cutaneous immune responses of humans with deeply pigmented skin. J Invest Dermatol 1991: 97: 729-734.

7. El-Ghorr AA, Norval M. The UV waveband dependencies in mice differ for the suppression of contact hypersensitivity, delayed-type hypersensitivity and cisurocanic acid formation. J Invest Dermatol 1999; 112: 757-762.

8. Gibbs NK, Norval M, Traynor NJ, Crosby JC, Lowe G, Johnson BE. Comparative potency of broad-band and narrow-band phototherapy sources to induce edema, sunburn cells and urocanic acid photoisomerization in hairless mouse skin. Photochem Photobiol 1993; 58: 643-647.

9. Jones CD, Guckian M, El-Ghorr AA, Gibbs NK, Norval M. Effects of phototherapy on the production of cytokines by peripheral blood mononuclear cells and on systemic antibody responses in patients with psoriasis. Photodermatol Photoimmunol Photomed 1996; 12: 204-210.

10. Kelly DA, Young AR, McGregor JM, Seed PT, Potten CS, Walker SL. Sensitivity to sunburn is associated with susceptibility to ultraviolet radiation-induced suppression of cutaneous cell-mediated immunity. J Exp Med 2000; 191: 561-566.

11. Jansen C, Leszczynski D, Pastila R, Koulu L, Laihia J et al. Immunosuppressive, carcinogenic and metastase-related effects of solar UV radiation. Publications of The Finnish Research Programme on Environmental Health, SYTTY 2000; 1: 241247.

12. Cooper KD, Oberhelman L, Hamilton TA. Baadsgaard O, Terhune M. LeVee G, Anderson T, Koren H. UV exposure reduces immunization rates and promotes tolerance to epicutaneous antigens in humans: Relationship to dose, CD1a-DR+ epidermal macrophage induction, and Langerhans cell depletion. Proc Natl Acad Sci USA 1992; 89: 8497-8501.

13. Kelly DA, Walker SL, McGregor JM. Young AR. A single exposure of solar simulated radiation suppresses contact hypersensitivity responses both locally and systemically in humans: quantitative studies with high-frequency ultrasound. $\mathbf{J}$ Photochem Photobiol B: Biology 1998; 44: 130-142.

14. Roos MT, Miedema F, Koot M, Tersmette M, Schaasberg WP, Coutinho RA, Schellekens PT. T-cell function in vitro is an independent progression marker for AIDS in human immunodeficiency virus-infected asymptomatic subjects. J Infect Dis 1995: 171: 531-536. 
15. Lévi FA, Canon C. Touitou Y, Reinberg A, Mathé G. Seasonal modulation of the circadian time structure of circulating $\mathrm{T}$ and natural killer lymphocyte subsets from healthy subjects. J Clin Invest 1988; 81: 407-413.

16. Roberts JE. Visible light induced changes in the immune response through an eyebrain mechanism (photoneuroimmunology). J Photochem Photobiol B: Biology 1995; 29: 3-15.

17. Breuer-McHam J, Simpson E, Dougherty I, Bonkobara M, Ariizumi K, Lewis DE, Dawson DB, Duvic M, Cruz PD. Activation of HIV in human skin by ultraviolet B radiation and its inhibition by NFKB blocking agents. Photochem. Photobiol 2001; 74: 805-810.

18. Saah AJ, Horn TD, Hoover DR, Chen C, Whitmore SE, Flynn C, Wesch J, Detels R, Anderson R. Solar ultraviolet radiation exposure does not appear to exacerbate HIV infection in homosexual men. AIDS 1997; 11: 1773-1778.

19. Akaraphanth R, Lim HW. HIV, UV and immunosuppression. Photodermatol Photoimmunol Photomed 1999; 15: 28-31.

20. Duthie MS, Kimber I, Norval M. The effects of ultraviolet radiation on the human immune system. Br J Dermatol 1999; 140: 995-1009.

21. Pierpaoli W, Maestroni GJM. Melatonin: a principal neuroimmunoregulatory and anti-stress hormone: its anti-aging effects. Immunol letters 1987; 16: 355-62.

22. MacMurray JP, Barker JP, Armstrong JD, Bozzetti LP, Kuhn IN. Circannual changes in immune function. Life Sciences 1983; 32: 2363-2370.

23. Sleijffers A, Garssen J, De Gruijl FR, Boland GJ, Van Hattum J, Van Vloten WA, Van Loveren $\mathrm{H}$. Influence of Ultraviolet $\mathrm{B}$ exposure on immune responses following Hepatitis B vaccination in human volunteers. J Invest Dermatol 2001; 117: 1144-1150.

24. Kaskel P, Sander S, Kron M, Kind P, Peter RU, Krähn G. Outdoor activities in childhood: a protective factor for cutaneous melanoma? Results of a case-control study in 271 matched pairs. Br J Dermatol 2001; 145: 602-609.

25. Koopman L.P., Smit H.A., Heijnen M.L., Wijga A., van Strien R.T., Kerkhof M., Gerritsen J., Brunekreef B., de Jongste J.C., Neijens H.J. Respiratory Infections in Infants: Interaction of Parental Allergy, Day Care, and Siblings: The PIAMA study. Pediatrics 2001: 108: 943-948.

26. De Gruijl FR. Health effects from solar UV radiation. Radiation Protection Dosimetry 1997; 72: 177-196.

27. Timonen TTT. A hypothesis concerning deficiency of sublight, cold temperature, and influenza epidemics associated with the onset of acute lymphoblastic leukemia in northern Finland. Ann Hematol 1999; 78: 408-414.

28. Holick MF. Sunlight "D"ilemma: risk of skin cancer or bone disease and muscle weakness. The Lancet 2001; 357: 4-5.

29. Manolagas SC, Provvedini DM, Tsoukas CD. Interactions of 1,25dihydroxyvitamin D3 and the immune system. Mol Cel Endocrinol 1985; 43: 113122.

30. Müller K, Bendtzen K. 1,25-dihydroxyvitamin D3 as a natural regulator of human immune function. J Invest Dermatol Symp Proc 1996; 1: 68-71.

31. Tangpricha V, Pearce EN, Chen TC, Holick MF. Vitamin D deficiency among free-living healthy young adults. Am J Med 2002; 112: 659-662. 



\section{Samenvatting in het Nederlands}

Uit diverse proefdiermodellen en uit experimenteel onderzoek bij mensen is gebleken dat ultraviolette straling (UV), met name de B-fractie (golflengte $280-315 \mathrm{~nm}$ ), de potentie heeft diverse immuunresponsen te onderdrukken. Belangrijk hierbij is dat uit de proefdierstudies is gebleken dat deze UV-geïnduceerde onderdrukking van immuunresponsen kan leiden tot een duidelijk verminderde weerstand tegen zowel tumoren als infecties. Het is bekend dat ook bij mensen overmatige blootstelling aan ultraviolette straling, zoals in zonlicht voorkomt, gezondheidsschade kan veroorzaken. Blootstelling aan zonlicht is een belangrijke risicofactor voor onder andere het ontstaan van bepaalde typen huidkanker. Dat het immuunsysteem een belangrijke rol speelt bij de bescherming tegen deze tumoren komt aan het licht bij niertransplantatiepatiënten. Door het gebruik van immuunsuppressieve middelen tegen transplantaatafstoting hebben deze patiënten een verhoogde kans op het ontstaan van huidtumoren op zonbeschenen lichaamsdelen. UV zou dan ook huidkanker kunnen veroorzaken door middel van zowel inductie van DNA schade als onderdrukking van de immunologische weerstand. Daarnaast zou de onderdrukking van diverse immuunresponsen door UV ook bij mensen gevolgen kunnen hebben voor de weerstand tegen infecties of op het beloop van een infectie, indien reeds aanwezig. Het is uit ethisch oogpunt niet mogelijk mensen experimenteel met een bepaald micro-organisme te infecteren en vervolgens het effect van zonlicht of artificieel UV op de immunologische weerstand tegen het betreffende micro-organisme te onderzoeken. Om die reden zijn we aangewezen op het extrapoleren van bevindingen uit proefdierstudies naar de mens en op nauwgezette analyse en interpretatie van data uit observationele studies. In dit proefschrift worden een aantal observationeelepidemiologische studies beschreven die tot doel hadden na te gaan of alledaagse en niet-experimentele blootstelling aan UV in humane populaties geassocieerd is met een verminderde weerstand tegen infecties (hoofdstuk 1.1).

In de inleiding worden een aantal experimentele studies van anderen beschreven die nader inzicht verschaffen in de mechanismen van UV-geïnduceerde immuunsuppressie (hoofdstuk 1.2). UV-geïnduceerde immuunsuppressie blijkt mede in gang gezet te worden door acute beschadiging van DNA in immunologisch belangrijke cellen in de huid (o.a. keratinocyten en Langerhans cellen). Een voor dit proefschrift belangrijke bevinding bij een van de beschreven proefdierstudies is dat een bepaald defect in de DNA-herstelmechanismen ('nucleotide excision repair') gepaard bleek te gaan met een verhoogde gevoeligheid voor immuunsuppressie, terwijl een defect in een ander deel van de DNA-herstelmechanismen juist weer gepaard bleek te gaan met een verhoogde gevoeligheid voor erytheem (zonverbranding). Verder blijkt dat de golflengte-afhankelijkheid voor erytheem niet overeenkomt met die voor de modulatie van diverse immuunparameters. Erytheem en immuunsuppressie zijn dan ook waarschijnlijk in mechanistische zin onafhankelijke effecten van UV. Dit wordt onderstreept door diverse proefdierstudies die laten zien dat UV, bij een bestralingsdosis die geen erytheem veroorzaakt, in staat is de weerstand tegen diverse infecties te onderdrukken. Het betreft hierbij zowel infecties van de huid (bijvoorbeeld herpes simplex) als infecties die niet met de huid geassocieerd zijn (bijvoorbeeld Trichinella spiralis). Echter, er worden ook een aantal humaan-experimentele studies beschreven die laten zien dat de immuunsuppressieve effecten van UV op contactovergevoeligheid in de mens pas aan het licht treden bij doseringen die ook erytheem veroorzaken. Een aantal andere humane studies hebben laten zien dat dit zeker opgaat als het een immunologische respons ver van het 
bestraalde stukje huid betreft (de 'systemische' of distante immuunsuppressie) of om de inductie van immunologische tolerantie. In een beschreven extrapolatie studie wordt rekening gehouden met de waarschijnlijkheid dat mensen beduidend minder gevoelig zijn voor de immuunsuppressieve effecten van UV dan de muizen en ratten die in proefdiermodellen gebruikt worden. Het blijkt dan dat UV bij doseringen die relevant zijn voor alledaagse blootstelling aan zonlicht in staat is bij mensen de weerstand tegen infecties te onderdrukken. Omdat zo'n extrapolatie model op een aantal onzekerheden berust, o.a. voor wat betreft het geëigende actiespectrum dat nodig is om te kunnen corrigeren voor verschillen in spectrale samenstelling tussen zonlicht en UV-lampen in het laboratorium, is nader epidemiologisch onderzoek van belang. Uitgaande van de beschreven bevindingen uit humaan en proefdieronderzoek worden vervolgens een aantal hypothesen geformuleerd die als basis dienen voor de beschreven studies uit dit proefschrift (hoofdstuk 1.3).

Allereerst veronderstelden we dat de verminderde weerstand tegen infecties door blootstelling aan UV aan het licht treedt met name bij mensen die reeds een verminderd functioneren van hun immuunsysteem hebben. In een cohort niertransplantatie-patiënten, die reeds eerder in een studie naar het effect van zonlicht op het ontstaan van huidkanker geïncludeerd waren, onderzochten we of er een verband was tussen blootstelling aan zonlicht en het voorkomen van huidinfecties in de jaren na de niertransplantatie (hoofdstuk 2). Gegevens met betrekking tot gediagnostiseerde huidinfecties werden retrospectief uit de statussen van deze patiënten verzameld. Zowel het verband met een maat voor de levenslangcumulatieve blootstelling aan zonlicht als het verband met een maat voor de blootstelling op korte termijn werden onderzocht. Een maat voor levenslangcumulatieve blootstelling werd berekend op basis van gegevens uit een vragenlijst die al was afgenomen bij deze patiënten in het kader van de studie naar huidkanker. Er waren geen gegevens met betrekking tot de zonlichtblootstelling kort voor het moment van de diagnose van een huidinfectie beschikbaar. Om deze reden werd voor deze studie het seizoen van diagnose beschouwd als indicatief voor de blootstelling aan UV rond het moment van de klinisch manifeste infectie. Omdat uit diverse proefdierstudies gebleken is dat de verminderde weerstand tegen infecties direct na blootstelling aan UV kan optreden, werd verwacht dat de maat voor blootstelling aan zonlicht op korte termijn belangrijker is dan de maat voor de lange termijn. De maat voor zonlichtblootstelling op de lange termijn is waarschijnlijk meer van belang als het gaat om het ontstaan van huidkanker, wat een jarenlang proces van opeenhoping van DNA schade en mutaties is. Aan de andere kant, een associatie tussen infecties en een maat voor blootstelling aan zonlicht in het verleden kan niet bij voorbaat uitgesloten worden, omdat UV, ook bij langdurige chronische blootstelling, in staat is immunologische tolerantie (d.w.z. de inductie van antigen-specifieke suppressor Tcellen) te veroorzaken en daarmee dus een blijvend immunologisch effect.

De resultaten lieten zien dat het zonnige seizoen geassocieerd is met het vóorkomen van herpes simplex en, alhoewel iets minder duidelijk, met het vóorkomen van herpes zoster. Voor deze virale infecties werd geen associatie met de maat voor zonlichtblootstelling op lange termijn gevonden. Acute effecten van UV op het ontstaan van klinisch manifeste herpes simplex infecties zijn reeds eerder beschreven bij mensen, en een seizoensrelatie zoals door ons gevonden zou dan ook goed vanuit wisselingen in blootstelling aan UV uit de omgeving verklaard kunnen worden. Omdat het bij de herpes virussen gaat om infecties die vaak jarenlang (in latente vorm) meegedragen worden, zou het hier met name kunnen gaan om 
immuunresponsen die een belangrijke rol spelen bij het onder controle houden van een reeds aanwezige infectie. Verder, UV zou het herpesvirus zelf ook direct of indirect kunnen activeren, naast een effect op de immunologische weerstand. Voor de bacteriële infecties werd geen duidelijke seizoensfluctuatie gevonden. De zomer leek eerder met een verlaagd voorkomen geassocieerd te zijn. Er bleek wel een trendmatig verband te zijn richting een hoger voorkomen met een hogere levenslang-cumulatieve blootstelling aan zonlicht. Verder, en misschien nog belangrijker, gerapporteerde zonverbrandingen in het verleden bleken significant samen te hangen met een verhoogde kans op bacteriële huidinfecties. Een verhoogde kans op infectie in samenhang met zonverbranding werd ook gevonden voor hoge luchtweginfecties (zie hieronder en hoofdstuk 7) en humaan papillomavirus (zie hieronder en hoofdstuk 8 ). De bevindingen voor de bacteriële huidinfecties suggereren dat blootstelling aan UV in het verleden van belang kan zijn voor de weerstand tegen bepaalde infecties.

Ten tweede veronderstelden we dat het belang van UV voor immuniteit en infecties met name aan het licht kan treden bij een infectie met een immuunmodulerend virus waarvan bekend is dat het door UV geactiveerd kan raken. In de onderzoeken beschreven in de volgende twee hoofdstukken (hoofdstuk 3 en hoofdstuk 4) werd nagegaan of blootstelling aan zonlicht van invloed is op de ziekteprogressie bij HIV infectie. In hoofdstuk 3 wordt een studie beschreven onder een selectie van HIVpositieve deelnemers van de Amsterdamse Cohort Studie (ACS) onder homoseksuele mannen (GG\&GD Amsterdam). Met behulp van een retrospectieve vragenlijst kon de recente zonlichtblootstelling in de voorafgaande twee jaar ingeschat en de relatie met een aantal voor de HIV-ziekteprogressie belangrijke immuunparameters onderzocht worden. Er bleek geen verband te zijn tussen de cumulatieve zonlichtblootstelling over de twee jaar en de achteruitgang in het aantal $\mathrm{CD} 4^{+} \mathrm{T}$-cellen, de ratio $\mathrm{CD}^{+} / \mathrm{CD}^{+} \mathrm{T}$-cel aantal of de $\mathrm{T}$-cel reactiviteit in dezelfde tijdsperiode. Een trendmatig effect richting lagere waarden van deze immuunparameters volgend op een kortdurende episode van hoge blootstelling (bijvoorbeeld een vakantie periode) werd gesuggereerd, maar bleek niet statistisch significant te zijn.

In de studie beschreven in hoofdstuk 4 werd in het gehele cohort van HIVpositieve homoseksuele mannen van de ACS onderzocht of er een seizoensrelatie was voor de eerder genoemde immuunparameters. Het voordeel van deze seizoensanalyse was dat de data van alle HIV-positieve homoseksuele deelnemers van de ACS vanaf 1984 gebruikt konden worden, omdat er geen ingewikkelde expositiebepaling met behulp van vragenlijstgegevens uitgevoerd werd. Subtiele effecten van UV op immuunparameters zouden door het grotere aantal gegevens gemakkelijker aan het licht kunnen komen. In deze studie bleek dat het zonnige seizoen statistisch significant geassocieerd was met een kleine daling van zowel het aantal CD4 ${ }^{+} \mathrm{T}$ cellen als de ratio $\mathrm{CD} 4^{+} / \mathrm{CD} 8^{+} \mathrm{T}$-cel aantal, wat goed te verklaren zou zijn door het effect van een hoge blootstelling uit de omgeving in de zomer op de virale replicatie en de cellulaire immuniteit. Echter, de T-cel reactiviteit bleek verhoogd te zijn in het zonnige seizoen. Dit is een opmerkelijke bevinding, omdat deze immuunparameter algemeen wordt beschouwd als een belangrijke maat voor de cellulaire immuniteit en, naast het aantal $\mathrm{CD} 4^{+} \mathrm{T}$-cellen, een gevoelige marker voor de ziekteprogressie bij HIV. Er wordt dan ook geconcludeerd dat er geen eenduidig en klinisch belangrijk effect van UV op de ziekteprogressie bij HIV vastgesteld kon worden. Dit is in overeenstemming met enkele andere buitenlandse studies. Dat HIV in de huid onder invloed van UV gereactiveerd kan raken is ook bij mensen aangetoond. Echter, deze locale reactivering heeft waarschijnlijk geen belangrijke systemische gevolgen. 
mogelijk omdat geïnfecteerde T-cellen in de epidermis juist ook door UV uitgeschakeld kunnen worden.

Ten derde veronderstelden we dat vaccinaties gegeven in het zonnige seizoen door de hogere blootstelling aan UV in de omgeving met een lagere antistofvorming gepaard zouden kunnen gaan dan vaccinaties gegeven in de winter (hoofdstuk 5). Acute effecten van UV op de primaire immuunrespons tegen een antigen, d.w.z. een respons volgend op het eerste contact met een bepaald antigen, zijn bij menselijke vrijwilligers al eerder in de literatuur beschreven. Een vaccinatierespons is belangrijk, omdat het gaat om een immunologische reactie die bedoeld is als bescherming tegen een bepaalde infectie. Bovendien, als de blootstelling aan UV hoog was voorafgaande aan de eerste toediening van het vaccin zou het effect blijvend kunnen zijn. Ook als een eventueel verlaagde respons niet direct een verminderde bescherming zou betekenen tegen de infectie waartegen het vaccin bedoeld was, dan zou de betreffende respons nog wel als een model kunnen dienen voor UV-geïnduceerde immuunmodulatie in het algemeen. Bij de antistofvorming volgend op een vaccinatie zijn tenslotte diverse 'wegen' van het immuunsysteem (zowel cellulaire als humorale) betrokken, wat het mogelijk tot een bijzonder geschikt uitleessysteem voor immunotoxiciteit maakt.

In een studie onder paramedische studenten die een standaard vaccinatieprotocol tegen hepatitis $\mathrm{B}$ ( $\mathrm{Hbs} \mathrm{Ag}$ op 0,1 maand en 6 maanden) ontvingen, werd een enigszins vertraagde immuunrespons gevonden als het eerste vaccin werd gegeven in een seizoen met hoge zonlichtblootstelling. Echter, aan het eind van het vaccinatieprotocol werd geen verschil gevonden in antistoftiters tussen de deelnemers die het protocol in de zomer waren begonnen en de deelnemer die het protocol in de winter waren begonnen. Uit een andere data bron bleek dat er geen verschil was in antistoftiters tegen mazelen en rubella tussen jonge kinderen die ooit de betreffende vaccinatie (bof-, mazelen-, rubella-vaccin op de leeftijd van 14 maanden) in de zomer en kinderen die ooit deze vaccinatie in de winter hadden gekregen. De conclusie is dan ook dat er weliswaar een voorbijgaand seizoensgebonden verschil in vaccinatieresponsen is gevonden, maar geen aanwijzing voor een blijvend effect op de uiteindelijke beschermende antistoftiter na vaccinatie. Echter, diverse andere seizoensgebonden factoren kunnen de resultaten beïnvloed hebben, zoals daglengte, temperatuur en chronobiologische jaarritmes. Bovendien is het effect van seizoen en de daarmee samenhangende blootstelling aan UV onderzocht op groepsniveau, en is geen rekening gehouden met verschillen in individuele blootstelling of verschillen in individuele gevoeligheid. In de volgende twee hoofdstukken wordt een studie beschreven waarin de individuele blootstelling aan UV werd gemeten en gecorrigeerd werd voor het mogelijk verstorende effect van seizoen op de uitkomst (hoofdstuk 6 en hoofdstuk 7).

Ten vierde veronderstelden we dat het effect van zonlicht op de weerstand tegen hoge luchtweginfecties aan het licht zou kunnen treden als in een multivariate analyse gecorrigeerd wordt voor het overbekende effect van seizoen op hoge luchtweginfecties (hoofdstuk 6 en hoofdstuk 7). Hoge luchtweginfecties komen meer voor in de herfst en winter dan in de het zonnige seizoen, waarschijnlijk door het effect van koude en vochtigheid of door de verhoogde kans op persoon-op-persoon transmissie van micro-organismen bij frequent verblijf binnenshuis. Echter, een hoge individuele blootstelling aan UV in het zonnige seizoen zou dan toch nog (subtiel) geassocieerd kunnen zijn met een verhoogde kans op klachten van de hogere luchtwegen. In een cohort van jonge kinderen onderzochten we het verband tussen de 
individueel gemeten blootstelling aan zonlicht op korte termijn en het optreden van verkoudheidsklachten gedurende de zonnige maanden van april tot september. Deze kinderen nemen deel aan een langlopende studie naar determinanten van astma en allergie en worden vanaf de geboorte tot aan de leeftijd van 8 jaar gevolgd met behulp van een jaarlijks terugkerende vragenlijst.

Met behulp van een retrospectieve vragenlijst, die gelijktijdig met de jaarlijks terugkerende vragenlijst werd afgenomen, werd de zonlichtblootstelling gedurende de voorafgaande 6 weken ingeschat (hoofdstuk 6). Gevraagd werd aan de ouders van de toenmalig eenjarige kinderen om voor hun kind het aantal uren buiten gedurende de voorafgaande 6 weken te rapporteren, en dit voor verschillende weken in Nederland en in het buitenland, indien van toepassing. Informatie met betrekking tot geografische ligging en tijdstip van het jaar maakte het mogelijk deze uren te 'wegen' voor het effect van breedtegraad en seizoen. Gerapporteerde informatie met betrekking tot kleding en weersomstandigheden gedurende de uren buiten maakte het mogelijk om deze uren ook te wegen voor de effecten van deze factoren op de hoeveelheid ontvangen UV. De berekende blootstelling in de vorm van het aantal gewogen uren werd vergeleken met objectieve UV grondmetingen in het midden van Nederland (RIVM, Bilthoven) gedurende dezelfde 6 weken om een indruk te krijgen van de betrouwbaarheid van de gerapporteerde gegevens.

Een groot deel van de ouders bleek niet in staat te zijn om de vragenlijst compleet in te vullen, waaruit blijkt dat het erg lastig is om zelfs gegevens met betrekking tot blootstelling in het zeer recente verleden te rapporteren. De expositieberekeningen op basis van de wel compleet ingevulde vragenlijsten lieten zien dat het individueel aantal gerapporteerde uren blootstelling zonder enige weging nauw gecorreleerd was met het aantal uren gewogen voor het effect van breedtegraad. seizoen en weersomstandigheden. Echter, deze correlatie werd beduidend zwakker wanneer de uren ook gewogen werden voor het effect van kleding op de hoeveelheid ontvangen UV. Informatie met betrekking tot kleding lijkt dan ook cruciaal te zijn om deelnemers goed in te kunnen delen met betrekking tot de hoeveelheid ontvangen UV die een biologisch effect kan geven. Verder bleek dat vakanties in het buitenland, zonnige weken in Nederland (objectief vastgesteld met de UV-grondmetingen), en de rapportage van (lichte) zonverbranding nauw geassocieerd waren met een hogere UV. blootstelling zoals geschat met behulp van de vragenlijstgegevens. Dit ondersteunt de geschiktheid van de vragenlijst en de beschreven expositieberekening om deelnemers te classificeren met betrekking tot hun recente zonlichtblootstelling.

Vervolgens werd de berekende blootstellingsmaat op individueel niveau gekoppeld aan gerapporteerde gegevens met betrekking tot hoge luchtwegklachten gedurende de afgelopen 4 weken en andere relevante data uit de jaarlijks terugkerende vragenlijst (hoofdstuk 7). Zelfs binnen het zonnige seizoen bleek er een duidelijk seizoenseffect te zijn, met het laagste voorkomen van hoesten, loopneus, en oorpijn/ loopoor in de maanden juli en augustus. Na correctie voor dit effect van seizoen in een multivariaat logistisch regressie model bleek er een negatief en statistisch significant verband te zijn tussen de berekende maat voor blootstelling aan UV en het voorkomen van deze klachten in ongeveer dezelfde periode. Bij nadere analyses leek dit verband niet verklaard te kunnen worden door de mogelijkheid dat kinderen met klachten ziek binnen blijven en daardoor minder aan zonlicht blootgesteld worden. Echter, onafhankelijk van seizoen en de individuele blootstelling op zich bleek er een positief verband te zijn tussen zonverbranding en genoemde klachten. Voor de klacht 'oorpijn/ loopoor' was het verband statistisch significant. 
Deze resultaten laten zien dat blootstelling aan UV die met erytheem gepaard gaat een ongunstig effect kan hebben op de weerstand tegen infecties. Echter, bij suberythemale doseringen kon geen ongunstig effect van UV op het voorkomen van hoge luchtweginfecties gevonden worden. In de range van sub-erythemale doseringen worden de immuunsuppressieve effecten van UV waarschijnlijk overschaduwd door andere (gunstige) factoren die nauw samenhangen met blootstelling aan zonlicht.

Tenslotte veronderstelden we dat blootstelling aan zonlicht een ongunstig effect heeft op het voorkomen van humaan papillomavirus (HPV) (hoofdstuk 8). De levenslangcumulatieve blootstelling aan zonlicht en zonverbrandingen in het verleden vormen een belangrijke risicofactor voor het ontstaan van plaveiselcel-carcinoom van de huid. Zowel het schadelijk effect van UV op DNA in cellen van de epidermis als het schadelijk effect van UV op de immunologische weerstand tegen tumoren zijn waarschijnlijk verantwoordelijk voor deze associatie. Daarnaast blijken bepaalde typen van HPV (de zgn. epidermodysplasia verruciformis-geassocieerde typen) frequent aanwezig te zijn bij patiënten met huidkanker en mogelijk dat dit virus causaal betrokken is bij de oncogenese. Omdat UV ook de weerstand tegen infecties kan ondermijnen, veronderstelden we dat, parallel aan de associatie tussen zonlicht en de kans op plaveiselcel-carcinoom, er een positief verband is tussen zonlicht in het verleden en huidig dragerschap van een aantal HPV typen (type 5, 8, 15, 20, 24 en 38). Dit werd onderzocht met behulp van data uit de "Leiden Skin Cancer Study", een patiënt-controle studie waarin determinanten van huidkanker onderzocht worden. De zonlichtblootstelling gedurende het gehele leven en het aantal verbrandingen gedurende verschillende leeftijdsperioden werden ingeschat met behulp van een eenmalig afgenomen vragenlijst.

Pijnlijke verbrandingen, met name op de leeftijd van 13-20 jaar, bleken geassocieerd te zijn met een verhoogde kans op huidig HPV dragerschap. Echter, een hogere levenslang-cumulatieve zonlichtblootstelling bleek daarentegen geassocieerd te zijn met een lagere kans op HPV infectie, zowel bij gezonde controles als bij patiënten met een plaveiselcel-carcinoom in de anamnese. De conclusie is dat het ongunstig verband met zonverbrandingen in het verleden de hypothese ondersteunt dat UV de weerstand tegen HPV infecties kan verminderen en dat UV ook langs deze infectieuze weg de oncogenese kan bevorderen. Echter, de gevonden gunstige associatie tussen de cumulatieve maat voor zonlichtblootstelling en HPV dragerschap contrasteert met de bekende ongunstige associatie tussen de cumulatieve zonlichtblootstelling en de kans op plaveiselcel-carcinoom. De raadselachtig rol van HPV bij het ontstaan van huidkanker wordt hierdoor onderstreept.

Onze observationele en epidemiologische studies hebben laten zien dat het verband tussen alledaagse niet-experimentele blootstelling aan ultraviolette straling in de zon en infecties niet simpel en eenduidig is. Het ongunstig effect van zonlicht op het voorkomen van klinisch manifeste herpes infecties bij mensen was reeds eerder vastgesteld, en dit werd door onze studie onder niertransplantatie-patiënten in de vorm van een seizoensfluctuatie ondersteund. Echter, er werden geen eenduidige en klinisch relevante effecten van zonlichtblootstelling op de ziekteprogressie bij HIV en op de antistofvorming volgend op een aantal standaardvaccinaties in de algemene bevolking gevonden. Voor symptomen die wijzen op hoge luchtweginfecties bij jonge kinderen en voor de prevalentie van HPV bij volwassenen werd zelfs een omgekeerde (d.w.z. gunstige) associatie met zonlicht gevonden. Echter, zonverbranding bleek daarentegen juist weer in ongunstige zin geassocieerd te zijn met bacteriële huid- 
infecties in de studie onder niertransplantatie-patiënten, met respiratoire klachten in de studie onder jonge kinderen en met de prevalentie van HPV bij volwassen deelnemers van de studie naar huidkanker. Blootstelling aan zonlicht kan dus met tegengestelde effecten gepaard gaan. Voor verdere studies naar het effect van zonlicht op het immuunsysteem, het ontstaan van tumoren en infecties is het belangrijk om onderscheid te maken tussen blootstelling aan zonlicht op zich en zonverbranding als schadelijk effect. Omdat zonverbranding een belangrijke risicofactor lijkt te zijn voor zowel het ontstaan van huidkanker als bepaalde infecties, is nader onderzoek naar de achterliggende mechanismen en het vaststellen van een veilige range van doseringen van belang. Voor wat betreft de weerstand tegen infecties is er op dit moment geen reden om blootstelling aan zonlicht bij sub-erythemale doseringen af te raden. UV blootstelling die erytheem veroorzaakt moet daarentegen beschouwd worden als een gevarenzone voor zowel het ontstaan van huidkanker als de weerstand tegen bepaalde infecties. 



\section{Curriculum vitae}

Fabian Termorshuizen is geboren op 22 december 1964 te Rotterdam. Het VWO-B diploma werd behaald in 1983 aan het Streeklyceum te Ede. Daarna is hij begonnen met de studie Geneeskunde aan de Faculteit der Medische Wetenschappen van de Katholieke Universiteit Nijmegen en behaalde in 1988 zijn doctoraal diploma met bijvak wijsbegeerte. Na een 'tussenstop' met verblijf in achtereenvolgens Israël, Egypte en voormalig West-Duitsland werd in 1992 begonnen met een verkort doctoraal Gezondheidswetenschappen met afstudeerrichting Epidemiologie aan bovengenoemde faculteit. Na zijn afstuderen in 1994 heeft hij onderzoek verricht naar de behandeling van psoriasis bij de afdeling Dermatologie van het Academisch Ziekenhuis Nijmegen (1995), naar de verspreiding van AIDS, seksueel overdraagbare aandoeningen en hepatitis A bij het Centrum voor Infectieziekten Epidemiologie van het Rijksinstituut voor Volksgezondheid en Milieu (RIVM) te Bilthoven (1996-1999) en naar het effect van UV-straling op immuniteit en infecties binnen een samenwerkingsproject van de afdeling Dermatologie van het Universitair Medisch Centrum Utrecht en het Laboratorium voor Pathologie en Immuunbiologie van het RIVM (1998-2001). Dit laatstgenoemde onderzoeksproject heeft geresulteerd in de artikelen van dit proefschrift. Op dit moment werkt hij tijdelijk bij de afdeling Klinische Epidemiologie en Biostatistiek van het Academisch Medisch Centrum te Amsterdam aan een aantal statistische analyses van longitudinale gegevens uit een cohortstudie onder patiënten met chronisch nierfalen die met hemo- of peritoneaal dialyse behandeld worden (Netherlands Cooperative Study on the Adequacy of Dialyis, NECOSAD)(2001-2003). Daarnaast werkt hij als epidemioloog bij de Amsterdamse Cohort Studies onder druggebruikers van de GG\&GD Amsterdam, waar zijn loopbaan de komende jaren voortgezet zal gaan worden met onderzoek naar het beloop van verslaving aan harddrugs op lange termijn en strategieën voor harm reduction $(2002-)$. 


\section{List of publications}

Van Dooren-Greebe RJ, Kuijpers ALA, Termorshuizen F, van de Kerkhof PCM. Interruption of long-term methotrexate treatment in psoriasis. Acta Derm Venereol (Stockh) 1995; 75: 393-396.

Termorshuizen F, Duynhoven YTPH van, Reintjes R, Houweling H, van de Laar MJW. Voorkomen van SOA in Nederland. In: Seksueel Overdraagbare Aandoeningen in Nederland; update 1996 (pp 19-68). Redactie van de Laar MJW en Ossewaarde JM. Report 441500.006. National Institute of Public Health and the Environment (RIVM). Bilthoven, 1997.

Van de Laar MJW, Termorshuizen F, van den Hoek JAR. Partner referral by patients with gonorrhea and chlamydial infection: case-finding observations. Sex Trans Dis 1997: 24: 334-342.

Termorshuizen F, Houweling H. Bindels PJE, van Wijngaarden JK. AIDS-epidemie in Nederland: recente ontwikkelingen naar transmissieroute, leeftijd en nationaliteit. Ned Tijdschr Geneeskd 1997; 141: 830-835.

Termorshuizen F, Houweling H. HIV/aids in Nederland: betere behandelingsmogelijkheden maken HIV- in plaats van aidssurveillance noodzakelijk [brief aan de redactie]. Ned Tijdschr Geneeskd 1997; 141: 1928-1929.

Van de Laar MJW, Termorshuizen F, Slomka MJ, van Doornum GJJ, Ossewaarde JM, Brown DWG, Coutinho RA, van den Hoek JAR. Prevalence and correlates of herpes simplex virus type 2 infection: evaluation of behavioural risk factors. Int Journal Epidemiol 1998; 27: 127-134.

Houweling H, Hamers FF, Termorshuizen F, Gill ON, Jager JC, Coutinho RA. A birth cohort analysis of AIDS in Europe: high incidence among young persons at risk. AIDS 1998; 12: 85-93.

Termorshuizen F, van de Laar MJW. De epidemiologie van hepatitis A in Nederland: 1957-1998. Ned Tijdschr Geneeskd 1998; 142: 2364-2368.

Termorshuizen F, van de Laar MJW. Upsurge of hepatitis A in the Netherlands early 1998. Eurosurveillance 1998; 3: 110-112.

Houweling H, Wiessing LG, Hamers FF, Termorshuizen F, Gill ON, Sprenger MJ. An age-period-cohort analysis of 50,875 AIDS cases among injecting drug users in Europe. Int J Epidemiol. 1999; 28:1141-1148.

Reintjes R, Termorshuizen F, van de Laar MJW. Assessing the sensitivity of STD surveillance in the Netherlands: an application of the capture-recapture method. Epidemiol Infect 1999; 122: 97-102.

Termorshuizen F, Garssen J, Maas J, Goettsch W, Matthijsen J, Houweling H, van Loveren H. UVB and infectious diseases: exposure assessment by means of a retrospective questionnaire for an epidemiological study. Report 640300.001 . National Institute of Public Health and the Environment (RIVM). Bilthoven, 1999.

Termorshuizen F, Dorigo-Zetsma JW, de Melker HE, van den Hof S, Conyn-van Spaendonck MAE. The prevalence of antibodies to hepatitis A virus and its determinants in the Netherlands; a population-based study. Epidemiol Infect 2000; 124: 459-466.

Termorshuizen F, Sleijffers A, van den Hof S, de Melker H, Garssen J, Boland GJ, van Hattum J, de Gruijl FR, van Loveren H. Vaccine-induced antibody responses in relation to season. An analysis on Hepatitis B, Rubella and Measles. Report 640300.004. National Institute of Public Health and the Environment (RIVM). Bilthoven, 2001. 
Termorshuizen F, Garssen J, Norval M, Koulu L, Laihia J, Leino L, Jansen CT, de Gruijl FR, Gibbs NK, de Simone C, van Loveren H. A review of studies on the effects of ultraviolet irradiation on the resistance to infections: evidence from rodent infection models and verification by experimental and observational human studies. Int Immunopharm 2002; 2: 263-275.

Termorshuizen F, Wijga A, Garssen J, den Outer P, Slaper H, van Loveren H. Exposure to solar ultraviolet radiation in young Dutch children: assessment by means of a six-week retrospective questionnaire. J Expo Anal Environ Epidemiol 2002; 12: 204-213.

Maas J, Termorshuizen F, Geskus RB, Goettsch W, Coutinho RA, Miedema F, van Loveren H. Amsterdam Cohort Study on HIV and AIDS: impact of exposure to UVR as estimated by means of a 2-year retrospective questionnaire on immune parameters in HIV-positive males. Int J Hyg Environ Health 2002; 205: 373-377

Termorshuizen F, Geskus RB, Roos MT, Coutinho RA, van Loveren H. Seasonal influences on immunological parameters in HIV-infected homosexual men: searching for the immunomodulating effects of sunlight. Int J Hyg Environ Health 2002; 205: 379-384.

Termorshuizen F, Korevaar JC, Dekker FW, Jager KJ, van Manen JG, Boeschoten EW, Krediet RT. Time trends in initiation and dose of dialysis in end-stage renal disease patients in the Netherlands. Nephrol Dial Transplant 2003; 18: 552-558.

Termorshuizen F, Korevaar JC, Dekker FW, van Manen JG, Boeschoten EW, Krediet RT. The relative importance of residual renal function compared to peritoneal clearance for patient survival and quality of life: An analysis of the Netherlands Cooperative Study on the Adequacy of Dialysis (Necosad)-2. Am J Kidney Dis 2003: 41: 1293-1302.

Termorshuizen F, Korevaar JC, Dekker FW, van Manen JG. Boeschoten EW. Krediet RT. Hemodialysis and peritoneal dialysis: Comparison of adjusted mortality rates according to the duration of dialysis: Analysis of the Netherlands Cooperative Study on the Adequacy of Dialysis. J Am Soc Nephrol 2003; 14: 2851-2860.

Termorshuizen F. Hogewoning AA, Bouwes Bavinck JN, Goettsch W, de Fijter JW, van Loveren H. Skin infections in renal transplant recipients and the relation with solar ultraviolet radiation. Clin Transplantation 2003; 17: 522-527. 


\section{Dankwoord}

Op 2 januari 1996 begon ik op het CIE (Centrum voor Infectieziekten Epidemiologie, RIVM) met mijn eerste serieuze baan en bij de kennismakingsronde kwam ik Wim Goettsch als een van de eerste collega's tegen. Hij legde uit onlangs gepromoveerd te zijn en vertelde iets over zijn onderzoek naar het effect van ultraviolette straling op huid en immuunsysteem. Ik geloof niet dat ik er toen erg veel van begreep en kon ook maar niet onthouden of UV straling nu ongunstig of juist gunstig was voor het immuunsysteem. In ieder geval, hij wilde na jaren van laboratoriumonderzoek op het LPI (Laboratorium voor Pathologie en Immuunbiologie, RIVM) de grenzen van het UV onderzoek toch eens gaan verleggen richting epidemiologie. Zijn wilde en deels in uitvoering zijnde epi-plannen zijn ongeveer 2 jaar later bij mij terechtgekomen. Ik begon aan dit onderzoek voor een aantal uur op het CIE naast mijn andere werk daar, een dik jaar later voortgezet in de vorm van een full-time aanstelling via de afdeling Dermatologie van het UMC Utrecht en gestationeerd op het LPI.

En zo kom ik nu bij de persoon die ik als allereerste wil bedanken, en dat is mijn promotor Prof. Henk van Loveren (LPI, RIVM en Universiteit Maastricht). Want jij zag als eerste dat de eigenwijze drs. Alexander Pieps een keer zou moeten gaan promoveren. En zonder jouw ideeën, initiatieven richting subsidiegevers en EU fondsen, lange ervaring in de fotobiologie en niet te vergeten de volhardendheid naar mij zou dit proefschrift er dan ook nooit geweest zijn. Met het tot stand komen van de artikelen hadden we onze voor- en tegenslagen, maar uiteindelijk had jij gelijk: dit proefschrift moest er komen. Als tweede dank ik Wim Goettsch voor al zijn voorbereidend werk op het CIE en de vele contacten die hij al gelegd had en/ of onderhield met diverse mensen van de GG\&GD Amsterdam, het LUMC in Leiden, het UMC Utrecht, het Laboratorium voor Stralingsonderzoek (LSO, RIVM) en het Centrum voor Chronische Ziekten Epidemiologie (CZE, RIVM). Al deze instanties hebben mij voorzien van de gegevens voor de hoofdstukken van dit proefschrift en aan het dankwoord komt dan ook nog even geen einde! Maar allereerst zijn er nog twee personen die zeer nauw betrokken zijn geweest bij het UV-onderzoeksproject waar dit proefschrift een deel van uitmaakt en daarom ook boven in het dankwoord thuishoren. Johan Garssen (LPI, RIVM), jij bent met je wetenschappelijke gedrevenheid en doorzettingsvermogen echt een bron van inspiratie voor menig beginnend onderzoekertje. Diverse ideeën uit dit proefschrift waren oorspronkelijk van jou afkomstig! Verder een woord van dank aan mijn co-promotor Frank de Gruijl (afdeling Dermatologie, LUMC Leiden, voorheen afdeling Dermatologie, UMC Utrecht). Bij jou kreeg ik altijd het gevoel dat wetenschap een esoterische dimensie heeft. Misschien komt dat omdat dingen die je eigenlijk niet helemaal snapt het meest intrigerend zijn. Bedankt voor je bijdrage en co-promotorschap. Vanuit de epidemiologische 'kreukelzone' (en daarnaast nog eens woonachtig in Den Haag) kan ik nog wel het een en ander van jou als natuurwetenschapper leren. En je moet me toch nog steeds eens uitleggen hoe de inductie van immunologische tolerantie nu precies in zijn werk gaat.

Jan Nico Bouwes Bavinck (afdeling Dermatologie, LUMC Leiden), grote dank voor je zeer plezierige samenwerking en voor het ter beschikking stellen van alle gegevens uit de diverse Leidse onderzoeken. De wat moeizame en explorerende 'UV NTP studie' (hoofdstuk 2) aan het begin van het project en het even toch wat flitsender beloop van de 'zonlicht HPV studie' (hoofdstuk 8) op de valreep helemaal 
aan het eind: in de wetenschap kan blijkbaar het een niet zonder het ander en uiteindelijk vallen de puzzelstukjes toch in elkaar! Ik wil bij deze ook graag Mariet Feltkamp (afdeling Microbiologie/ Virologie, LUMC Leiden) bedanken. We hebben 'maar' kort samengewerkt, maar zonder jouw cruciale bijdrage voor de HPV studie was het -m.i.- mooiste hoofdstuk van dit boekje er niet geweest.

lk geloof dat de GG\&GD Amsterdam om een een of andere reden altijd op de voor- of achtergrond van mijn loopbaan aanwezig geweest is. Het begon al in het eerste jaar op het CIE met een bron- en contactonderzoek naar gonorroe en chlamydia in samenwerking met de SOA-poli op de Groenburgwal en nu helemaal nu ik voor een aantal dagen op de GG\&GD gedetacheerd ben voor een onderzoek naar het beloop van verslaving als chronische ziekte. Twee hoofdstukken uit dit proefschrift zijn geschreven in nauwe samenwerking met onderzoekers van de Amsterdamse HIV cohortstudies. Prof. Roel Coutinho, Ronald Geskus en Jaap Maas, hartelijk dank voor de mogelijkheid een extra vragenlijst in het HIV cohort uit te zetten, het ter beschikking stellen van de benodigde gegevens en jullie inhoudelijke en statistische ondersteuning. En we zijn geloof ik al weer ver op weg naar het volgend artikel!

Prof. J. van Hattum en Greet Boland (afdeling Gastroenterologie/ Hepatologie, UMC Utrecht), antistofvorming volgend op hepatitis B vaccinatie als uitleessyteem voor immuuntoxiciteit heeft altijd een bijzondere aantrekkingskracht gehad voor het UV onderzoek. En daarom kan ik al twee proefschriften binnen één jaar bedenken met een bijdrage vanuit jullie vakgebied. Bij deze mijn dank! Ik kan me herinneren dat ik op de Najaarsvergadering van de Nederlandse Vereniging voor Hepatalogie 1999 ons onderzoekje naar seizoensfluctuaties op Hepatitis B antistofvorming presenteerde en prof. van Hattum een opmerking vanuit het gehoor opving van 'dit is gewoon lekker gek'. En misschien daarom staat het 'hepatitis B-seizoenshoofdstuk', dan niet in het begin of aan het eind, maar wel precies in het centrum van dit boekje (hoofdstuk 5 van de 9 ) op zijn plaats.

Voor hoofdstuk 6 en hoofdstuk 7 kom ik weer even bij andere onderzoekers van het RIVM uit. Alet Wijga (CZE, RIVM), grote dank voor je plezierige samenwerking. En dank via jou aan de hele PIAMA studiegroep voor de mogelijkheid een extra vragenlijst in het PIAMA cohort uit te zetten en het ter beschikking stellen van alle benodigde gegevens. Het tot stand brengen van hoofdstuk 6 en 7 is met veel geploeter gepaard gegaan, maar jij was gelukkig af en toe onze steun en toeverlaat. Ons UV-onderzoek naar respiratoire klachten bij jonge kinderen was inderdaad wel een beetje 'roekeloos'. Maar soms moeten we gebaande wegen durven verlaten, en de resultaten zijn eigenlijk toch helemaal niet zo gek! Ook wil ik Harry Slaper, Jan Matthijsen en Peter den Outer (LSO, RIVM) zeer hartelijk bedanken voor het ter beschikking stellen van alle benodigde stralingsgegevens en de inhoudelijke bijdrage bij het verwerken en inpassen van de gegevens, met name voor hoofdstuk 6. Danny Houthuijs (LBM, RIVM), dank voor je epidemiologische ondersteuning. Ik hoop dat je met plezier dit boekje leest waarin je de losse stukjes, waar jij ook bij betrokken geweest bent, in één geheel en daarmee misschien eens in een ander licht geplaatst ziet. Verder mijn dank aan Susan van den Hof en Hester de Melker (CIE, RIVM) voor het ter beschikking stellen van extra gegevens uit de PIENTER data-base voor hoofdstuk 5.

Naast de mensen die inhoudelijk een bijdrage geleverd hebben, zijn er ook mensen die op een andere manier een belangrijke rol gespeeld hebben en die ik even in het zonnetje wil zetten. Mijn kamergenoten op het RIVM, Yvonne Wallbrink en Liset de 
la Fonteyne, we hadden het af en toe wel erg gezellig in de grote 'rommel kamer' (is die al opgeruimd?, en staan al mijn mappen er nog?, nu kunnen ze echt allemaal weg!). Yvonne, ik heb je recepten allemaal nog bewaard en 'Nobeltje' staat ook nog in de kast. Ook Els van Amerongen wil ik graag heel erg bedanken. Of het nu gaat om het editen van een rapport of het toesturen van een promotiereglement: zonder sectretariële ondersteuning kunnen we elk onderzoek wel vergeten. Sandra de Waal, Sisca de Vlugt, Jolanda Vermeulen, en Bert Verlaan, met jullie ging ik vaak lunchen en daarna after-lunch koffie en bonbons (en desalniettemin is dit proefschrift er gekomen). Ik vraag me af of jullie op het LPI nog steeds bijgestaan worden door kaboutertjes?

Rebecca Kiekens, ja, ook jij komt in dit dankwoord voor! We hebben elkaar leren kennen in de korte tijd dat ik full-time op de afdeling Dermatologie van het UMC Utrecht heb gewerkt. Ik zie ons nog staan tijdens de borrel van de Immunologie dagen in Noordwijk, nippend aan een wijntje. Terwijl iedereen had het over T-cellen, allergie, antistoffen en andere erg ingewikkelde zaken, raakten wij maar niet uitgepraat over onze katten. Aan jou heb ik de komst van twee Maine Coones in ons huis te danken. Al die eenzame uurtjes thuis achter de pc waar ik zat te zwoegen: Azraël, mijn kleine toverkat, lag naast me te spinnen op een grote stapel geleerde papieren en dat gaf altijd weer nieuwe moed.

Jeannette van Manen, we hebben op het AMC nauw samengewerkt op het NECOSAD onderzoek. Ik hoor je nog zeggen: ik dwing je te promoveren. Nou, hierbij dan. Ons 'artikel-fabriekje' heeft op volle toeren gedraaid afgelopen jaar. Bovendien, met onze artikelen in de J Am Soc Nephrol (jij één en ik één) kunnen we onszelf nu zonder bescheiden te zijn tot de 'wereldtop' rekenen. Dank dat je paranimf hebt willen worden. Judith Zegers, van alle mensen tot nu toe genoemd ken ik jou het langst. Het begon in de Wetenschapswinkel van de KU in Nijmegen in 1995. Nu we het toch over de Wetenschapswinkel hebben, misschien kunnen ze daar mijn proefschrift te koop aanbieden. Jouw huis in Nijmegen is nog steeds een van de onveranderlijke punten van mijn leven in het bijzonder en van de kosmos in het algemeen. Ook grote dank dat je paranimf hebt willen worden.

Maarten, van alle mensen in dit boekje genoemd ken ik jou het allerlangst! Grote dank voor al je morele steun de afgelopen jaren, al vanaf het allereerste begin van mijn loopbaan in de Gezondheidswetenschappen in januari 1992. Afgelopen jaar zul je wel af en toe wanhopig geweest zijn van het zoveelste wazige artikel (en waar gaat het nu weer over: nierziekten, verslaving, of zonlicht?). Gelukkig bestaat het leven uit meer dan alleen werken en hebben we altijd nog tijd gehad voor zwemtrainingen, pianospelen, concerten, de 'opvoeding' van onze drie poezen en om ons af en toe onder te dompelen in de magie van films als Lord of the Rings. Komend jaar moeten we eindelijk wel weer eens echt op vakantie, en dan natuurlijk met veel zon!

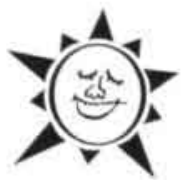

\section{Einde}



